\title{
ADAPTAÇÃO DO MODELO CROPGRO PARA SIMULAÇÃO DO CRESCIMENTO E DESENVOLVIMENTO DO FEIJÃO CAUPI (Vigna unguiculata (L.) WALP.) SOB DIFERENTES CONDIÇÕES HÍDRICAS, NO ESTADO DO PIAUÍ
}

\section{EDSON ALVES BASTOS}

Engenheiro Agrônomo

Orientador: Prof. Dr. Marcos Vinícius Folegatti

Tese apresentada à Escola Superior de Agricultura "Luiz de Queiroz", Universidade de São Paulo, para obtenção do título de Doutor em Agronomia, Área de Concentração: Irrigação e Drenagem.

P I R A C I C A B A

Estado de São Paulo - Brasil

Outubro - 1999 
Dados Internacionais de Catalogação na Publicação (CIP) DIVISÃo DE BIBLIOTECA E DOCUMENTAÇÃO - Campus "Luiz de Queiroz"/USP

Bastos, Edson Alves.

Adaptação do modelo CROPGRO para simulação do crescimento e desenvolvimento do feijāo caupi Vigna unguiculata (L.) Walp. sob diferentes condiçōes hidricas, no Estado do Piaui / Edson Alves Bastos.-- Piracicaba, 1999.

$91 \mathrm{p}$.

Tese (doutorado) - Escola Superior de Agricultura Luiz de Queiroz, 1999. Bibliografia.

1. Caupi 2. Crescimento vegetal 3. Desenvolvimento vegetal 4. Irrigacão 5. Modelo matemático 6. Produtividade de grão 7.Variedades I. Titulo

CDD 635.652

"Permitida a copia total ou parclal deste documento, desde que citada a fonte 0 Autor" 
A DEUS, em espírito de amor e serviço,

Ofereço

\section{À minha esposa Maria Teresa,}

a meus pais e irmãos, pelo eterno amor e carinho, 


\section{AGRADECIMENTOS}

À DEUS, por ter sempre me dado forças e inspiração para que eu pudesse tudo realizar.

Ao Dr. Marcos Vinícius Folegatti, pela orientação e apoio para realização deste trabalho e por sua contínua dedicação ao Curso de Pós Graduação em Irrigação e Drenagem.

À Coordenadoria de Aperfeiçoamento de Pessoal de Nível Superior (CAPES), pela bolsa de estudos concedida durante a fase inicial deste curso.

À Empresa Brasileira de Pesquisas Agropecuraria/Embrapa Meio-Norte, pela liberação concedida para a conclusão deste curso.

Aos professores dos Departamentos de Engenharia Rural, Física-Meteorologia e Agricultura, ESALQ/USP, pelos ensinamentos transmitidos durante o curso.

Ao Dr. Rogério Teixeira de Faria, pesquisador do IAPAR, pelos ensinamentos na frea de modelagem, por sua atenção e preciosas sugestões na elaboração deste trabalho.

Aos professores Paulo César Sentelhas e José Antonio Frizzone, pela atenção e valiosas sugestões na redação final da tese.

À Eliana M. G. Sabino, pela revisão das referências bibliográficas.

Aos amigos Aderson Soares de Andrade Júnior e Milton José Cardoso, pelo fornecimento de dados experimentais utilizados neste trabalho e pelo constante apoio, atenção e sugestões na redą̧ão final.

Aos amigos do Curso de Pós-Graduação em lrrigação e Drenagem, em especial a Valdemício, Thales, Wellington, Alexandre, Dálcio, Odair, Almiro, Jaqueline, Edivânia, Maurício e Fabiano, pelo harmonioso convívio. 
Aos amigos João Batista, Ângela, Cândida, Estela, Ranyse, Maurisrąel, Jozivaldo, Regina, Belisa, Wanderlei e Cristina, pela grande amizade e carinho.

À toda comunidade piauiense presente em Piracicaba, por nosso alegre convívio.

À Maria Teresa, por seu incansável apoio, carinho e dedicą̧ão em todos os momentos deste curso. 


\section{SUMÁRIO}

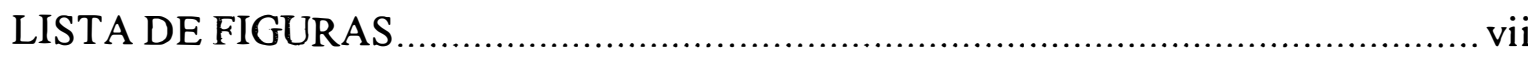

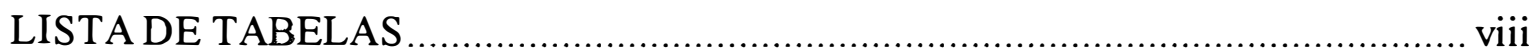

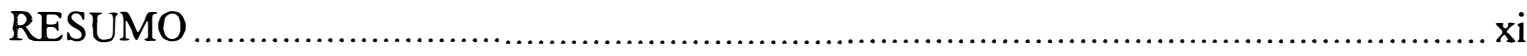

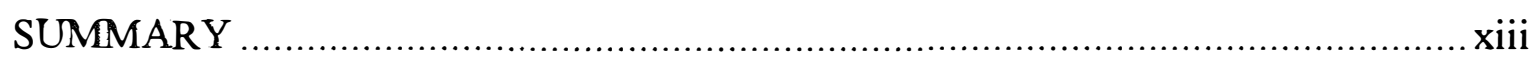

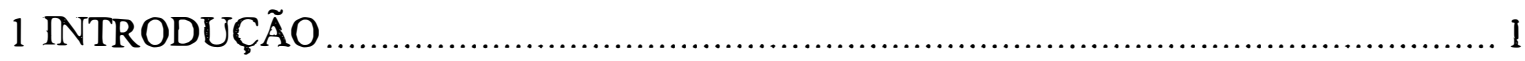

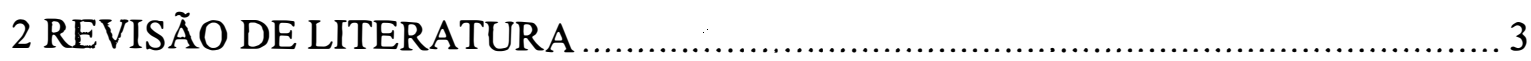

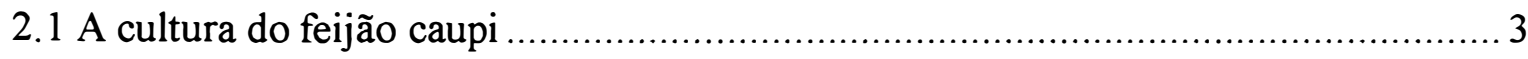

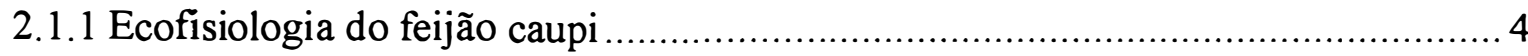

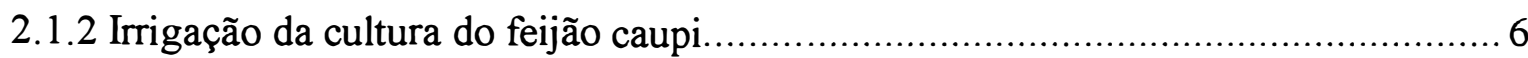

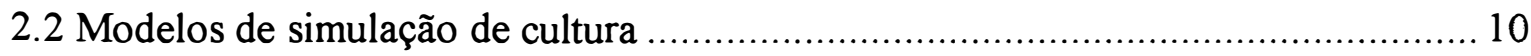

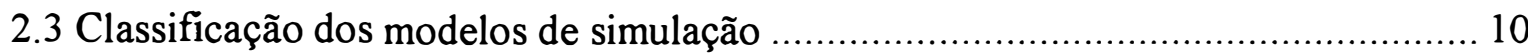

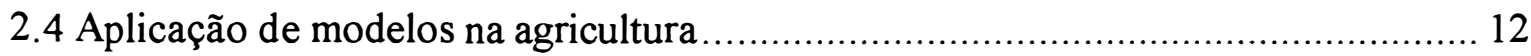

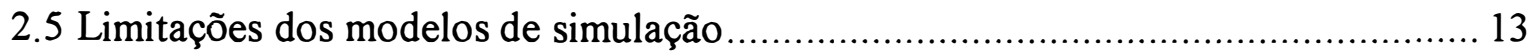

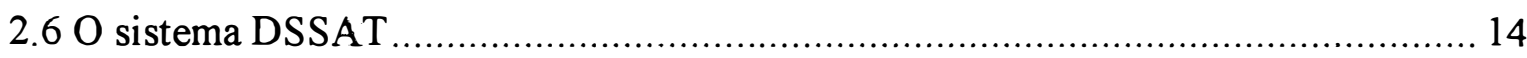

2.7 Calibração de modelos do sistema DSSAT ......................................................... 15

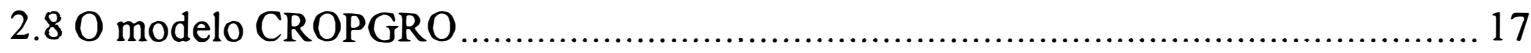

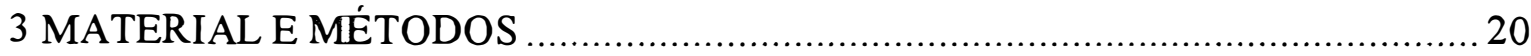

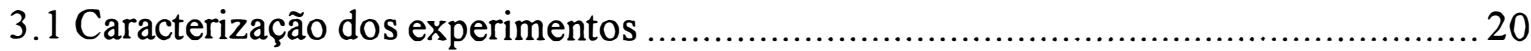

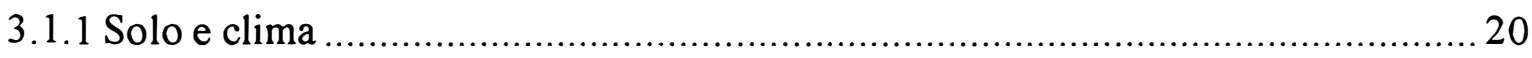

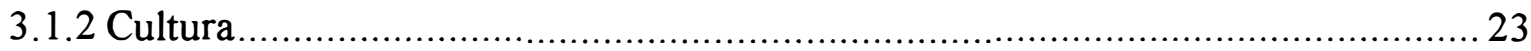

3.1.3 Experimentos utilizados na calibração do CROPGRO-cowpea........................... 24

3.1.4 Experimentos utilizados na avaliação do CROPGRO-cowpea ............................2. 25

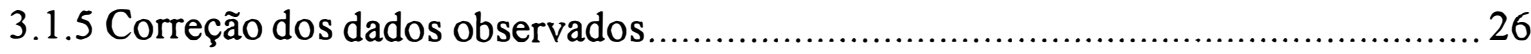

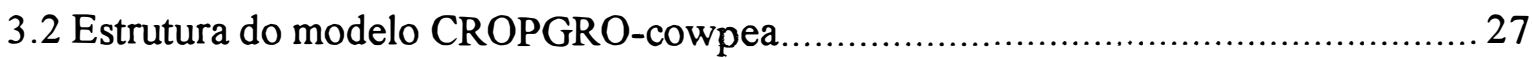

3.3 Equações utilizadas pelo modelo CROPGRO-cowpea.........................................2

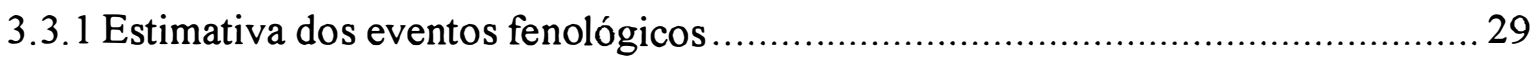

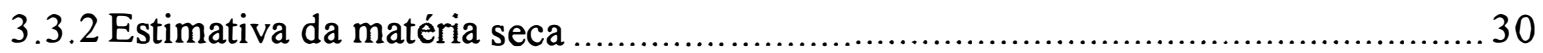




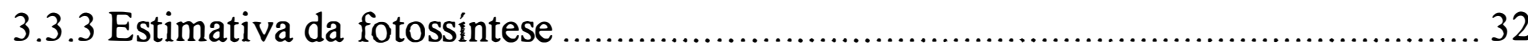

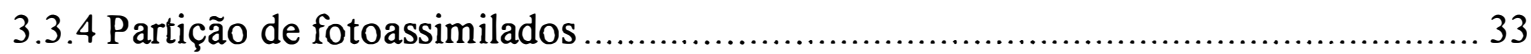

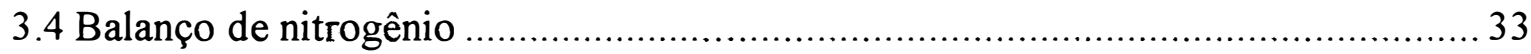

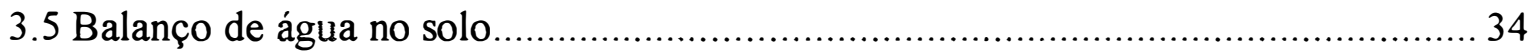

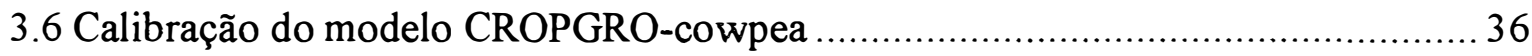

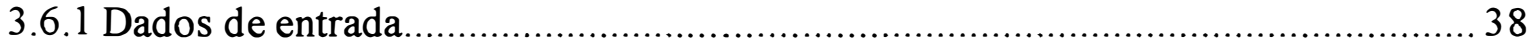

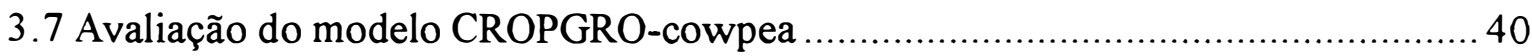

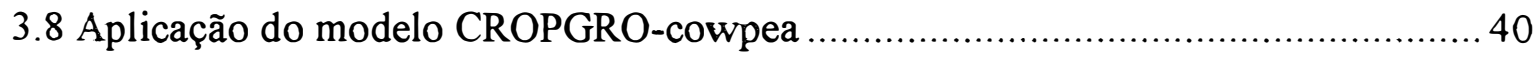

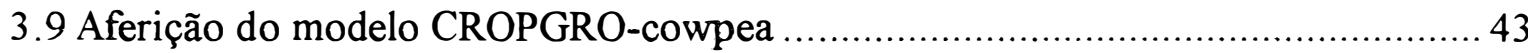

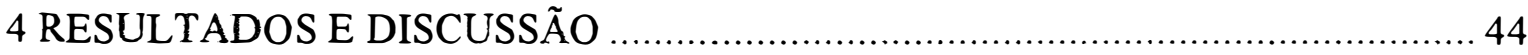

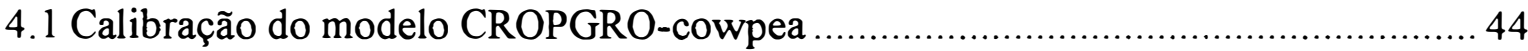

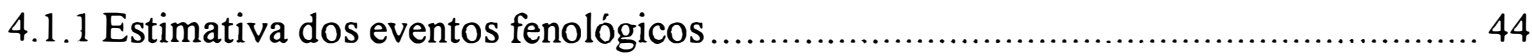

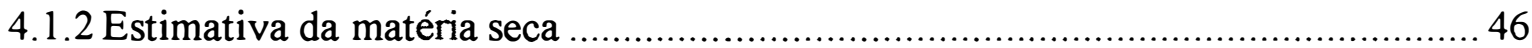

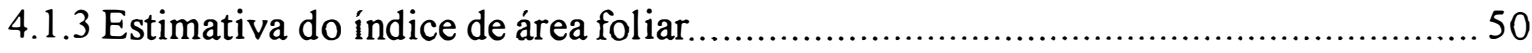

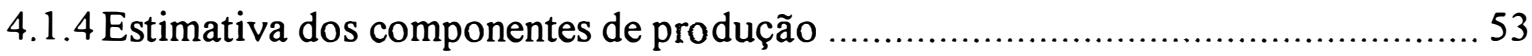

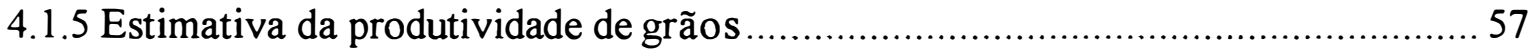

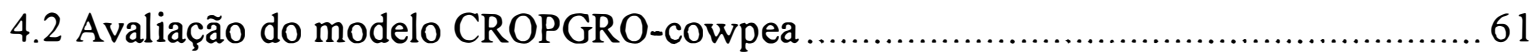

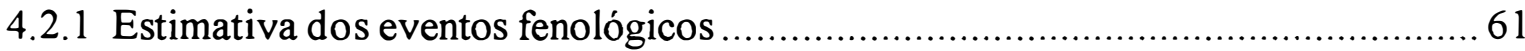

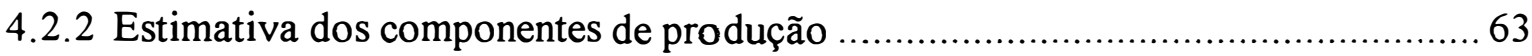

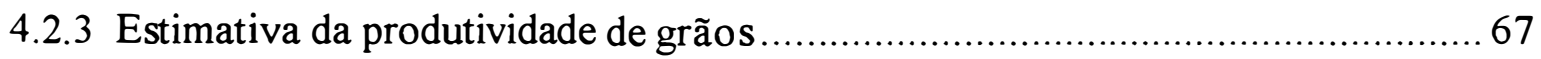

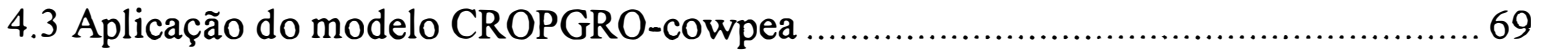

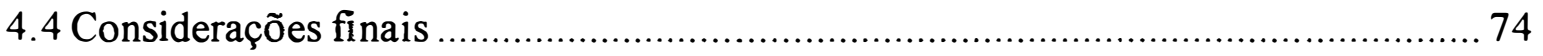

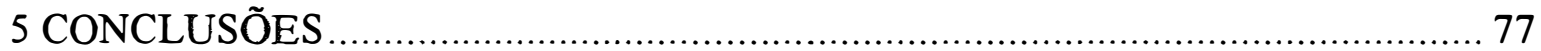

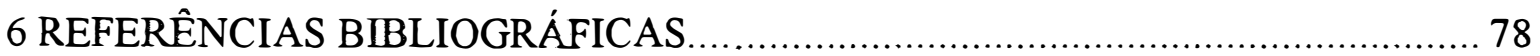




\section{LISTA DE FIGURAS}

Página

1 Curvas de retenção dos solos de Parnaíba (a) e de Teresina (b) 21

2 Valores das temperaturas máxima e mínima ocorridos durante os experimentos de 1996, nos municípios de Pamaíba e Teresina. 22

3 Valores das temperaturas máxima e mínima ocorridos durante os experimentos de 1997 e 1998, nos municípios de Parnaíba (a) e Teresina (b). 22

4 Valores de radiação solar estimados a partir dos dados de insolação (h) para os municípios de Parnaíba (a) e Teresina (b), durante a fase experimental de (b)....... 23

5 Representação esquemática da estrutura do modelo CROPGRO-cowpea. 28

6 Fator de restrição do crescimento, $\mathrm{f}(\mathrm{T})$, em função da temperatura do ar para a fase vegetativa do feijão caupi. 30

7 Relação entre a capacidade de água disponível (CAD) e o potencial matricial dos solos de Pamaíba (a) e de Teresina (b).

8 Valores de biomassa de duas cultivares de feijão caupi, na fase de calibração do modelo CROPGRO-cowpea para Pamaíba, PI, durante os anos de 1997 (a e c) e 1998 (b e d).

9 Valores de biomassa de duas cultivares de feijão caupi, na fase de calibração do modelo CROPGRO-cowpea para Teresina, PI, durante os anos de 1997 (a e c) e 1998 (b e d).

10 Valores de índice de área foliar (IAF) de duas cultivares de feijão caupi, na fase de calibração do modelo CROPGRO-cowpea para Pamaíba, PI, durante os anos de 1997 (a e c) e 1998 (b e d).

11 Valores de índice de área foliar (IAF) de duas cultivares de feijão caupi, na fase de calibração do modelo CROPGRO-cowpea para Teresina, PI, durante os anos de 1997 (a e c) e 1998 (b e d). 


\section{LISTA DE TABELAS}

Página

1 Resumo das características químicas dos solos das áreas experimentais dos municípios de Teresina e Parnaíba, Piauí.

2 Resumo das características físico-hídricas dos solos das áreas experimentais dos municípios de Teresina e Parnaíba, Piauí.

3 Características agronômicas das cultivares de feijão caupi estudadas 23

4 Lâminas de irrigação aplicadas nos diferentes tratamentos com o feijão caupi (cvs. BR 14 - Mulato e BR 17 - Gurguéia). 24

5 Tratamentos utilizados nos experimentos com a cultura do feijão caupi sob irrigação, nos municípios de Teresina e Parnaíba, Piauí. 25

6 Grupos de solos utilizados para estimar o número da curva de escoamento. 35

7 Número da curva de escoamento em função do grupo hidrológico.

8 Parâmetros dos arquivos de cultivar e de ecótipo modificados para a calibração do modelo CROPGRO-cowpea.

9 Parâmetros de espécie modificados a partir dos parâmetros do feijão comum Phaseolus vulgaris L para calibração do modelo CROPGRO-cowpea.

10 Tratamentos utilizados na avaliação econômica do manejo de irrigação para a produção de grãos do feijão caupi, utilizando-se o modelo CROPGRO-cowpea. ... 43

11 Valores dos eventos fenológicos de duas cultivares de feijão caupi, na fase de calibração do modelo CROPGRO-cowpea para Parnaíba, PI, 1997. 45

12 Valores dos eventos fenológicos de duas cultivares de feijão caupi, na fase de calibração do modelo CROPGRO-cowpea para Parnaíba, PI, 1998.

13 Valores dos eventos fenológicos de duas cultivares de feijão caupi, na fase de calibração do modelo CROPGRO-cowpea para Teresina, PI, 1997 
14 Valores dos eventos fenológicos de duas cultivares de feijão caupi, na fase de calibração do modelo CROPGRO-cowpea para Teresina, PI, 1998. 46

15 Valores da relação grão/vagem de duas cultivares de feijão caupi, na fase de calibração do modelo CROPGRO-cowpea para Parnaíba e Teresina, PI, em 1997 e 1998.

16 Valores do peso de 100 grãos de duas cultivares de feijão caupi, na fase de calibração do modelo CROPGRO-cowpea para Parnaíba e Teresina, PI, em 1997 e 1998.

17 Valores do número de vagens por planta de duas cultivares de feijão caupi, na fase de calibração do modelo CROPGRO-cowpea para Parnaíba e Teresina, PI, em 1997 e 1998. 56

18 Valores do número de grãos por vagem de duas cultivares de feijão caupi, na fase de calibração do modelo CROPGRO-cowpea para Teresina, PI, em 1997 e 1998....... 57

19 Valores da produtividade de grãos de duas cultivares de feijão caupi, na fase de calibração do modelo CROPGRO-cowpea para Parnaíba e Teresina, PI, em 1997 e 1998.

20 Diferença da produtividade de grãos da cv. BR 14 - Mulato entre os anos de 1997 e 1998, em Parnaíba e Teresina, PI.

21 Diferença da produtividade de grãos da cv. BR 17 - Gurguéia entre os anos de 1997 e 1998, em Parnaíba e Teresina, PI.

22 Valores dos eventos fenológicos do feijão caupi, cv. BR 17 - Gurguéia, na fase de avaliação do modelo CROPGRO-cowpea para Pamaíba, PI, 1996.

23 Valores dos eventos fenológicos do feijão caupi, cv. BR 17 - Gurguéia, na fase de avaliação do modelo CROPGRO-cowpea para Teresina, PI, 1996

24 Valores do peso de 100 grãos do feijão caupi, cv. BR 17 - Gurguéia, na fase de avaliação do modelo CROPGRO-cowpea para Parnaíba e Teresina, PI, 1996 64 
25 Valores do número de grãos por vagem do feijão caupi, cv. BR 17 - Gurguéia, na fase de avaliação do modelo CROPGRO-cowpea para Pamaíba e Teresina, PI, 1996.

26 Valores do número de vagens por planta do feijão caupi, cv. BR 17 - Gurguéia, na fase de avaliação do modelo CROPGRO-cowpea para Pamaíba e Teresina, PI, 1996.

27 Valores de produtividade de grãos do feijão caupi, cv. BR 17 - Gurguéia, na fase de avaliação do modelo CROPGRO-cowpea para Parnaíba, PI, 1996 68

28 Valores de produtividade de grãos do feijão caupi, cv. BR 17 - Gurguéia, na fase de avaliação do modelo CROPGRO-cowpea para Teresina, Piauí, 1996.

29 Valores médios simulados da produtividade de grãos (PG) e da receita líquida (RL), na fase de aplicação do modelo CROPGRO-cowpea para Pamaíba e Teresina, PI. 72

30 Precipitação (P) média e valores médios simulados da evapotranspiração da cultura (ETC) e da lâmina de irrigação (L) para Pamaíba e Teresina, Piauí. 73 


\section{ADAPTAÇÃO DO MODELO CROPGRO PARA SIMULAÇÃO DO CRESCIMENTO E DESENVOLVIMENTO DO FEIJÃO CAUPI (Vigna unguiculata (L.) WALP.), SOB DIFERENTES CONDIÇÕES HÍDRICAS, NO ESTADO DO PIAUÍ}

Autor: Edson Alves Bastos Orientador: Prof. Marcos Vinícius Folegatti

\section{RESUMO}

O modelo CROPGRO, do sistema DSSAT (Decision Support System for Agrotechnology Transfer) foi adaptado para simular o crescimento e desenvolvimento do feijão caupi (Vigna unguiculata (L.) Walp.) sob diferentes práticas de manejo, no Estado do Piauí. O modelo adaptado (CROPGRO-cowpea) foi aplicado para diferentes condições hídricas e épocas de semeadura, visando fornecer ao agricultor informações sobre um manejo econômico da irrigação. No modelo CROPGRO, foram modificados apenas parâmetros que definem os arquivos de espécie (.SPE), de cultivar (.CUL) e de ecótipo (.ECO), visando caracterizar a cultura do feijão caupi. Estas informações foram obtidas a partir da literatura e de resultados de pesquisas conduzidas na Embrapa MeioNorte, nos municípios de Pamaíba e Teresina, Piauí, durante os anos de 1996 a 1998. Também foram criados arquivos contendo as características de solo e de clima dos referidos locais. Para calibrar o modelo, foram utilizados experimentos cujos tratamentos consistiram na aplicação de diferentes lâminas de irrigação. Nestes experimentos, foram avaliados a biomassa acumulada, o índice de área foliar, os componentes de produção e a produtividade de grãos de duas cultivares de feijão caupi (BR 14 - Mulato e BR - 17 Gurguéia). Para avaliação do modelo, foram utilizados experimentos, em que foram aplicadas diferentes doses de fósforo e densidades de plantas. Nessa fase, foram comparados os valores observados e simulados dos 
componentes de produção e de produtividade de grãos. Após calibrado e avaliado, o modelo CROPGRO-cowpea foi aplicado para identificar estratégias de manejo de irrigação que proporcionassem a maior receita líquida ao produtor. Para isso, foram simulados experimentos, onde se avaliou o efeito de cinco níveis de água associados a quatro épocas de semeadura, sobre a produtividade econômica de grãos da cultivar BR 17 - Gurguéia para os municípios de Parnaíba e Teresina, Piauí. Os resultados da fase de calibração evidenciaram ajustes satisfatórios do modelo na estimativa da biomassa e do índice de área foliar para as duas cultivares, locais e anos estudados, constatados pelos elevados valores de $r^{2}$ (em média, 0,95 para biomassa e 0,91 para o IAF) e baixos valores de erro absoluto médio (EAM) (em média, 350,2 kg.ha ${ }^{-1}$ para a biomassa e 0,34 para o IAF). Tanto na calibração como na avaliação do modelo, houve boas estimativas dos eventos fenológicos do feijão caupi, com erros variando de 0 a 5 dias. O modelo também apresentou uma boa performance nas simulações dos componentes de produção, exceto para o peso de 100 grãos, cujos erros de estimativa variaram de 3,4 a 49,2\% (Fase de calibração) e de 2,8 a 30,8\% (Fase de avaliação). Considerando os valores médios de produtividade de grãos dos dois anos (Fase de calibração), o modelo apresentou erros variando de 5,6 a 14,9\% (Parnaíba) e de 3,8 a $5,3 \%$ (Teresina). Na fase de avaliação, os melhores ajustes foram obtidos para os tratamentos sem limitação de fósforo. De acordo com os resultados da aplicação do modelo para os dois locais, o manejo da irrigação que maximiza a receita líquida ao produtor de feijão caupi é a manutenção do teor de água no solo em níveis de até $50 \%$ da capacidade de água disponível, realizando-se a semeadura em 15/06. Concluiu-se que o CROPGRO-cowpea simula satisfatoriamente o crescimento e desenvolvimento do feijão caupi para as condições de solo e clima do Estado do Piauí e que o referido modelo constitui-se em uma importante ferramenta para auxiliar produtores rurais na busca de um manejo econômico da irrigação. 


\section{ADAPTATION OF CROPGRO MODEL FOR SIMULATION OF THE GROWTH AND DEVELOPMENT OF COWPEA (Vigna unguiculata (L.) Walp.) UNDER DIFFERENT WATER REGIMES IN PIAUÍ STATE, BRAZIL}

Author: Edson Alves Bastos Adviser: Prof. Marcos Vinícius Folegatti

\section{SUMMARY}

The CROPGRO model, which is part of DSSAT system (Decision Support System for Agrotechnology Transfer), was adapted for simulating the growth and development of the cowpea crop under different management practices in Piauí State, Brazil. The adapted model (CROPGRO-cowpea) was applied for different water regimes and planting dates to obtain information about economic irrigation management. In the CROPGRO, only input parameters that define a crop species, cultivars, and ecotype were changed in order to characterize cowpea crop. These information were obtained from literature search and some experiments carried out at Embrapa MeioNorte in Parnaíba and Teresina, Piauí, from 1996 to 1998. Soil and climate files were created for the localities considered. Experiments with different irrigation depth were used to calibrate this model. In these experiments, dry matter, leaf area index (LAI), yield components and grain yield of cowpea (cvs. BR 14 Mulato and BR 17 Gurguéia) were evaluated. Other experiments, where treatments consisted of different phosphorus levels and plant population, were used to validate this crop model. The yield components and grain yield were used to compare observed and simulated values. After calibration and validation, the CROPGRO-cowpea model was applied to identify strategies of economic irrigation management. For that, experiments with 20 treatments (five water regimes and four planting dates combination) were simulated, considering the soil and climate conditions of Parnaiba and Teresina. Calibration showed good fit 
for dry matter and LAI estimates to the cultivars, localities and years considered. The medium values of $\mathrm{r}^{2}$ and medium absolute error (MAE) were 0.95 and $350.2 \mathrm{~kg} \cdot \mathrm{ha}^{-1}$ to dry matter, and 0.91 and 0.34 to LAI. The difference between observed and estimated values of plant phenology varied from 0 to 5 days on the calibration and validation of the model. The model also presented a good performance on yield components estimates, excluding the 100 grains weight, that presented errors from 3.4 to $49.2 \%$ (calibration) and 2.8 to $30.8 \%$ (validation). Considering the yield medium value of two years- (calibration phase), the model presented errors from 5.6 to $14.9 \%$ (Parnaiba) and from 3.8 to $5.3 \%$ (Teresina). In the validation phase, the best fit was obtained for the treatments without phosphorus limitation. The irrigation management that offers the maximum economic return to cowpea producers is to maintain the soil moisture up $50 \%$ of soil water available, with the planting date in 15/06. The results showed that the CROPGRO-cowpea model simulates the growth and development of cowpea crop with reasonable accuracy for the soil and climate conditions of Piaui State. This model is an important tool to identify strategies of economic irrigation management. 


\section{INTRODUÇÃO}

O feijão caupi (Vigna unguiculata (L.) Walp.), também conhecido como feijão de corda ou feijão macassar, é a leguminosa alimentar mais importante das regiões Norte e Nordeste do Brasil. Segundo Leite et al. (1997), ocupa cerca de 95 a $100 \%$ do total da área plantada com feijão nos Estados do Amazonas, Maranhão, Piauí, Ceará e Rio Grande do Norte. Seu uso é bastante diversificado, podendo ser consumido como grãos secos ou verdes. Os ramos e folhas podem ser utilizados para alimentação animal ou como adubo verde.

No Piauí, como em outros estados da região Nordeste, o feijão caupi apresenta produtividade média de grãos em torno de $300 \mathrm{~kg} \mathrm{ha}^{-1}$ (Cardoso et al., 1995; Leite et al., 1997), estando muito aquém do potencial produtivo da cultura.

A recomendação de novas técnicas, visando o aumento de produtividade, demanda muito tempo e recursos, uma vez que qualquer tecnologia de cultivo necessita ser avaliada em vários locais para se tornar uma prática de uso generalizado. Uma alternativa, para tal avaliação, é o uso de modelos de simulação, que estimam a produtividade da cultura sob diversas condições ambientais. A grande vantagem desses modelos é a obtenção de resultados de forma rápida e com baixo custo, além de poder auxiliar eficientemente o agricultor em um planejamento e manejo agrícola que proporcionem melhores rendas líquidas.

Pesquisadores de todo o mundo têm se preocupado em desenvolver modelos de simulação de cultura. Não é uma tarefa fácil e, normalmente, é requerida uma equipe multidisciplinar, pois são inúmeras as variáveis que influenciam o crescimento e o desenvolvimento vegetal. 
$\mathrm{Na}$ literatura existem modelos confiáveis e disponíveis que podem ser calibrados e aplicados às condições de diferentes regiões, obtendo-se resultados satisfatórios, com uma grande economia de tempo e de recursos financeiros.

Nesse contexto, pode-se destacar o DSSAT (Decision Support System for Agrotechnology Transfer), que é um sistema computacional, que inclui um conjunto de modelos de crescimento de culturas e que tem sido aplicado eficientemente em todo o mundo por pesquisadores, extensionistas e produtores rurais (Hoogenboom et al., 1992). Assim, tem-se constituído em uma ótima alternativa para obtenção de informações que auxiliam o planejamento e manejo da produção agrícola.

Dentre os modelos de simulação presentes no DSSAT, destaca-se o CROPGRO, que é um modelo genérico para leguminosas e permite a simulação do crescimento e desenvolvimento da soja, amendoim e feijão comum. Uma das características do DSSAT é permitir a inclusão de outras culturas, através de modificações nos arquivos de espécie, de cultivar e de ecótipo.

Como no Brasil não existem modelos de simulação para a cultura do feijão caupi e dada sua importância para o país, o presente estudo propõe:

- Adaptar o modelo CROPGRO, do sistema DSSAT, para simular o crescimento e desenvolvimento do feijão caupi sob diferentes práticas de manejo, no Estado do Piauí, e

- Aplicar o modelo adaptado (CROPGRO-cowpea) para diferentes condições hídricas e épocas de semeadura, visando fornecer ao agricultor informações sobre um manejo econômico da irrigação. 


\section{REVISĀO DE LITERATURA}

\subsection{A cultura do feijão caupi}

O feijão caupi (Vigna unguiculata (L.) Walp.) é uma leguminosa de elevado valor nutricional presente nas regiões tropicais e subtropicais e amplamente distribuída no mundo (Ehlers \& Hall, 1997). A espécie é, provavelmente, originária da África, onde vários locais são apontados como centros de domesticação (Ng \& Maréchal, 1985).

O feijão caupi apresenta resistência considerável à seca e a elevadas temperaturas, em comparação à outras espécies cultivadas (Ehlers \& Hall, 1997). É também tolerante à baixa fertilidade do solo, devido às suas altas taxas de fixação do nitrogênio (Elowad \& Hall,.1987) e simbiose efetiva com micorrizas (Kwapata \& Hall, 1985).

No Brasil, o feijão caupi é cultivado, predominantemente, para produção de grãos nas regiões de climas quentes, seja úmida ou semi-árida, do Norte e Nordeste, respectivamente (Oliveira \& Carvalho, 1988). Constitui a principal cultura de subsistência no sertão semi-árido nordestino, que se caracteriza por períodos curtos de plantio, baixa disponibilidade hídrica e, em algumas áreas, solos rochosos com baixos teores de nutrientes. Também em áreas isoladas da Amazônia o feijão caupi encontrou seu habitat, com alta pluviosidade e solos com limitado nível de fertilidade (Teixeira et al., 1988). 


\subsubsection{Ecofisiologia do feijão caupi}

No Brasil, poucos estudos de fisiologia do feijão caupi têm sido conduzidos com a finalidade de se verificar a resposta desta cultura aos fatores ambientais. A maioria destas informações são obtidas por meio de trabalhos realizados em outros países.

A radiação solar pode ser considerada um fator de grande importância para o crescimento e desenvolvimento vegetal, pois influencia diretamente na fotossíntese das plantas. Loomis \& Williams (1963) comentaram que, sob condições favoráveis de solo e clima e quando pragas e doenças deixam de ser fatores limitantes, a máxima produtividade de uma cultura passa a depender principalmente da taxa de interceptação de luz e da assimilação de dióxido de carbono pelas plantas.

Segundo Pukkala et al. (1991), a interceptação da luz pelo dossel da cultura depende de uma série de fatores: latitude, posição do sol, índice de área foliar (IAF), coeficientes de transmissão e de reflexão das folhas, coeficiente de extinção de luz, etc.

De acordo com Phogat et al. (1984), a interceptação da energia luminosa no feijão caupi geralmente é alta devido às folhas glabras e de coloração verde escura. Os autores, avaliando a taxa de fotossíntese líquida e a absorção da radiação fotossinteticamente ativa por esta cultura, encontraram coeficientes médios de reflexão, de transmissão e de absorção iguais a 0,043; 0,199 e 0,758, respectivamente, indicando que apenas $4,3 \%$ da energia luminosa foi refletida pelas folhas de feijão caupi, em condições ótimas de água no solo.

O coeficiente de extinção $(\mathrm{K})$ indica a quantidade de luz que passa pelas folhas e chega ao solo. Quanto maior o valor de $\mathrm{K}$ mais luz é interceptada pelas folhas e menor quantidade chega ao solo (Gil Martinez, 1995).

Monsi \& Saeki ${ }^{1}$ citado por Wien (1982) comentaram que o coeficiente de extinção de luz é 0,85 para plantas de folhas largas. Wien (1982) observou que plantas de feijão caupi, com IAF igual a 3, interceptaram até $95 \%$ da energia disponível.

${ }^{11}$ MONSI, M.; SAEKI, T. Über den lichfaktor in den Pflanzengesellschaften und seine bedeutung für die stoffproduktion. Jpn. J. Bot., v.14, p.22-52, 1953. 
Outros fatores de extrema importância para o crescimento e desenvolvimento do feijão caupi são o fotoperíodo e a temperatura. Segundo Steele \& Mehra (1980) existem cultivares de feijão caupi sensíveis e outras insensíveis ao fotoperíodo, cujo crescimento vegetativo, arquitetura da planta e desenvolvimento reprodutivo são principalmente determinados pela interação de genótipos com a duração do dia e temperaturas do ar.

As cultivares de feijão caupi sensiveis ao fotoperíodo são consideradas plantas de dias curtos (Craufurd et al., 1996b; Hadley et al., 1983), as quais têm o seu florescimento atrasado quando o fotoperíodo é maior que o fotoperíodo crítico. Quando genótipos ou cultivares são insensíveis ao fotoperíodo, o crescimento e desenvolvimento da cultura são funções apenas da temperatura do ar (Craufurd et al., 1996a).

O feijão caupi é adaptado a regiões de clima quente. Entretanto, diversos estudos têm mostrado o efeito deletério de temperaturas muito elevadas $\left(>33^{\circ} \mathrm{C}\right)$ sobre o crescimento e desenvolvimento desta cultura, com abortamento de flores e reduções na produtividade de vagens e de grãos (Craufurd et al., 1998; Huxley \& Summerfield, 1976; Roberts et al., 1978; Shouse et al., 1981; Summerfield et al., 1978; Wien \& Summerfield, 1980).

Temperaturas baixas $\left(<19^{\circ} \mathrm{C}\right)$ também influenciam negativamente a produtividade do feijão caupi, retardando o aparecimento de flores e aumentando o ciclo da cultura (Huxley \& Summerfield, 1976; Leite et al., 1997; Littleton et al., 1979b; Roberts et al., 1978; Summerfield et al., 1978)

Tem-se assumido, freqüentemente, que o crescimento do feijão caupi cessa quando ocorrem temperaturas abaixo de $10^{\circ} \mathrm{C}$ (temperatura-base). Segundo Hadley et al. (1983) a temperatura-base (TB) do feijão caupi deve ser igual a $8^{\circ} \mathrm{C}$ para a maioria das situações. Estes autores encontraram, entretanto, uma cultivar com um padrão atípico, com uma $\mathrm{TB}$ entre 15 e $16^{\circ} \mathrm{C}$, justificando por se tratar de uma cultivar originada de uma região (nordeste da Nigéria) árida e quente, onde é comum a ocorrência de elevadas temperaturas do $\operatorname{ar}\left(35^{\circ} \mathrm{C}\right)$.

Littleton et al. (1979a), estudando o crescimento e desenvolvimento do feijão caupi sob condições tropicais, encontraram cultivares com TB igual a $20^{\circ} \mathrm{C}$, indicando que a expansão foliar poderia ser prejudicada por temperaturas noturnas baixas. 
Wien \& Summerfield (1980) comentaram que cultivares podem apresentar padrões de respostas à temperatura diferenciados. Foi observado que cultivares originadas do IITA ("International Institute of Tropical Agriculture") reduziram a produtividade de grãos em $29 \%$ quando a temperatura passou de 27 para $33^{\circ} \mathrm{C}$. Nesta mesma temperatura $\left(33^{\circ} \mathrm{C}\right)$, genótipos originados de outras localidades, aumentaram a produtividade de grãos em $3 \%$, indicando serem bastante adaptados à elevadas temperaturas.

Doto \& Whittington (1981) avaliaram a resposta de variedades e híbridos de feijão caupi à temperatura e observaram maior produtividade de grãos tanto em regimes mais frios como em condições mais quentes, dependendo do material utilizado. Assim, estes resultados indicam a importância e a necessidade de um maior entendimento da natureza das respostas ao ambiente para selecionar novas variedades.

Neste contexto, a modelagem pode ser útil pois, através da análise de sensibilidade dos modelos, pode-se avaliar o efeito de diferentes combinações térmicas sobre o crescimento e desenvolvimento de uma cultura.

\subsubsection{Irrigação da cultura do feijão caupi}

Apesar de ser considerada uma cultura tolerante à seca, pesquisas têm mostrado que a ocorrência de déficit hídrico no feijão caupi, principalmente nas fases de florescimento e enchimento de grãos, pode provocar severas reduções na produtividade de grãos (Babalola, 1980; Cordeiro et al., 1998; Costa et al., 1997; Labanauskas et al., 1981; Santos et al., 1998; Shouse et al., 1981; Shouse et al.; 1982).

Stamford et al. (1990) avaliaram o efeito de diferentes períodos de indução de deficiência hídrica na nodulação, na fixação de $\mathrm{N}_{2}$ e na produção de matéria seca de duas cultivares de feijão caupi, crescendo em dois solos da região semi-árida brasileira. Foi observado que o estresse hídrico reduziu o peso de nódulos, o nitrogênio acumulado e a produção de matéria seca da parte aérea, principalmente quando a deficiência hídrica foi imposta na segunda e quinta semanas após a semeadura. 
Estas reduções devem estar associadas ao fato de que o estresse hídrico afeta vários processos fisiológicos relacionados com a assimilação de nitrato e fixação simbiótica de nitrogênio nas leguminosas, reduzindo o peso da matéria fresca dos nódulos e da parte aérea das plantas (Costa et al.,1996). A alteração destes processos fisiológicos reflete no decréscimo da produtividade de grãos ou sementes.

Phogat et al. (1984) observaram que o suprimento adequado de água para o feijão caupi proporciona um aumento do índice de área foliar e da taxa de crescimento da cultura devido à manutenção da turgescência das folhas, resfriamento do dossel, maior absorção da radiação fotossinteticamente ativa e maiores taxas de fotossíntese.

Os trabalhos visando um manejo adequado da irrigação do feijão caupi têm enfatizado basicamente a resposta da cultura à aplicação de lâminas de irrigação, isoladamente ou associadas ao uso de algum nutriente.

Para as condições edafoclimáticas de Petrolina (PE), Silva (1978) analisou os efeitos da aplicação de cinco lâminas de água $(235,285,378,466$ e $471 \mathrm{~mm})$ e quatro doses de adubação nitrogenada $\left(0,40,80\right.$ e $\left.120 \mathrm{~kg} \cdot \mathrm{ha}^{-1}\right)$ sobre a produção e seus componentes. Verificou-se que a aplicação das lâminas de irrigação aumentaram linearmente a produtividade de grãos, alcançando o maior valor $\left(1.376 \mathrm{~kg} . \mathrm{ha}^{-1}\right) \mathrm{com}$ a aplicação de $471 \mathrm{~mm}$ associado a $120 \mathrm{~kg} \cdot \mathrm{ha}^{-1}$ de N. Dentre os componentes de produção, o número de vagens por planta apresentou efeito linear para a aplicação das lâminas de irrigação.

Nas condições de clima e solo do município de Governador Dix-Sept Rosado $(\mathrm{RN})$, Espínola et al. (1992) avaliaram o efeito da aplicação de cinco lâminas de água $(320,285,235,175$ e $125 \mathrm{~mm})$ e três densidades de plantio $(1,0 \mathrm{~m} \times 1,0 \mathrm{~m} ; 1,0 \mathrm{~m} \times 0,75 \mathrm{~m}$ e $1,0 \mathrm{~m} \times 0,5 \mathrm{~m}$ ) sobre a produção e componentes de produção. As maiores produtividade de grãos $\left(1.302,6\right.$ e 1.165,6 kg.ha $\left.{ }^{-1}\right)$ foram obtidas com a aplicação das lâminas de irrigação de 320 e $285 \mathrm{~mm}$, respectivamente, utilizando-se uma densidade de plantio de $1,0 \mathrm{~m} \times 0,5 \mathrm{~m}$. Quanto aos componentes de produção, as lâminas de irrigação influenciaram o número de vagens/planta e o número de grãos/vagem, os quais foram superiores com a aplicação das maiores lâminas de irrigação. 
No Piauí, Cardoso et al. (1996a; 1996b), em pesquisas visando identificar os melhores niveis de fósforo e densidades de plantas para o feijão caupi, sob irrigação, nos municípios de Teresina e Parnaíba, obtiveram produtividade de grãos acima de 2.000 kg.ha ${ }^{-1}$.

Nogueira \& Nogueira (1995) avaliaram o efeito de quatro lâminas de irrigação $(77,7 ; 154,1 ; 263,7$ e $415,7 \mathrm{~mm})$ e três doses de fósforo $\left(60,120\right.$ e $\left.180 \mathrm{~kg} \cdot \mathrm{ha}^{-1}\right)$ sobre a produtividade da cv. BR 12 - Canindé. A maior produtividade de grãos $\left(1.300 \mathrm{~kg} \cdot \mathrm{ha}^{-1}\right)$ foi obtida com a aplicação da lâmina de irrigação de $415,7 \mathrm{~mm}$ combinado com a dose de 180 kg.ha ${ }^{-1}$ de fósforo.

Lima et al. (1999), trabalhando com um solo Aluvial Eutrófico, avaliaram o efeito de cinco lâminas de irrigação $(291,8 ; 251,7 ; 219,0 ; 175,7$ e 141,2mm) sobre a produtividade de grãos de três cultivares de feijão caupi (João Paulo II, Pitiúba e Setentão). De acordo com a análise de regressão, os valores máximos de produtividade estimados e as respectivas lâminas de água aplicadas foram: $1.429,0$ kg.ha ${ }^{-1} / 240,27 \mathrm{~mm}$ (cv. João Paulo II); 970,99 kg.ha ${ }^{-1} / 225,88 \mathrm{~mm}$ (cv. Pitiúba)e 1.271,12 kg.ha ${ }^{-1} / 250,64 \mathrm{~mm}$ (cv. Setentão).

Alguns estudos têm procurado estabelecer o manejo de irrigação em feijão caupi, com base em informações relacionadas com o teor e/ou potencial de água no solo. Silva \& Millar (1981) analisaram a influência do conteúdo $(6,6 ; 5,5 ; 4,0 ; 3,5$ e 3,0\% em peso) e, como conseqüência, do potencial matricial $(-30,-50,-120,-220$ e $-460 \mathrm{kPa})$ em resposta à aplicação de diferentes lâminas de irrigação sobre o potencial produtivo da cultura. Concluíram que o teor de água no solo afetou a produtividade de grãos e que o valor máximo de $991,4 \mathrm{~kg} . \mathrm{ha}^{-1}$ foi alcançado com um conteúdo de água no solo de 5,5\% em peso, correspondendo a manutenção de um potencial matricial de $-50 \mathrm{kPa}$.

Resultados semelhantes foram obtidos por Bezerra \& Saunders (1992) em estudo conduzido com o objetivo de avaliar a produtividade de duas cultivares de feijão caupi (Pitiúba e João Paulo II), quando submetidos a dois potenciais matriciais (-40 e $-70 \mathrm{kPa})$. Concluíram que a produtividade média de grãos diminuiu $(\mathrm{P}<0,05)$ quando o potencial matricial do solo passou de $-40 \mathrm{kPa}\left(1.503,74 \mathrm{~kg} \cdot \mathrm{ha}^{-1}\right)$ para $-70 \mathrm{kPa}\left(583,18 \mathrm{~kg} \cdot \mathrm{ha}^{-1}\right)$. 
Entretanto, Ziska et al. (1985) obtiveram resultados distintos dos autores citados anteriormente. Foram avaliados métodos para o manejo da irrigação do feijão caupi que permitissem a redução do uso de água, porém com elevada produtividade de sementes. Os autores observaram que a manutenção de um estresse hídrico durante a fase vegetativa, associado com os manejos da irrigação efetuados quando o solo atingia $25 \%$ $\left(2,22\right.$ t.ha $\left.^{-1}\right), 50 \%\left(2,17\right.$ t.ha $\left.^{-1}\right)$ e $75 \%\left(2,22\right.$ t.ha $\left.{ }^{-1}\right)$ da água disponível não reduziram $(\mathrm{P}>0,05)$ a produtividade de sementes.

Pelos resultados dos trabalhos de pesquisa apresentados, pode-se constatar que não existem dúvidas quanto à viabilidade técnica da irrigação do feijão caupi. Entretanto, o mesmo não se pode afirmar quanto à viabilidade econômica, uma vez que poucos foram os trabalhos conduzidos com esse objetivo.

Dentre os trabalhos visando o manejo econômico da irrigação, apenas um está relacionado com a cultura do feijão caupi (Cardoso et al., 1995), no qual os autores procederam a uma avaliação agroeconômica da produção de sementes da cv. BR 14 Mulato nas condições de solo e clima de Teresina, Piauí. Verificaram que a condução da cultura, visando a produção de sementes, apresenta elevada rentabilidade econômica, obtendo-se uma receita líquida de $\mathrm{R} \$ 3.674,61$ por hectare e uma relação beneficio/custo da atividade de 4,78 .

De acordo com Peiter (1998) existem dificuldades de pesquisas visando a escolha de estratégias ótimas de irrigação, pois, normalmente, são exigidos grandes áreas e repetições anuais, gerando custos muito elevados. No entanto, a maximização da renda líquida ao produtor é cada vez mais necessária, em função do crescente aumento no custo e na disponibilidade da água, aliada à instabilidade dos valores de mercado dos produtos agrícolas. Como alternativa, destaca-se o uso de modelos de simulação de cultura, uma vez que, por meio deles, pode-se testar diferentes estratégias de manejo, com significativas reduções de tempo, mão-de-obra e recursos financeiros. 


\subsection{Modelos de simulação de cultura}

Monteith (1996) definiu modelos de simulação de cultura como um conjunto de equações para estimar o crescimento e desenvolvimento de uma cultura a partir de uma série de coeficientes genéticos e variáveis do ambiente.

Os primeiros modelos de cultura surgiram na década de 1960 e passaram por quatro fases até os dias de hoje. A primeira fase foi caracterizada pelo início do uso dos computadores e o desenvolvimento de conceitos de analistas de sistema. Depois, com a popularização da tecnologia computacional, houve um expressivo crescimento dos modelos de cultura. Fatores que influenciavam o crescimento da planta foram incluídos nos modelos, que passaram a estimar o acúmulo de biomassa. Avanços importantes na descrição de vários subcomponentes da assimilação de carbono também foram feitos nesta fase. Posteriormente, os modelos de cultura passaram por uma fase de transição, em que se procurou desenvolver modelos muito complexos, porém, sem muito sucesso. Atualmente, com o acúmulo de experiência e conhecimento, os modeladores conseguiram definir com mais precisão os limites do sistema e a natureza dos fatores limitantes, desenvolvendo modelos mais robustos e práticos (Sinclair \& Seligman, 1996).

Boote et al. (1996) resumiram a aplicação dos modelos em três itens: a) como ferramenta importante para sintetizar o conhecimento científico; b) auxiliar o agricultor na tomada de decisões e c) em atividades de planejamento. Segundo Costa (1997), pode-se acrescentar duas aplicações: d) como uma ferramenta didática e e) na orientação e racionalização do uso de experimentos convencionais.

\subsection{Classificação dos modelos de simulação}

Devido à grande variedade de modelos desenvolvidos nos últimos tempos, surgiu a necessidade de classificá-los. Entretanto, de acordo com Wisiol (1987), não existe uniformidade de classificação entre os modeladores e vários tipos de modelos são definidos. Para este autor, existem os modelos estáticos e os dinâmicos. Estes últimos 
podem ser mecanísticos ou empíricos, determinísticos ou estocásticos, discretos ou contínuos ou, ainda, uma combinação destes.

Os modelos estáticos são representados por equações algébricas destituídas de variáveis de tempo, não necessitando, portanto, considerar o estado inicial do sistema. Os dinâmicos têm características opostas e devido à sua estrutura, podem armazenar informações ao longo do tempo (Wisiol, 1987).

De acordo com Monteith (1996), os modelos mecanísticos quantificam os processos por meio de bases físicas e/ou fisiológicas, enquanto os empíricos são constituídos de funções que são escolhidas arbitrariamente com o objetivo apenas de promover bons ajustes entre os dados observados e simulados.

Os determinísticos são aqueles que fornecem resultados sem considerar a probabilidade de ocorrência do evento. Os modelos estocásticos apresentam um grau de probabilidade associado à sua resposta (Gedanken, 1998).

Jones et al. (1987) caracterizaram os modelos contínuos como aqueles cujas variáveis de estado podem mudar ligeiramente em pequenos intervalos de tempo e não são restritos à valores inteiros. Por outro lado, os modelos discretos são aqueles cujas variáveis descrevem o estado do sistema, considerando apenas valores inteiros.

Passioura (1996) propôs ainda uma outra classificação: a) Modelos Científicos, aqueles que auxiliam os pesquisadores a entender os processos fisiológicos e as interações que ocorrrem entre a planta e o ambiente e b) Modelos de Engenharia, os que orientam os fazendeiros a desenvolver o melhor manejo da cultura.

Existem outros tipos de classificação na literatura, que variam de acordo com o critério adotado pelo modelador. No entanto, o que mais importa é que o usuário saiba aplicar o modelo para atender seus objetivos específicos, tendo consciência das limitações desta ferramenta a fim de evitar erros em suas áreas de atuação. 


\subsection{Aplicação de modelos na agricultura}

A literatura científica é rica em exemplos de aplicações de modelos para atender aos mais diversos objetivos: balanço de água no solo (Belmans et al., 1983; Faria \& Madramootoo, 1996; Ritchie, 1985); simulação do crescimento e desenvolvimento de culturas (Boote et al., 1987; Colson et al., 1995); estratégias ótimas para manejo de irrigação (Bernardo et al., 1988; Faria et al., 1997a; Rogers \& Elliot, 1989), controle de pragas (Boote et al., 1993); manejo de fertilidade do solo (Thornton, 1995); impacto da erosão sobre o solo (Bowen et al., 1993); descrição do processo de fotossíntese (Boote \& Pickering, 1994); impacto global devido as mudanças climáticas (Siqueira et al., 1994), dentre outros.

Segundo Ritchie (1994) os modelos de simulação de cultura constituem-se nas principais ferramentas para proporcionar o desenvolvimento das ciências agrárias. Gedanken (1998) acrescenta, que os modelos permitem uma melhor orientação das pesquisas, pois auxiliam a montagem de experimentos direcionados ao entendimento de questões específicas. Segundo o autor, a modelagem possibilita também uma aplicação mais completa dos dados obtidos em experimentação convencional.

Os modelos podem ser úteis em programas de melhoramento de plantas, uma vez que estimam com precisão o crescimento e o desenvolvimento das culturas. Futuros modelos deveriam ser melhor integrados com informações genéticas e simular experimentos objetivando aspectos qualitativos, tais como teores adequados de óleo e proteína e mecanismos de resistência à pragas e doenças (White, 1998).

De acordo com Ritchie (1994), informações computadas sistematicamente nos modelos serão necessárias para fazer projeções realísticas sobre produtividades futuras e degradações ambientais. Para o autor, a modelagem não trará soluções dos problemas, mas permitirá uma eficiente transferência de tecnologia de tal modo a resolver problemas particulares.

Cabe ressaltar que todas as informações geradas pelos modelos, seja para atender ao pesquisador ou ao produtor, são obtidas em apenas alguns minutos, o que torna os 
modelos ferramentas de grande versatilidade no tempo e espaço. No entanto, é importante que se esclareça as limitações desta técnica.

\subsection{Limitações dos modelos de simulação}

É fácil compreender que a maior dificuldade na arte de modelar reside na impossibilidade de se equacionar matematicamente todos os processos que ocorrem na natureza. Nesse sentido, Monteith (1996) comenta que o uso de modelos de simulação deve ser feito de forma cautelosa, pois grandes erros podem ser cometidos, seja porque as relações empíricas desenvolvidas pelos modelos podem ser baseadas em evidências experimentais limitadas ou impróprias, ou por conterem funções arbitrárias destituídas de bases mecanísticas. Outro aspecto ressaltado pelo autor é que as relações empíricas inerentes aos modelos são extrapoladas, às vezes, além das condições onde foram derivadas e testadas.

Segundo Passioura (1996), os modelos podem apresentar estruturas erradas e que, neste caso, ajustar parâmetros não é suficiente para chegar a bons resultados. Mesmo com estruturas corretas, os modelos dificilmente podem ser aplicados em campo devido à grande variabilidade dos parâmetros. Além disso, podem haver muitas falhas nos modelos quando os mesmos baseiam-se em hipóteses de crescimento de plantas que não foram testadas.

De acordo com Boote et al. (1996), as maiores falhas quanto à utilização de modelos são, muitas vezes, devidas à má qualidade dos dados de entrada. Em alguns casos, modelos simples não são adequados pois não estão programados para equacionar determinados fenômenos particulares. Por outro lado, modelos complexos podem ser inadequados, uma vez que requerem dados que não são disponíveis em campo.

Face a estas limitações, os resultados gerados pelos modelos de culturas não devem ser encarados como verdade absoluta, devendo apenas servir de base para orientar o produtor no planejamento ou tomada de decisões. Assim, além da qualidade do modelo, o modelador deve considerar o usuário que ele deseja atender. Este deve ser 
suficientemente esclarecido para que possa utilizar o modelo da melhor forma possível, sabendo interpretar os resultados com clareza.

\subsection{O sistema DSSAT}

O DSSAT (Decision Support System for Agrotechnology Transfer) foi desenvolvido por uma equipe de pesquisadores internacionais e constitui-se em um conjunto de modelos de crescimento de várias culturas.

Este sistema computacional é coordenado pela IBSNAT (International Benchmark Sites Network for Agrotechnology Transfer) e teve sua primeira versão publicada em 1989, na qual foram utilizados modelos das culturas de milho (CERESmaize), trigo (CERES-wheat), soja (SOYGRO) e amendoim (PNUTGRO). Nesta versão, os dados de entrada e saída eram limitados às características de solo, clima, condições nutricionais da planta, espaçamento, arquitetura da planta e manejo da cultura. Em 1994, uma segunda versão (DSSAT v3.0) foi elaborada, incluindo um maior número de dados de entrada e de saída, mais variáveis e outras condições ambientais. Isto tornou o modelo mais flexível, facilitando a inclusão de novas mudanças no futuro (Jones et al., 1994).

Segundo Jame \& Cutforth (1996), o DSSAT v3.0 permite ao usuário: a) organizar, armazenar e entrar com dados de cultura, solo e tempo; b) calibrar e avaliar modelos de crescimento; e c) avaliar diferentes práticas de manejo em um determinado ambiente. São feitas simulações para diferentes tipos de solos, de culturas, datas de semeadura e densidades de plantas. Assim, o agricultor pode selecionar a cultura, a cultivar, época de semeadura, práticas culturais, manejo de água e nutrientes, de tal forma a lhe proporcionar os menores riscos.

Para estes autores o programa também possibilita análises da produtividade das culturas, retorno líquido ao agricultor, eficiência do uso de água, absorção e lixiviação de nitrogênio, identificando, assim, as melhores estratégias de manejo. Para auxiliar a determinação das melhores estratégias, o modelo dispõe de funções cumulativas de probabilidade que são apresentadas graficamente. Outra aplicação do DSSAT v.3.0 é a 
simulação de um sistema agrícola, prevendo rotações de culturas e avaliando seu impacto sobre a disponibilidade de $\mathrm{N}$ e matéria orgânica. A nível regional, é possível selecionar as melhores opções para exploração agrícola, considerando o uso da terra, os tipos de solos e as condições climáticas de cada região.

Em 1998, surgiu a terceira e atual versão do DSSAT (v3.5). Segundo Hoogenboom (1998), esta nova versão apresenta melhorias significativas na estrutura dos modelos já existentes, especialmente nas rotinas de crescimento e desenvolvimento das plantas. Três novos programas foram incorporados na estrutura do DSSAT, sendo um para apresentar gráficos de umidade e nitrogênio do solo em função do tempo e os outros dois, com o objetivo de conectar os modelos de cultura com o Sistema de Informação Geográfica (SIG). Atualmente, o DSSAT contempla modelos para 16 culturas e todos possuem módulos idênticos para simular os balanços de água e de nitrogênio no solo.

Os modelos de simulação de cultura do sistema DSSAT necessitam de uma criteriosa calibração e avaliação no local onde vai ser aplicado. Para melhorar a performance os modelos utilizam coeficientes genéticos e de espécie, o que pode se constituir, entretanto, em obstáculo na fase de calibração.

\subsection{Calibração de modelos do sistema DSSAT}

A calibração de modelos do sistema DSSAT para outras regiões tem sido uma prática comum em todo o mundo. Siqueira et al. (1994) calibraram os modelos CERESwheat, CERES-maize e SOYGRO para avaliar o efeito potencial de mudanças climáticas sobre a produção brasileira de trigo, milho e soja. Em função do aumento da temperatura, previsto pelos modelos GISS, GFDL e UKMO, foram estimados encurtamento do ciclo e redução da produtividade de trigo (1,2 milhão $t)$ e de milho $(3,5$ milhões t). Em relação à soja, foi prevista uma elevação de 2,8 milhões de toneladas na produção nacional.

Colson et al. (1995) adaptaram o modelo de soja (SOYGRO) para condições européias, estimando satisfatoriamente a produção de vagens, sementes e a 
produtividade potencial da cultura da soja. O SOYGRO foi ajustado em relação ao fotoperíodo, termoperíodo, capacidade fotossintética e partição de fotoassimilados e, por meio de uma análise de sensibilidade, foram identificados os principais coeficientes genéticos.

Lima (1995) calibrou o modelo CERES-maize para simular o crescimento e desenvolvimento de três híbridos de milho (XL-520, XL-380 e XL-678), nas condições tropicais do Brasil. O índice de área foliar máximo e biomassa dos três híbridos foram subestimados, com erros variando de 14 a 17\%. Em relação à produtividade de grãos, houve bons ajustes, com erros de estimativa inferiores à $7 \%$.

Thomton et al. (1995) calibraram o modelo CERES-maize para simular a produtividade de milho na região central de Malaui, utilizando dados de experimentos e de campos de produção, durante os anos de 1989 a 1991. Obtiveram uma boa correlação entre os dados observados e simulados, com $r^{2}$ variando de 0,81 a 0,94 .

Faria et al. (1997b) calibraram o modelo de feijão (BEANGRO) para as condições do norte do Paraná. Para estes autores, embora haja necessidade de refinamentos na estimativa de alguns processos, os resultados indicaram que o modelo é adequado para estimar a fenologia e produção de duas cultivares de feijoeiro em diferentes épocas de semeadura e regimes hídricos. Dessa forma, é possível a utilização deste método para estudos de riscos climáticos e de viabilidade técnica e econômica de culturas de feijoeiro em condições de sequeiro e irrigadas na região.

Giraldo et al. (1999) adaptaram o modelo CROPGRO para simular a produção de biomassa de Brachiaria decumbens (cv. Basilisk), considerando pastos com diferentes idades de rebrote $(3,6,9$ e 12 semanas). As simulações foram realizadas para períodos de máxima e de mínima precipitação, em diferentes condições de solo e clima da Colômbia. Em geral, foram observados bons ajustes na estimativa da biomassa de $B$. decumbens para as diversas situações estudadas, com erros de estimativa variando de 0 a $12 \%$.

Tubiello et al. (1999) calibraram o modelo CERES-wheat, visando simular a produção da cultura do trigo (Triticum aestivum L. cv. Yecora Rojo), sob dois níveis de irrigação e duas concentrações de $\mathrm{CO}_{2}\left(350\right.$ e $\left.550 \mu \mathrm{mol} \mathrm{mol}^{-1}\right)$. Além da produtividade 
de grãos, foram comparados os valores simulados da fenologia e produção de biomassa. As melhores estimativas dos eventos fenológicos (erros de 2 a 3 dias) foram obtidas nos tratamentos sem déficit hídrico e sob condições ambiente de $\mathrm{CO}_{2}\left(350 \mu \mathrm{mol}^{\mathrm{mol}} \mathrm{m}^{-1}\right)$. A diferença entre os valores observados e simulados de biomassa e produtividade de grãos foi de aproximadamente $10 \%$, exceto no tratamento com maior concentração de $\mathrm{CO}_{2}$ $\left(550 \mu \mathrm{mol} \cdot \mathrm{mol}^{-1}\right)$.

\subsection{O modelo CROPGRO}

O CROPGRO faz parte do sistema DSSAT e teve sua primeira versão publicada em 1994. É um modelo genérico para leguminosas e simula o crescimento e desenvolvimento de culturas como soja (Glycine max (L.) Merr.), amendoim (Arachis hypogea L.) e feijão comum (Phaseolus vulgaris L.). Antes, estas culturas apresentavam modelos específicos, os quais eram denominados SOYGRO (soja), PNUTGRO (amendoim) e BEANGRO (feijão comum) (Tsuji et al., 1994b).

Segundo Boote et al. (1998b), a união dos três modelos foi realizada para tornálo mais flexível a melhorias futuras e, desta forma, eliminar a necessidade de mudanças nos códigos dos modelos isoladamente. No CROPGRO, existem três tipos de arquivos para cada leguminosa, constituindo os dados de entrada relativos à planta:

- Arquivo .SPE, que caracteriza a espécie, contendo coeficientes utilizados para caracterizar a composição básica dos tecidos e para descrever vários processos da planta como fotossíntese, respiração, assimilação de nitrogênio, partição de fotoassimilados, senescência, fenologia e crescimento.

- Arquivo .CUL, que apresenta informações inerentes à própria cultivar, tais como: sensibilidade ao fotoperíodo, características fenológicas, taxa de fotossíntese à luz saturada, área foliar específica, máximo peso de sementes e outras.

- Arquivo .ECO, que caracteriza o ecótipo, contendo alguns atributos genéticos, os quais permitem diferenciar cultivares de hábito de crescimento determinado e indeterminado. 
Quanto aos tratos culturais, são incluídas informações sobre o manejo da cultura, tais como, aplicações de fertilizantes e de lâminas de irrigação, incorporação de resíduos e rotação de culturas, espaçamento entre plantas e entre fileiras, data da semeadura, profundidade de plantio, dentre outras. Estas informações compõem o arquivo X (Tsuji et al., 1994a).

Segundo estes autores, além dos dados relacionadas com a planta, o modelo CROPGRO requer informações sobre o solo, clima e tratos culturais. Os parâmetros do solo incluem as características físicas, químicas e hídricas em todo o perfil, além de alguns coeficientes específicos do modelo.

Em relação ao clima, são requeridos dados diários de temperaturas máxima e mínima $\left({ }^{\circ} \mathrm{C}\right)$, precipitação $(\mathrm{mm})$ e radiação solar $\left(\mathrm{MJ} \cdot \mathrm{m}^{-2} \cdot \mathrm{dia}^{-1}\right)$. Esta última pode ser estimada através de dados de insolação (h ou \%). Para preencher possíveis falhas na série de dados climáticos, o modelo dispõe de dois programas, WGEN (Richardson) ${ }^{2} \mathrm{e}$ SIMMETEO (Geng et al) ${ }^{3}$ citados por Tsuji et al. (1994). O primeiro estima os elementos climáticos a partir de valores diários enquanto o segundo requer apenas médias mensais.

Como saída de dados, o modelo inclui dois arquivos, OVERVIEW.OUT e SUMMARY.OUT descritos por Jones et al. (1994). No primeiro, uma breve descrição dos experimentos é apresentada, com os nomes dos tratamentos e cultivares, local e data em que foram conduzidos, as opções de manejo adotadas na simulação e um resumo dos dados de entrada do solo e da cultura. O SUMMARY.OUT relaciona um resumo dos resultados simulados do crescimento e desenvolvimento da planta, do balanço de carbono e de nitrogênio e do balanço de água no solo. Estes arquivos são incluídos para gerar gráficos detalhados e comparações numéricas entre os valores simulados e observados ao longo do ciclo da cultura.

De acordo com Boote et al. (1998a, 1998b), o balanço de carbono (C) inclui conversão e condensação de $\mathrm{C}$ nos tecidos da planta; perda de $\mathrm{C}$ devido à abscisão de

\footnotetext{
${ }^{2}$ RICHARDSON, C.W. Wheather simulation for crop management models. ASAE paper, n 84-4541, 1985.

${ }^{3}$ GENG, S. AUBURN, J.; BRANDSTETTER, E.; LI, B. A program to simulate meteorological variables: Documentation to SIMMETEO. Agronomy reporter n.204, UCLA, Davis, California.
} 
órgãos, ao crescimento e à respiração de manutenção; expansão da área foliar; mobilização de carboidratos; adição de vagens e de sementes, dentre outros processos. $\mathrm{O}$ balanço de nitrogênio $(\mathrm{N})$ leva em conta a absorção diária de $\mathrm{N}$ pela planta, fixação de $\mathrm{N}_{2}$, utilização do $\mathrm{N}$ para tecidos em crescimento e perda de $\mathrm{N}$ devido a abscisão de órgãos. No balanço de água no solo, são contabilizados a infiltração da chuva ou da irrigação, a absorção de água pelas raízes, a drenagem na zona radicular e a transpiração das plantas.

Além de possuir uma base fisiológica constistente, o CROPGRO permite aos usuários calibrar e aplicar o modelo em distintas condições de solo e clima, por meio de modificações nos arquivos .CUL e .ECO. Também é possível acrescentar outras espécies ao modelo, modificando os coeficientes do arquivo .SPE (Jones et al., 1998). Para isto, é necessário que se tenha uma série de informações sobre a fisiologia da cultura, bem como suas interações com o ambiente. 


\section{MATERIAL E MÉTODOS}

\subsection{Caracterização dos experimentos}

Para calibrar e avaliar o modelo CROPGRO-cowpea, foram utilizados dados de pesquisas conduzidas durante os anos de 1996 a 1998, em campos experimentais da Embrapa Meio-Norte, localizados nos municípios de Teresina (latitude: $5^{\circ} 5^{\prime} \mathrm{S}$; longitude: $42^{\circ} 48^{\prime} \mathrm{W}$ e altitude: $74,4 \mathrm{~m}$ ) e Parnaiba (latitude: $3^{\circ} 5^{\prime} \mathrm{S}$; longitude: $41^{\circ} 47^{\prime} \mathrm{W}$ e altitude: $46,8 \mathrm{~m}$ ), Piauí (Sudene, 1990).

\subsubsection{Solo e clima}

Os experimentos foram instalados nos solos Aluvial Eutrófico, em Teresina e Areia Quartzosa, em Parnaíba (Jacomine, 1986). Um resumo das características químicas e físico-hídricas destes solos encontra-se nas Tabelas 1 e 2, respectivamente. $\mathrm{Na}$ Figura 1, são apresentadas as curvas de retenção para os solos de Parnaíba (a) e Teresina (b). Estas curvas foram ajustadas pelo modelo de Van Genuchten (1980), utilizando-se o programa "Soil Water Retention Curve" (Dourado Neto et al. ${ }^{4}$ ).

O clima dos dois municípios é Aw' segundo a classificação de Köppen, com média anual de umidade relativa do ar em torno de $75 \%$ e precipitação pluviométrica média anual entre 1200 e $1400 \mathrm{~mm}$. Nas Figuras 2 e 3 são apresentados os valores das temperaturas máxima e mínima, ocorridas durante a fase experimental, nos dois municípios. Os valores da radiação solar, estimadas a partir do método de AngströmPrèscott $(a=0,25$ e $b=0,50)$, para os mesmos locais e períodos, encontram-se na Figra 4 .

\footnotetext{
${ }^{4}$ DOURADO NETO, D.; NIELSEN, D.R.; HOPMANS, J.W.; PARLANGE, M.B. Soil Water Retention Curve, versão 1.0, 1995. Departamento de Agricultura, ESALQ/USP, Piracicaba, SP
} 
Tabela 1. Resumo das características químicas dos solos das áreas experimentais dos municípios de Teresina e Parnaiba, Piauí.

\begin{tabular}{lccccccc}
\hline \multirow{2}{*}{ Município } & Tipo de & $\mathrm{pH}$ em & \multicolumn{2}{c}{${\mathrm{Mg} \cdot \mathrm{dm}^{-3}}$} & \multicolumn{3}{c}{$\mathrm{Mmol}_{\mathrm{c}} \cdot \mathrm{dm}_{-}{ }^{3}$} \\
\cline { 4 - 8 } & Solo & Água (1:2,5) & $\mathrm{P}$ & $\mathrm{K}^{+}$ & $\mathrm{Ca}^{2+}$ & $\mathrm{Mg}^{2+}$ & $\mathrm{Al}^{3+}$ \\
\hline Teresina & $\mathrm{AE}$ & 6,0 & 37,6 & 160,9 & 37,0 & 21,0 & 0,9 \\
Parnaíba & $\mathrm{AQ}$ & 6,0 & 15,0 & 110,0 & 30,0 & 13,0 & 0,0 \\
\hline
\end{tabular}

Fonte: Laboratório de Fertilidade de Solos da Embrapa Meio-Norte $\mathrm{AE}=$ Aluvial Eutrófico; $\mathrm{AQ}=$ Areia Quartzosa .

Tabela 2. Resumo das características físico-hídricas dos solos das áreas experimentais dos municípios de Teresina e Parnaíba, Piauí.

\begin{tabular}{|c|c|c|c|c|c|c|c|}
\hline \multirow[t]{2}{*}{ Solo } & \multicolumn{3}{|c|}{ Composição granulométrica (\%) } & \multirow{2}{*}{$\begin{array}{c}\text { Densidade } \\
\left(\mathrm{g} . \mathrm{cm}^{3}{ }^{3}\right)\end{array}$} & \multicolumn{3}{|c|}{ Umidade $\left(\mathrm{cm}^{3} \cdot \mathrm{cm}^{-3}\right)$} \\
\hline & Areia & Silte & Argila & & $\theta_{\mathrm{SAT}}$ & $\theta_{\mathrm{CC}}$ & $\theta_{\mathrm{PMP}}$ \\
\hline $\mathrm{AE}_{(0-20)}$ & 12 & 51 & 37 & 1,19 & 0,402 & 0,195 & 0,069 \\
\hline $\mathrm{AE}_{(20-40)}$ & 24 & 50 & 26 & 1,40 & 0,391 & 0,242 & 0,083 \\
\hline $\mathrm{AQ}_{(0-20)}$ & 65 & 25 & 10 & 1,42 & 0,171 & 0,139 & 0,042 \\
\hline $\mathrm{AQ}_{(20-40)}$ & 84 & 9 & 7 & 1,44 & 0,210 & 0,175 & 0,058 \\
\hline
\end{tabular}

Fonte: Laboratório de Fertilidade de Solos da Embrapa Meio-Norte

$\mathrm{AE}=$ Aluvial Eutrófico; $\mathrm{AQ}=$ Areia Quartzosa. Números entre parênteses significam a profundidade do solo $(\mathrm{cm})$.
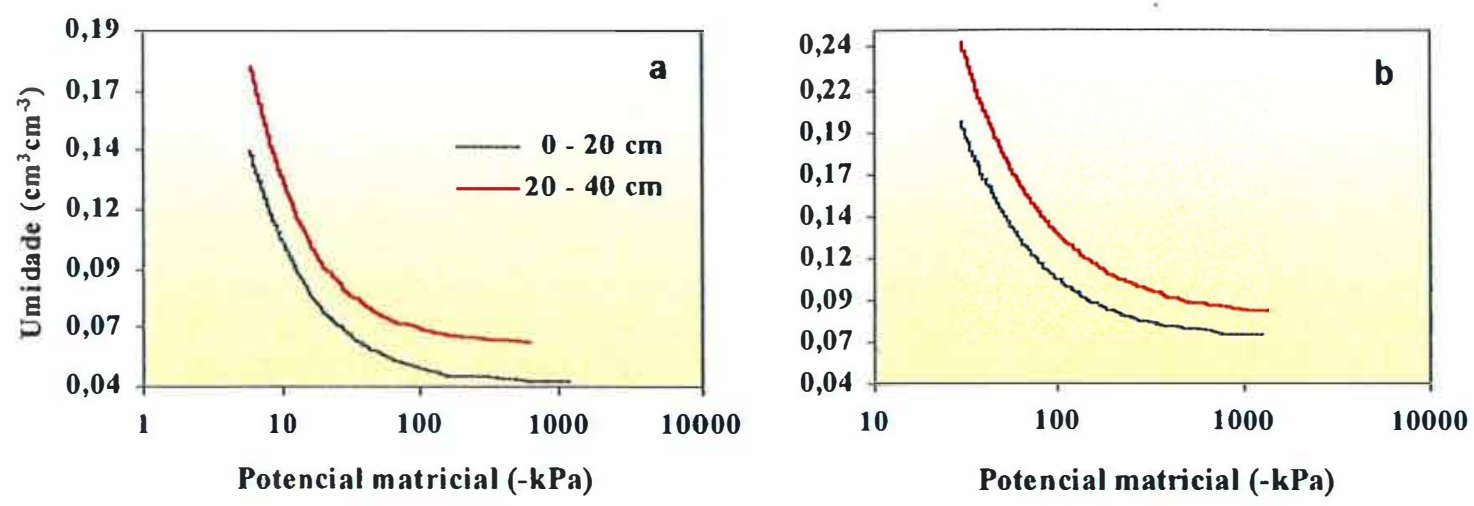

Figura 1. Curvas de retenção dos solos de Parnaíba (a) e de Teresina (b). 


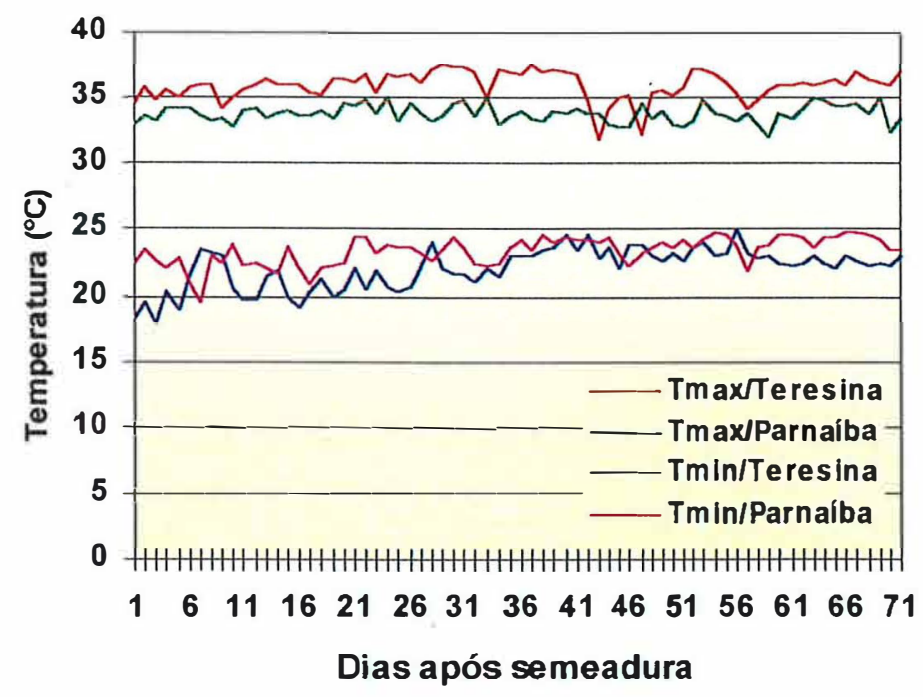

Figura 2. Valores das temperaturas máxima e mínima ocorridos durante os experimentos de 1996, nos municípios de Parnaíba e Teresina.
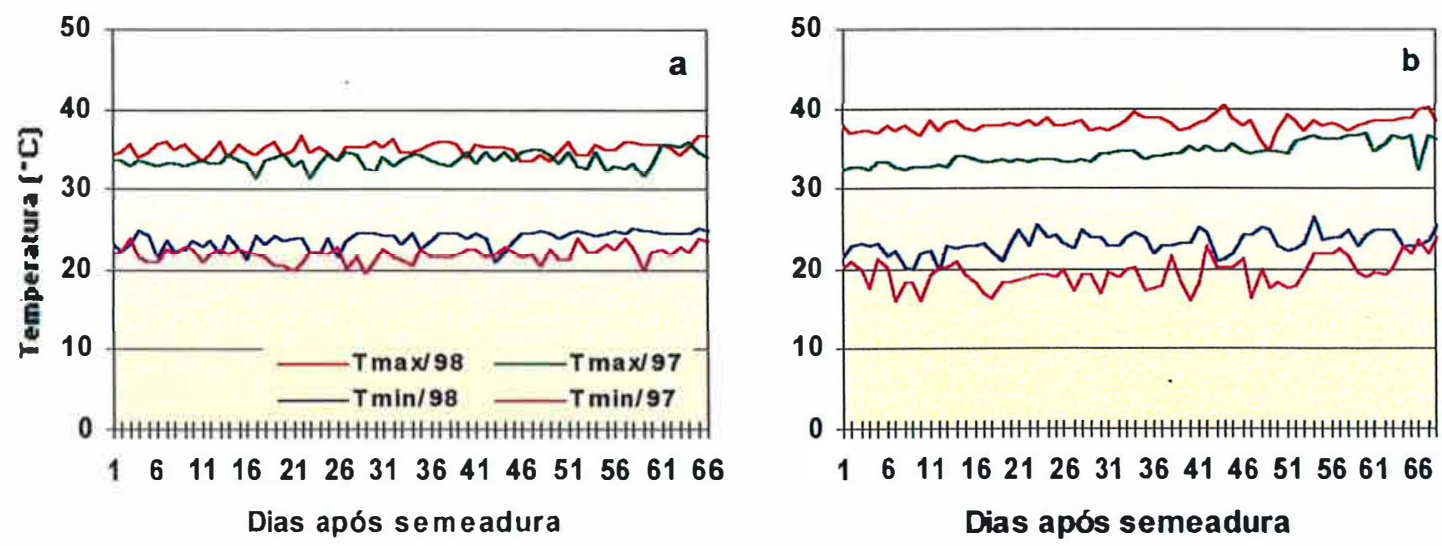

Figura 3. Valores das temperaturas máxima e mínima ocorridos durante os experimentos de 1997 e 1998, nos municípios de Parnaíba (a) e Teresina (b). 

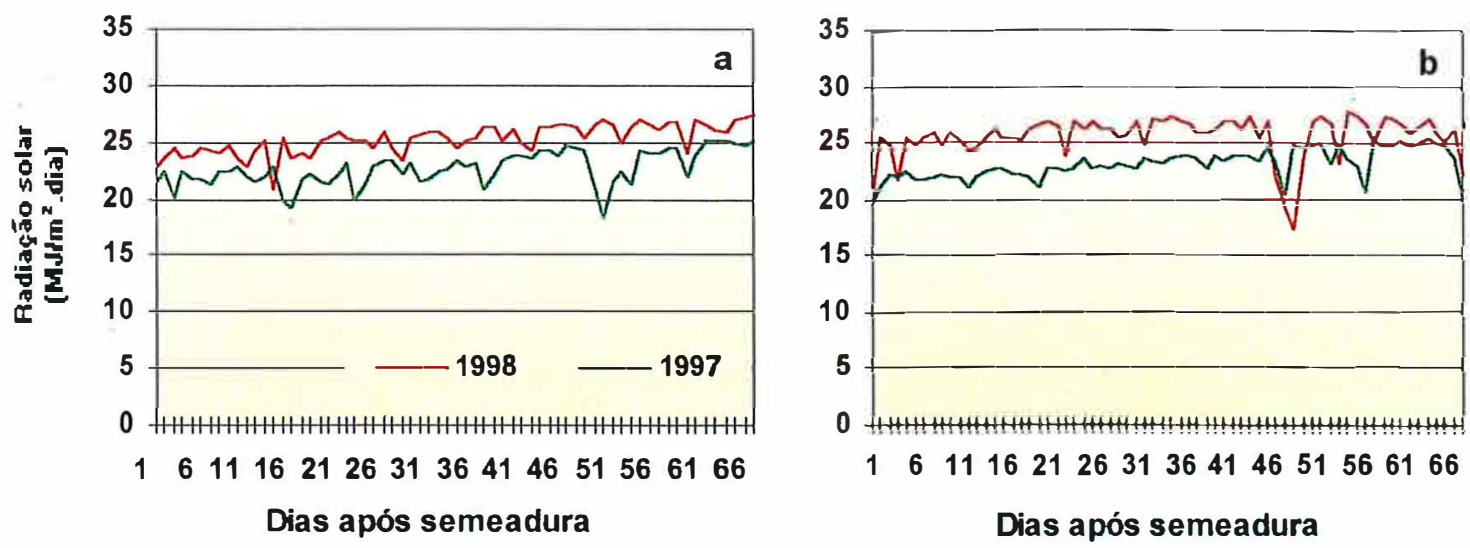

Figura 4. Valores de radiação solar estimados a partir dos dados de insolação (h) para os municípios de Parnaíba (a) e Teresina (b), durante a fase experimental.

\subsubsection{Cultura}

Foram utilizadas as cultivares de feijão caupi BR 14 - Mulato (Cardoso et al. 1990) e BR 17 - Gurguéia (Freire Filho et al., 1994). Um resumo das características agronômicas das duas cultivares encontra-se na Tabela 3.

Tabela 3. Características agronômicas das cultivares de feijão caupi estudadas.

\begin{tabular}{lcc}
\hline Caracter & BR 14 - Mulato & BR 17 - Gurguéia \\
\hline Hábito de crescimento & Indeterminado & Indeterminado \\
Porte & Enramador & Enramador \\
Floração média (dias) & 45 a 55 & 52 \\
Comprimento médio de vagem (cm) & 20 & 17 \\
Número médio de grãos por vagem & 17 & 15 \\
Cor do grão & Marrom & Esverdeada \\
Peso de 100 grãos (g) & 16 & 12,5 \\
Ciclo (dias) & 65 a 75 & 75 \\
\hline
\end{tabular}




\subsubsection{Experimentos utilizados na calibração do CROPGRO-cowpea}

A calibração do CROPGRO-cowpea foi feita com base em experimentos onde foi caracterizado o efeito de diferentes lâminas de irrigação sobre o crescimento, componentes de produção e produtividade de grãos do feijão caupi (Andrade Júnior et al., 1998; 1999).

Os tratamentos (Tabela 4) foram constituídos pela combinação de quatro lâminas de irrigação e duas cultivares de feijão caupi (BR 14 - Mulato e BR 17 - Gurguéia), dispostos em ambos os lados da linha de aspersores. As lâminas de irrigação foram aplicadas, utilizando-se um sistema de irrigação por aspersão convencional, dispostos no campo segundo o sistema de "aspersão em linha".

Durante a condução dos experimentos foi realizada análise de crescimento das plantas, determinando-se semanalmente a área foliar e matéria seca em cada tratamento. Também foram colhidos dados de componentes de produção e produtividade de grãos.

$\mathrm{O}$ delineamento experimental adotado foi o de blocos casualizados, em parcelas subdivididas com quatro repetições. As parcelas possuíam área de $76,8 \mathrm{~m}^{2}(6 \mathrm{~m} \times 12,8 \mathrm{~m})$ e as subparcelas (em número de quatro por parcela) tinham dimensões de $6 \mathrm{~m} \times 3,2 \mathrm{~m}$.

Tabela 4. Lâminas de irrigação aplicadas nos diferentes tratamentos com o feijão caupi (cvs. BR 14 - Mulato e BR 17 - Gurguéia).

\begin{tabular}{llllll}
\hline Município & \multirow{2}{*}{ Ano } & \multicolumn{5}{c}{ Lâminas $(\mathrm{mm})$} \\
\cline { 3 - 6 } & & L1 & L2 & L3 & L4 \\
\hline Parnaíba & 1997 & 455 & $\mathbf{3 3 0}$ & 274 & 190 \\
Parnaíba & 1998 & 449 & $\mathbf{4 2 9}$ & 317 & 194 \\
Teresina & 1997 & $\mathbf{4 0 3}$ & 428 & 331 & 200 \\
Teresina & 1998 & $\mathbf{4 3 4}$ & 459 & 453 & 361 \\
\hline
\end{tabular}

${ }^{1}$ Valores em negrito correspondem aos tratamentos utilizados na calibração do modelo. 
O modelo CROPGRO-cowpea foi calibrado com base nos tratamentos que proporcionaram maiores produtividade de grãos (L1 para Teresina e L2 para Parnaíba), considerando-se que, durante a fase de calibração, as simulações devem ser feitas para condições ótimas de solo e clima, sem ocorrência de estresse hídrico ou nutricional.

\subsubsection{Experimentos utilizados na avaliação do CROPGRO-cowpea}

A avaliação do CROPGRO-cowpea teve por base dados de experimentos que verificaram a influência de quatro níveis de fósforo associados a quatro densidades de plantas (Tabela 5) sobre a produtividade de grãos do feijão caupi (Cardoso et al., 1996a; 1996b).

Tabela 5. Tratamentos utilizados nos experimentos com a cultura do feijão caupi sob irrigação, nos municípios de Teresina e Parnaíba, Piauí.

\begin{tabular}{ccc}
\hline Tratamentos & $\mathrm{P}_{2} \mathrm{O}_{5}\left(\mathrm{~kg}^{\left.\mathrm{h} \mathrm{ha}^{-1}\right)}\right.$ & Plantas. $\mathrm{m}^{-2}$ \\
\hline P1 & 0 & 4 \\
P2 & 45 & 4 \\
P3 & 90 & 4 \\
P4 & 135 & 4 \\
P5 & 0 & 9 \\
P6 & 45 & 9 \\
P7 & 90 & 9 \\
P8 & 135 & 9 \\
P9 & 0 & 14 \\
P10 & 45 & 14 \\
P11 & 90 & 14 \\
P12 & 135 & 14 \\
P13 & 0 & 18 \\
P14 & 45 & 18 \\
P15 & 90 & 18 \\
P16 & 135 & 18 \\
\hline
\end{tabular}


Em cada tratamento foram determinados, na área útil, dados referentes a "stand" final, floração média ( $50 \%$ das plantas com flores), comprimento médio de vagens $(\mathrm{cm})$, número médio de grãos por vagem, número médio de vagens por planta, peso médio de 100 grãos $(\mathrm{g})$, produção média de grãos por planta $(\mathrm{g})$ e produtividade média de grãos $\left(\mathrm{kg} \mathrm{ha}^{-1}\right)$, a $13 \%$ de umidade.

O delineamento experimental foi o de blocos casualizados com quatro repetições e 16 tratamentos (Tabela 5), dispostos em esquema fatorial $4 \times 4$ (níveis de fósforo $\mathrm{x}$ densidade de plantas). Cada parcela continha quatro fileiras de $5 \mathrm{~m}$, espaçadas de $0,8 \mathrm{~m}$. A área útil foi constituída pelas duas fileiras centrais.

\subsubsection{Correção dos dados observados}

Os dados observados de produção de grãos e peso de 100 grãos foram corrigidos para umidade de $0 \%$ pela equação (1). Esta correção foi feita para possibilitar a comparação com os dados simulados pelo modelo.

$P C=\frac{P .(100-U)}{100}$

em que:

PC = Produção ou peso de grãos corrigido para $0 \%$ de umidade;

$\mathrm{P}=$ Produção ou peso de grãos após a colheita $\mathrm{e}$

$\mathrm{U}=$ Umidade do grão após a colheita (\%). 


\subsection{Estrutura do modelo CROPGRO-cowpea}

O CROPGRO-cowpea foi desenvolvido seguindo a mesma estrutura (Figura 5) do modelo CROPGRO do sistema DSSAT, que se encontra descrito em Boote et al. (1998a, 1998b) e Tsuji et al. (1994a).

O CROPGRO-cowpea simula o crescimento e desenvolvimento do feijão caupi. Para criá-lo, foram modificados, no CROPGRO, apenas parâmetros que definem os arquivos de espécie (.SPE), de cultivar (.CUL) e de ecótipo (.ECO), visando caracterizar a cultura do feijão caupi. Estas informações foram obtidas a partir da literatura e de resultados de pesquisas conduzidas na Embrapa Meio-Norte, nos municípios de Parnaíba e Teresina, Piauí, durante os anos de 1996 a 1998. Além disso, foram criados arquivos de solo e de clima dos locais onde foram conduzidos os experimentos.

Os arquivos relacionados com a planta de feijão caupi foram criados através de modificações nos arquivos originais do feijão comum (Phaseolus vulgaris L.), uma das leguminosas integrantes do CROPGRO. Estas adaptações são possíveis dentro da estrutura do CROPGRO e foi uma prática adotada para criação dos modelos de amendoim (PNUTGRO) e feijão (BEANGRO), que tiveram por base o modelo da soja (SOYGRO) (Hoogenboom et al., 1992). 


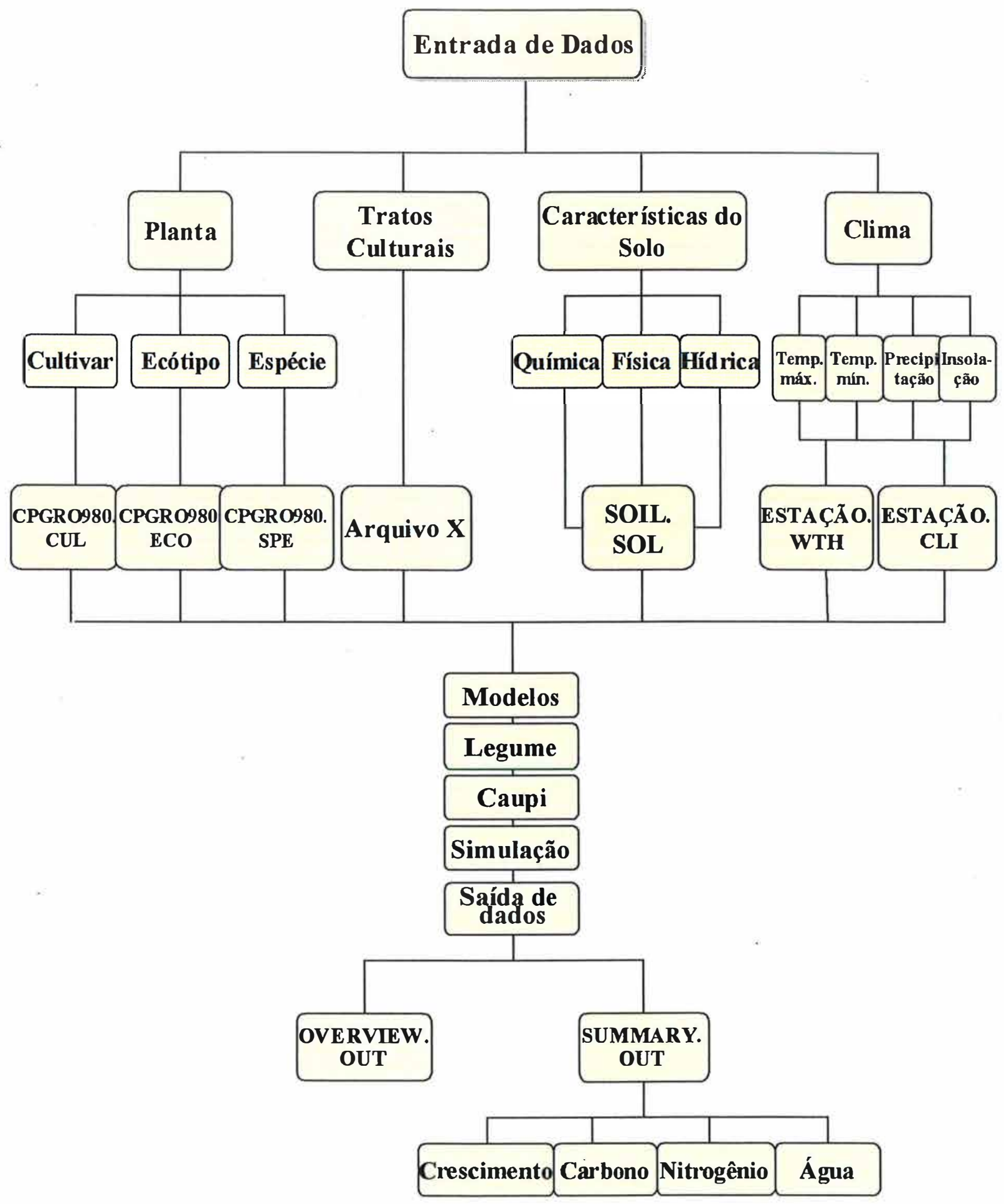

Figura 5. Representação esquemática da estrutura do modelo CROPGRO-cowpea. 


\subsection{Equações utilizadas pelo modelo CROPGRO-cowpea}

As estimativas dos eventos fenológicos, do ganho de matéria seca, da fotossíntese e da partição dos fotoassimilados, foram realizadas por meio das mesmas equações presentes no modelo CROPGRO. A seguir serão apresentadas as principais:

\subsubsection{Estimativa dos eventos fenológicos}

A estimativa do número de dias para o aparecimento da primeira flor, vagem e semente, bem como para completar a maturidade fisiológica, foi feita com base no conceito de dia fisiológico, de acordo com Boote et al. (1998a). A sua relação com o dia do calendário é expressa pela equação (2).

$\frac{P D}{\text { dia }}=f(T) \cdot f(P) \cdot f(W)$

em que:

$\mathrm{PD}=$ dia fisiológico;

$\mathrm{f}(\mathrm{T})=$ fator de restrição do crescimento devido à temperatura do ar;

$\mathrm{f}(\mathrm{P})=$ fator de restrição do crescimento devido ao fotoperíodo e

$\mathrm{f}(\mathrm{W})=$ fator de restrição do crescimento devido ao estresse hídrico.

Em condições ótimas de temperatura, de fotoperíodo e de água no solo, $\mathrm{f}(\mathrm{T})$, $\mathrm{f}(\mathrm{P})$ e $\mathrm{f}(\mathrm{W})$ são iguais a um e, neste caso, o dia fisiológico torna-se igual ao dia do calendário.

A Figura 6 ilustra como é estimado o $\mathrm{f}(\mathrm{T})$ na fase vegetativa do feijão caupi. Os quatro valores que definem a equação correspondem a temperatura basal (TB), temperaturas ótimas $\left(\mathrm{TO}_{1}\right.$ e $\left.\mathrm{TO}_{2}\right)$ e temperatura limite (TL). Estas são definidas nos arquivos de espécie. 


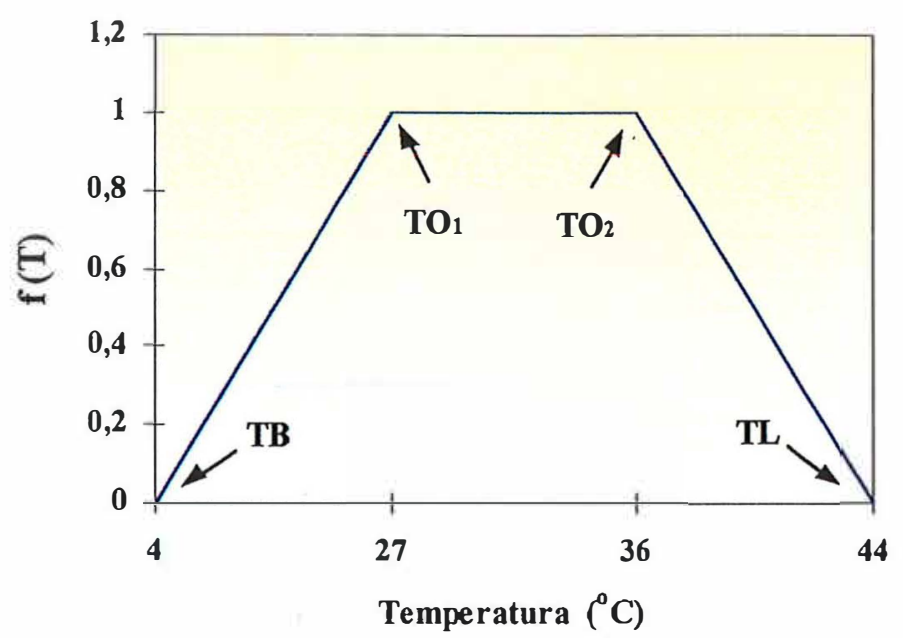

Figura 6. Fator de restrição do crescimento, $\mathrm{f}(\mathrm{T})$, em função da temperatura do ar para a fase vegetativa do feijão caupi.

No presente trabalho, considerou-se $\mathrm{f}(\mathrm{P})$ e $\mathrm{f}(\mathrm{W})$ iguais à unidade, uma vez que foi caracterizado que o feijão caupi era uma cultura insensível ao fotoperíodo e não houve restrições hídricas durante os experimentos.

\subsubsection{Estimativa da matéria seca}

Para descrever o ganho de matéria seca total (equação 3) e parcial, resultantes do balanço de carbono foram utilizadas equações diferenciais não lineares de primeira ordem (Boote et al., 1998a). Ressalta-se que no presente estudo, as palavras matéria seca e biomassa foram utilizadas como sinônimos.

$\frac{d W}{d t}=W^{+}-S_{L}-S_{S}-S_{R}-S_{S h}-C_{T}$

em que:

$\frac{d W}{d t}=$ taxa de variação da matéria seca total $\left(\mathrm{g} \cdot \mathrm{m}^{-2}\right)$ 
$S_{L}, S_{S}, S_{R}$ e $S_{S h}$ correspondem às taxas de abscisão de folhas, ramos, raízes e casca da vagem, respectivamente;

$\mathrm{C}_{\mathrm{T}}$ é o total de carboidratos mobilizados;

$\mathrm{W}^{+}$significa novo crescimento e é função da fotossíntese total (FT), respiração de manutenção $(\mathrm{Rm})$ e da eficiência de conversão $(\mathrm{E})$ de gramas de $\mathrm{CH}_{2} \mathrm{O}$ em gramas de matéria seca, sendo expresso por:

$$
\mathrm{W}^{+}=\mathrm{E}(\mathrm{FT}-\mathrm{Rm})
$$

Para o cálculo da taxa de variação da matéria seca nas folhas, nos ramos, nas raízes e na casca da vagem foram utilizadas as equações (5), (6), (7), (8) e (9), respectivamente.

$$
\begin{aligned}
& \frac{d W_{L}}{d t}=X_{L} \cdot W^{+}-S_{L}-M_{L}-C_{L} \\
& \frac{d W_{s}}{d t}=X_{S} \cdot W^{+}-S_{s}-M_{S}-C_{S} \\
& \frac{d W_{R}}{d t}=X_{R} \cdot W^{+}-S_{R}-M_{R}-C_{R} \\
& \frac{d W_{S h}}{d t}=X_{S h} \cdot W^{+}-S_{S h}-M_{S h}-C_{S H} \\
& \frac{d W_{S d}}{d t}=X_{S d} \cdot W^{+}+a\left(M_{L}+M_{S}+M_{R}+M_{S h}\right)
\end{aligned}
$$

em que:

$X_{L}, X_{S}, X_{R}, X_{S h}$ e $X_{S d}$ representam os coeficientes de partição de fotoassimilados para as folhas, ramos, raizes, casca da vagem e sementes, respectivamente. Eles variam de acordo com o estádio fenológico da cultura.

$\mathrm{M}_{\mathrm{L}}, \mathrm{M}_{\mathrm{S}}, \mathrm{M}_{\mathrm{R}}$ e $\mathrm{M}_{\mathrm{Sh}}$ descrevem a quantidade de proteína ( $\mathrm{g}$ ) mobilizada diariamente nas folhas, ramos, raízes e casca da vagem, respectivamente.

$\mathrm{C}_{\mathrm{L}}, \mathrm{C}_{\mathrm{S}}, \mathrm{C}_{\mathrm{R}}$ e $\mathrm{C}_{\mathrm{Sh}}$ descrevem a quantidade de carboidratos (g) mobilizada diariamente nas folhas, ramos, raízes e casca da vagem, respectivamente. 


\subsubsection{Estimativa da fotossintese}

O modelo CROPGRO dispõe de duas opções para a estimativa da fotossíntese: uma é com base em valores diários, a nível do dossel da cultura e a outra é com base em valores horários, a nível de folha (Boote et al., 1998a).

No presente estudo, utilizou-se a primeira opção, cuja taxa fotossintética é calculada separadamente para folhas expostas ao sol e folhas sombreadas. A função que rege o processo (equações 10 e 11) é uma exponencial assintótica (Boote \& Pickering, 1994).

$$
\begin{aligned}
& F_{S u n}=P_{\max } \cdot\left[1-e^{\left(-Q e \cdot K d \cdot(1-\sigma) P F D / P_{\max }\right)}\right] \\
& F_{S h}=P_{\max } \cdot\left[1-e^{\left(-Q e \cdot P F D S h / P_{\max }\right)}\right] \\
& \mathrm{FT}=\mathrm{F}_{\text {sun }}+\mathrm{F}_{\mathrm{sh}} \\
& \text { em que: }
\end{aligned}
$$$$
\mathrm{F}_{\text {sun }}=\text { fotossíntese de folhas expostas ao sol }\left(\mu \mathrm{mol} \mathrm{CO} 2 \cdot \mathrm{m}^{-2} \cdot \mathrm{s}^{-1}\right) \text {; }
$$$$
\mathrm{F}_{\mathrm{sh}}=\text { fotossintese de folhas sombreadas }\left(\mu \mathrm{mol} \mathrm{CO}_{2} \cdot \mathrm{m}^{-2} \cdot \mathrm{s}^{-1}\right) \text {; }
$$$$
\mathrm{FT}=\text { fotossíntese total }\left(\mu \mathrm{mol} \mathrm{CO} 2 \cdot \mathrm{m}^{-2} \cdot \mathrm{s}^{-1}\right) \text {; }
$$$$
\mathrm{P}_{\max }=\text { taxa de fotossíntese à luz saturada }\left(\mu \mathrm{mol} \mathrm{CO} \cdot \mathrm{m}^{-2} \cdot \mathrm{s}^{-1}\right) \text {; }
$$$$
\mathrm{QE}=\text { eficiência do uso da radiação solar }\left(\mathrm{mol}^{\mathrm{mol}}{ }^{-1}\right) \text {; }
$$$$
\mathrm{PFD}=\text { radiação fotossinteticamente ativa total }\left(\mu \mathrm{mol} \cdot \mathrm{m}^{-2} \cdot \mathrm{s}^{-1}\right) \text {; }
$$$$
\mathrm{PFD}_{\mathrm{Sh}}=\text { radiação fotossinteticamente ativa por unidade de folha }\left(\mu \mathrm{mol} \cdot \mathrm{m}^{-2} \cdot \mathrm{s}^{-1}\right) \text {; }
$$$$
\mathrm{Kd}=\text { coeficiente de atenuação da luz difusa e }
$$$$
\sigma=\text { fração da PFD dispersa na folha. }
$$

$\mathrm{O}$ índice de área foliar das folhas expostas ao sol $\left(\mathrm{IAF}_{\text {sun }}\right)$ e das folhas sombreadas $\left(\mathrm{IAF}_{\mathrm{sh}}\right)$ foram calculados pelas equações $(12)$ e (13).

$$
I A F_{\text {Sun }}=\frac{P s h}{K d} \cdot\left[1-e^{\left(-K d \cdot \frac{L A F}{F s h}\right)}\right]
$$


sendo:

Psh = projeção da sombra;

IAF = índice de área foliar total;

$I A F_{S h}=I A F-I A F_{\text {Sun }}$

\subsubsection{Partição de fotoassimilados}

A partição dos fotoassimilados foi estimada de acordo com a equação (14) (Boote et al., 1998a).

$$
\mathrm{W}_{\mathrm{i}}^{+}=\text {Xi.Ei.(FT-Rm) }
$$

Em que:

$\mathrm{Wi}^{+}=$matéria seca nova produzida em cada componente da planta;

$\mathrm{Xi}=$ fator de partição para cada tecido da planta;

Ei = eficiência de conversão;

$\mathrm{Rm}=$ respiração de manutenção.

Segundo os autores, durante a fase vegetativa, todos os assimilados são alocados para os tecidos vegetativos como folhas, ramos e raizes. No estádio reprodutivo, novos drenos (paredes das vagens e sementes) são formados, alocando parte dos fotoassimilados.

\subsection{Balanço de nitrogênio}

O balanço de nitrogênio no solo foi o mesmo utilizado no modelo CERES do DSSAT e está descrito em Godwin \& Jones ${ }^{5}$ citado por Boote et al. (1998b). Segundo

\footnotetext{
${ }^{5}$ GODWIN, D.C.; JONES; C.A. Nitrogen dynamics in soil-plant systems. In: HANKS, J.; RITCHIE, J.T. (Eds.) Modeling soil and plant systems. Madison: American Society of Agronomy, ASAE monograph 31, p. 287-321, 1991.
} 
estes autores a absorção de $\mathrm{NO}_{3}{ }^{-}$e $\mathrm{NH}_{4}{ }^{+}$depende da concentração destas substâncias no solo, da disponibilidade de água e da concentração das raizes em cada camada do solo. A absorção diária de $\mathrm{N}$ pela cultura não pode ser maior que sua demanda. Esta é computada a partir do ganho de matéria seca em cada órgão da planta e da máxima concentração de $\mathrm{N}$ encontrada nos tecidos, cujos valores são definidos no arquivo .SPE.

\subsection{Balanço de água no solo}

O balanço de água no solo utilizado no CROPGRO-cowpea também foi o mesmo do modelo CERES do DSSAT, descrito em Ritchie (1985).

O solo é dividido em camadas e o teor de água em cada camada varia entre um limite inferior (umidade no ponto de murcha permanente) e um limite superior (umidade de saturação). Se o teor de água em uma determinada camada estiver acima da umidade correspondente à capacidade de campo, a água é drenada para a próxima camada, utilizando-se o coeficiente de drenagem que é especificado no arquivo de solo (SOIL.SOL).

A infiltração da água de chuva ou da irrigação e o escoamento superficial foram estimados pelo método do número da curva de escoamento superficial (Soil Conservation Service). Segundo Jones \& Kiniry ${ }^{6}$ citados por Lima (1995) este método descreve quatro grupos hidrológicos de solo (Tabela 6), devendo-se escolher o valor mais apropriado para representar o número da curva de escoamento do solo estudado.

No presente estudo, considerou-se que os solos, Areia Quartzosa (Parnaíba) e Aluvial Eutrófico (Teresina), enquadram-se nos grupos A e B, respectivamente (Tabela 6). Como os tratamentos constaram de fileiras simples e permaneceram sob boas condições hidrológicas, os números da curva de escoamento adotadas (Tabela 7) foram 78 (Aluvial Eutrófico) e 67 (Areia Quartzosa).

\footnotetext{
${ }^{6}$ JONES, C.A; KINIRY, J.R. CERES-maize: a simulation model of maize growth and development. College Station, Texas A \& M. University Press, 1986. 194 p.
} 
Em relação à estimativa da evapotranspiração de referência (ETo), o modelo CROPGRO dispõe de duas opções: a) Método de Priestley-Taylor, que é a opção "default" e b) Método de Penman-FAO. No presente estudo, utilizou-se o método de Priestley-Taylor, que requer apenas dados de temperatura do ar e radiação solar líquida.

Tabela 6. Grupos de solos utilizados para estimar o número da curva de escoamento

\begin{tabular}{cl}
\hline $\begin{array}{c}\text { Grupo de } \\
\text { Solos }\end{array}$ & \multicolumn{1}{c}{ Descrição } \\
\hline A & $\begin{array}{l}\text { Escoamento potencial baixo. Estão incluídas as areias profundas com } \\
\text { pouco sedimento e argila; perde rapidamente a permeabilidade com a } \\
\text { profundidade. }\end{array}$ \\
& $\begin{array}{l}\text { Escoamento potencial moderadamente baixo. Inclui especialmente solos } \\
\text { arenosos menos profundos que A e que perdem a permeabilidade mais } \\
\text { lentamente. O grupo apresenta, em geral, infiltração acima da média } \\
\text { após ser umedecido. }\end{array}$ \\
B & $\begin{array}{l}\text { Escoamento potencial moderadamente alto. Contempla solos rasos que } \\
\text { contenham considerável quantidade de argila e colóides, embora menos } \\
\text { que o grupo D. A infiltração é abaixo da média após pré-saturação. }\end{array}$ \\
D & $\begin{array}{l}\text { Escoamento potencial mais alto. Compreende a maior parte dos solos } \\
\text { argilosos e profundos, mas também estão incluídos, neste grupo, alguns } \\
\text { solos rasos com subhorizontes impermeáveis próximos da superficie. }\end{array}$ \\
\hline
\end{tabular}

Fonte: (Jones \& Kiniry ${ }^{6}$ ) citado por Lima (1995)

Tabela 7. Número da curva de escoamento em função do grupo hidrológico

\begin{tabular}{ccccccc}
\hline \multirow{2}{*}{ Sistema } & Condição & \multicolumn{5}{c}{ Grupo hidrológico } \\
\cline { 3 - 6 } & Hidrológica & A & B & C & D \\
\hline Fileiras simples & Pobre & 72 & 81 & 88 & 91 \\
Fileiras simples & Boa & 67 & 78 & 85 & 89 \\
Curvas de nível & Pobre & 70 & 79 & 84 & 88 \\
Curvas de nível & Boa & 65 & 75 & 82 & 86 \\
Terraplanagem & Pobre & 66 & 74 & 80 & 82 \\
Terraplanagem & Boa & 62 & 71 & 78 & 81 \\
\hline
\end{tabular}

Fonte: (Jones \& Kiniry ${ }^{6}$ ) citado por Lima (1995) 


\subsection{Calibração do modelo CROPGRO-cowpea}

A calibração consiste em se modificar os parâmetros do modelo para a obtenção dos melhores ajustes entre os dados simulados e os observados (Hoogenboom et al., 1992; Jones et al., 1987).

Para calibrar o CROPGRO-cowpea adotou-se a técnica descrita por Boote (1994). Inicialmente ajustaram-se as datas de florescimento, aparecimento do primeiro grão, primeira vagem e maturidade fisiológica. Estes ajustes foram obtidos, alterando-se os coeficientes que se relacionam com a fenologia da cultura (Tabela 8).

Posteriormente, procedeu-se os ajustes do acúmulo de matéria seca, índice de área foliar, peso unitário de grãos, número de grãos por vagem, número de vagens por planta, duração do período de enchimento de grãos e, finalmente, a produtividade de grãos. Nesta fase, houve necessidade de se modificar alguns coeficientes de espécie (Tabela 9).

Durante a calibração foram atribuídos valores aos parâmetros da planta e o modelo foi executado várias vezes até que os valores simulados de biomassa, índice de área foliar, fenologia, componentes de produção e produtividade de grãos estivessem bem próximos dos observados. 
Tabela 8. Parâmetros dos arquivos de cultivar e de ecótipo modificados para a calibração do modelo CROPGRO-cowpea.

\begin{tabular}{ll}
\hline Parâmetro & Valor utilizado $^{1}$ \\
\hline
\end{tabular}

a) Arquivo de cultivar

BR 14 BR 17

Tempo requerido entre a emergência e $1^{\mathrm{a}}$ flor $\left(\mathrm{DF}^{2}\right)$ $36 \quad 36$

Tempo requerido entre $1^{\underline{a}}$ flor e $1^{\underline{a}}$ vagem $(D F)$

$3 \quad 3$

Tempo requerido entre $1^{\text {a }}$ flor e $1^{\circ}$ grão (DF) 7

Tempo requerido entre $1^{\circ}$ grão e maturidade fisiológica (DF)

Tempo requerido entre $1^{\underline{a}}$ flor e o fim da expansão foliar (DF)

Área foliar específica em condições normais de crescimento $\left(\mathrm{cm}^{2} \cdot \mathrm{g}^{-1}\right)$

Área máxima de um trifólio $\left(\mathrm{cm}^{2}\right)$

Peso máximo de um grão $(\mathrm{g})$

$0,16 \quad 0,16$

Duração do período de enchimento de grãos (DF)

Número médio de grãos por vagem

b) Arquivo de ecótipo

Tempo requerido entre semeadura e emergência (DF)

Tempo requerido entre emergência e $1^{\underline{a}}$ folha verdadeira (DF)

Tempo requerido entre maturidade fisiológica e colheita (DF)

Valor máximo da relação grão/vagem (\%)

${ }^{1}$ Valores obtidos em experimentos conduzidos pela Embrapa Meio-Norte nos municípios de Parnaíba e Teresina, Piauí.

${ }^{2}$ Dias fisiológicos (DF): corresponde ao dia do calendário quando há condições ótimas de desenvolvimento para planta (item 3.3.1) 
Tabela 9. Parâmetros de espécie modificados a partir dos parâmetros do feijão comum Phaseolus vulgaris L para calibração do modelo CROPGRO-cowpea.

\begin{tabular}{|c|c|c|c|}
\hline \multirow[t]{2}{*}{ Parâmetros } & \multicolumn{2}{|c|}{ Valores } & \multirow[t]{2}{*}{ Fonte } \\
\hline & $\begin{array}{l}\text { Feijão } \\
\text { comum }\end{array}$ & $\begin{array}{l}\text { Feijão } \\
\text { caupi }\end{array}$ & \\
\hline
\end{tabular}

a) Fotossíntese

Coeficiente de extinção de luz (KCAN)

Coeficiente de temperatura (3) (FNPGT) ${ }^{2}$.

Coeficiente de temperatura (4) (FNPGT) ${ }^{2}$

Peso específico da folha $\left(\mathrm{g} . \mathrm{cm}^{-2}\right)($ SLWREF $)$

Concentração de $\mathrm{N}$ na folha (LNREF)

b) Composição de plantas

Concentração de proteína na folha (PROLFG) $\quad 0,16 \quad 0,228$ Nielsen et al. (1994)

Concentração de proteína no ramo (PROSTG) $\quad 0,100 \quad 0,09 \quad$ Nielsen et al. (1994)

Concentração de proteína na semente

c) Crescimento de folhas

Área foliar por trifólio $\left(\mathrm{cm}^{2}\right)$ (SIZREF)

${ }^{1}$ Fonte de onde foi retirado os valores dos coeficientes para o feijão caupi.

${ }^{2}$ Corresponde a uma curva definida por quatro valores que descreve a assimilação do dossel da cultura em função da temperatura média do ar. Foram modificados apenas o terceiro e quarto valores, com base nos dados da soja .

${ }^{3}$ Corresponde ao arquivo de espécie da soja no modelo CROPGRO.

\subsubsection{Dados de entrada}

Para calibrar o modelo CROPGRO-cowpea, foi necessário caracterizar os tratos culturais aplicados nos experimentos e fornecer os dados locais de solo e clima.

As informações relacionadas com os tratos culturais (manejo de irrigação e de fertilizantes), bem como data de semeadura, densidade de plantas e profundidade de plantio, aplicadas nos experimentos, foram armazenadas em arquivos do tipo X. Para cada experimento correspondeu um arquivo $\mathrm{X}$, contendo informações diferenciadas de ano, local, cultivar e manejo. Estes arquivos foram utilizados nas simulações das fases de calibração ou avaliação do modelo CROPGRO-cowpea. 
Em relação ao solo, foram requeridos os seguintes parâmetros:

- Profundidade do solo (m);

- Número de camadas no perfil;

- Espessura de cada camada (m);

- Textura;

- Teor de argila (\%);

- Teor de silte (\%);

- Densidade do solo $\left(\mathrm{g} . \mathrm{cm}^{-3}\right)$;

- Umidade correspondente à saturação $\left(\mathrm{cm}^{3} \cdot \mathrm{cm}^{-3}\right)$;

- Umidade correspondente à capacidade de campo $\left(\mathrm{cm}^{3} . \mathrm{cm}^{-3}\right)$;

- Umidade correspondente ao ponto de murcha permanente $\left(\mathrm{cm}^{3} . \mathrm{cm}^{-3}\right)$;

- Taxa de drenagem no perfil do solo $\left(\mathrm{dia}^{-1}\right)$;

- Número da curva de escoamento superficial;

- Fator de ponderação da distribuição das raízes (0 a 1);

- Fator de mineralização (0 a 1);

- Fator de fotossintese (0 a 1$)$;

- Carbono orgânico (\%);

- Nitrogênio total (\%); e

- $\mathrm{pH}$ em água.

Foram requeridos valores desses parâmetros para cada camada do perfil. O solo de Teresina (Aluvial Eutrófico) foi divido em oito camadas: 0 a $0,15 \mathrm{~m} ; 0,15$ a $0,30 \mathrm{~m}$; 0,30 a $0,45 \mathrm{~m} ; 0,45$ a $0,80 \mathrm{~m} ; 0,80$ a $1,0 \mathrm{~m} ; 1,0$ a $1,25 \mathrm{~m} ; 1,25$ a $1,50 \mathrm{~m}$ e 1,5 a $2,0 \mathrm{~m}$. O solo de Pamaiba (Areia Quartzosa), que é mais raso, foi caracterizado com as seguintes camadas: 0 a $0,20 \mathrm{~m} ; 0,20$ a $0,40 \mathrm{~m} ; 0,40$ a $0,60 \mathrm{~m} ; 0,60$ a $0,80 \mathrm{~m} ; 0,80$ a $1,0 \mathrm{~m}$ e 1,0 a $1,2 \mathrm{~m}$. Ressalta-se que as informações sobre as características químicas, fisicas e hídricas até $0,40 \mathrm{~m}$ (Tabelas 1 e 2), foram obtidas por meio de análises de solo, realizadas no Laboratório de Solos da Embrapa Meio-Norte. Para as outras camadas, foram usados valores obtidos na descrição do perfil feita por Jacomine et al. (1986) (solo 
de Teresina) e Andrade et al. (1992) (solo de Pamaíba). Todas estas informações foram armazenadas num arquivo denominado SOIL.SOL.

Em relação ao clima, foram utilizados dados diários de temperaturas máxima e mínima $\left({ }^{\circ} \mathrm{C}\right)$, precipitação pluviométrica $(\mathrm{mm})$ e insolação $(\mathrm{h})$ dos anos de 1997 e 1998, cujos valores foram armazenados em arquivos.WTH. Estes dados foram obtidos em postos meteorológicos, próximos aos campos experimentais.

\subsection{Avaliação do modelo CROPGRO-cowpea}

A avaliação do modelo é o processo pelo qual os dados simulados são comparados com valores observados de experimentos não utilizados durante a fase de calibração. Nesta etapa, os parâmetros do modelo não podem ser modificados (Hoogenbom et al., 1992; Jones et al., 1987).

Para as simulações nessa fase, foram utilizados os mesmos arquivos de planta (.SPE, .CUL e .ECO) e de solo (SOIL.SOL) aplicados na calibração e o arquivo contendo os dados climáticos de 1996, que foi o ano da instalação do experimento.

$\mathrm{Na}$ avaliação do CROPGRO-cowpea, foram comparados apenas os valores de fenologia, componentes de produção e produtividade de grãos dos experimentos descritos no item 3.1.4, uma vez que, nestes experimentos, não foi feita análise de crescimento. Nessa fase, foram utilizados somente dados referente à cv. BR 17 Gurguéia, em função da disponibilidade de informações.

\subsection{Aplicação do modelo CROPGRO-cowpea}

A aplicação do modelo CROPGRO-cowpea consistiu na avaliação econômica do manejo da irrigação para produção de grãos de feijão caupi (cv. BR 17 - Gurguéia). Os dados requeridos para esta avaliação, com os respectivos valores utilizados, foram:

- Preço de venda do grão $\left(\mathrm{R} \$ . \mathrm{t}^{-1}\right)=1.000,00$;

- Custo com adubo nitrogenado $\left(\mathrm{R} \$ . \mathrm{kg}^{-1}\right)=0,30$; 
- Custo com aplicação de nitrogênio (mão-de-obra) $(\mathrm{R} \$)=12,00$;

- Custo com a irrigação $\left(\mathrm{R} \$ . \mathrm{mm}^{-1}\right)=0,50$;

- Custo com a aplicação da lâmina de irrigação (mão-de-obra) $(\mathrm{R} \$)=12,00$; e

- Custo básico de produção (desconsiderando água e $\mathrm{N})\left(\mathrm{R} \$\right.$ ha $\left.^{-1}\right): 600,00$

Estes preços foram relativos ao mês de agosto de 1999, vigentes no mercado de Teresina, Piauí.

Foram simulados 20 tratamentos, originados da combinação de cinco níveis de extração da água disponível do solo com quatro épocas de semeadura (Tabela 10). A relação entre a capacidade de água disponível (CAD) e o potenical matricial dos dois solos estudados, encontra-se na Figura 7.

Em função da disponibilidade de dados climáticos de 1990 a 1998, em Parnaíba, e de 1977 a 1998, em Teresina, foram aplicadas 9 e 22 repetições para os dois locais, respectivamente. Estas simulações foram realizadas no módulo "SEASONAL" do sistema DSSAT, que permite a utilização de séries históricas de dados.

A caracterização dos experimentos simulados foi feita em arquivos do tipo .SNX (no módulo SEASONAL). Neste arquivo o manejo da irrigação foi definido com as seguintes características:

- Profundidade de manejo da irrigação: $20 \mathrm{~cm}$;

- Limite inferior da capacidade de água disponível (CAD): 30, 40, 50 ou 60\%, conforme o tratamento utilizado;

- Limite superior da CAD: $100 \%$;

- Método de irrigação: aspersão convencional;

- Lâmina de irrigação (pré-fixada): $10 \mathrm{~mm}$ (Parnaíba) e 20 mm (Teresina);

- Eficiência do sistema de irrigação: 0,75 (Parnaíba) e 0,80 (Teresina);

- Estádio da planta em que finalizou a irrigação: Plantas com 50\% das vagens amareladas; 

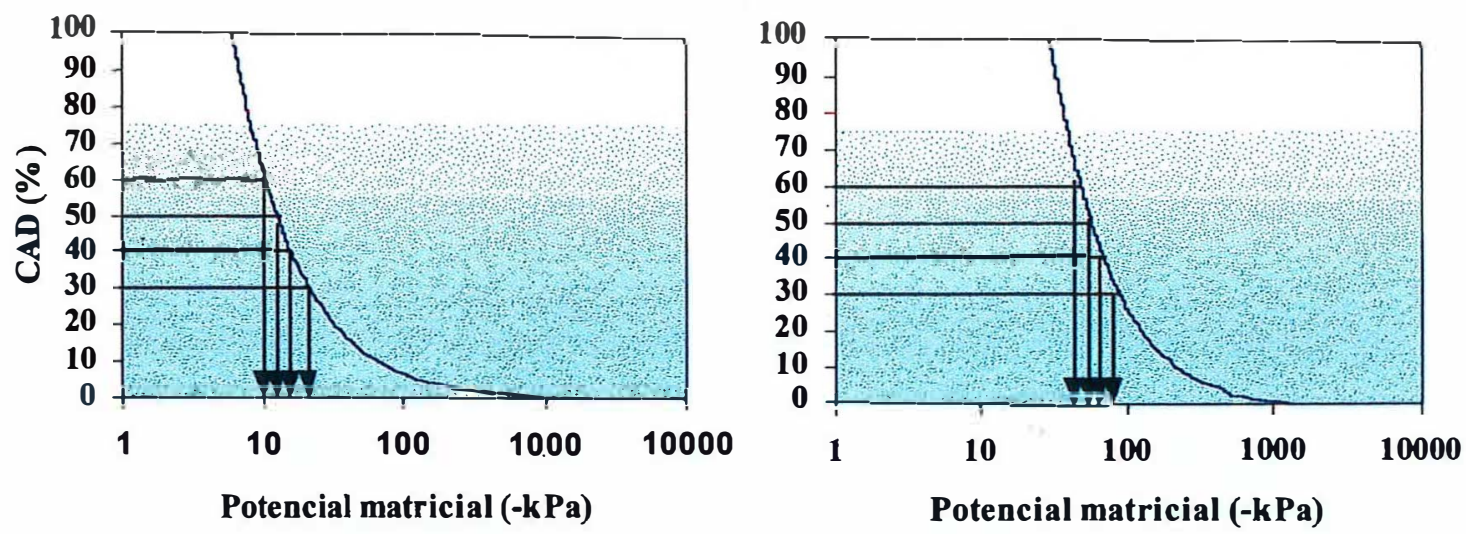

Figura 7. Relação entre a capacidade de água disponível (CAD) e o potencial matricial dos solos de Parnaíba (a) e de Teresina (b).

A análise da estratégia ótima do manejo da irrigação para a produção de grãos do feijão caupi foi feita com base na dominância de Gini ("Mean-Gini Dominance") (Thornton et al., 1994), comparando-se todos os tratamentos, dois a dois. De acordo com esse método, um tratamento (Tx) é mais eficiente que outro (Ty), se:

$E(T x) \geq E(T y)$ e $E(T x)-\Gamma(T x) \geq E(T y)-\Gamma(T y)$

Em que, no presente estudo:

$\mathrm{E}()=$. Esperança de receita líquida média $\left(\mathrm{R} \$ . \mathrm{ha}^{-1}\right)$ do tratamento considerado $\mathrm{e}$

$\Gamma()=$. coeficiente de distribuição de Gini do tratamento considerado $\left(\mathrm{R} \$ \cdot \mathrm{ha}^{-1}\right)$.

O coeficiente de Gini $(\Gamma)$ corresponde à metade do valor da "diferença média de Gini" (DMG), a qual é dada pela seguinte equação:

$$
\mathrm{DMG}=|\mathrm{A}-\mathrm{B}|
$$

Em que, A e B correspondem a valores aleatórios atribuídos para cada tratamento, considerando-se que a receita líquida segue uma distribuição triangular (Thornton \& Hoogenboom, 1994). 
Tabela 10. Tratamentos utilizados na avaliação econômica do manejo de irrigação para a produção de grãos do feijão caupi, utilizando-se o modelo CROPGROcowpea.

\begin{tabular}{ccc}
\hline Tratamentos & Época de semeadura & $\begin{array}{c}\text { Níveis de água no solo } \\
\left(\% \text { da } C A D^{1}\right)\end{array}$ \\
\hline T1 & $15 / 06$ & $60 \%$ \\
T2 & $15 / 06$ & $50 \%$ \\
T3 & $15 / 06$ & $40 \%$ \\
T4 & $15 / 06$ & $30 \%$ \\
T5 & $15 / 06$ & Sem irrigação \\
T6 & $15 / 07$ & $60 \%$ \\
T7 & $15 / 07$ & $50 \%$ \\
T8 & $15 / 07$ & $40 \%$ \\
T9 & $15 / 07$ & $30 \%$ \\
T10 & $15 / 07$ & $60 \%$ \\
T11 & $15 / 08$ & $50 \%$ \\
T12 & $15 / 08$ & $40 \%$ \\
T13 & $15 / 08$ & $30 \%$ \\
T14 & $15 / 08$ & Sem irrigação \\
T15 & $15 / 08$ & $60 \%$ \\
T16 & $15 / 09$ & $50 \%$ \\
T17 & $15 / 09$ & $40 \%$ \\
T18 & $15 / 09$ & $30 \%$ \\
T19 & $15 / 09$ & Sem irrigação \\
T20 & $15 / 09$ &
\end{tabular}

${ }^{1}$ Capacidade de água disponível no solo

\subsection{Aferição do modelo CROPGRO-cowpea}

Para aferir a performance do modelo utilizou-se o método gráfico. Plotou-se os valores observados e simulados do índice de área foliar e matéria seca acumulada versus tempo, utilizando-se o coeficiente de determinação $\left(r^{2}\right)$ e o erro absoluto médio (EAM), como critério estatístico. Para os dados de componentes de produção e produtividade de grãos do feijão caupi calculou-se o percentual da diferença entre os valores observados e simulados. 


\section{RESULTADOS E DISCUSSÃO}

\subsection{Calibração do modelo CROPGRO-cowpea}

\subsubsection{Estimativa dos eventos fenológicos}

Os valores observados e simulados da fenologia das duas cultivares de feijão caupi (BR 14 - Mulato e BR 17 - Gurguéia), nas condições de solo e clima de Parnaíba e Teresina, encontram-se nas Tabelas 11 a 14 . Verificou-se que as duas cultivares praticamente não diferiram em relação às datas de aparecimento da primeira flor, vagem e semente. Isto pode ser justificado em função das mesmas apresentarem, em média, o mesmo ciclo (Cardoso et al, 1990; Freire Filho et al., 1994).

Além disso, a maturidade fisiológica e a colheita dos grãos nos experimentos considerados ocorreram na mesma época, o que reforça a semelhança de ciclo entre as duas cultivares. Esta característica foi demonstrada pelo modelo, uma vez que os eventos fenológicos simulados foram praticamente iguais para as duas cultivares.

Verificou-se que as simulações da fenologia foram mais precisas em 1997. Neste ano, a diferença máxima entre os valores observados e simulados para as duas cultivares foi de apenas dois dias em Parnaíba e um dia em Teresina (Tabelas 11 e 13).

No ano de 1998, em ambos os locais, os valores experimentais indicaram uma redução do ciclo da cultura de três a cinco dias em relação ao ano anterior, o que não foi caracterizado pelo modelo. Essa diminuição no ciclo das duas cultivares,provavelmente, foi devido à ocorrência de temperaturas mais elevadas neste ano (Figura 3), fazendo com que as plantas atingissem mais cedo a soma calórica necessária ao florescimento. 
Ressalta-se que, o valor observado de 63 dias para completar a maturidade fisiológica é atípico para Parnaíba, principalmente considerando-se que as temperaturas deste município foram inferiores às de Teresina (Figura 3), onde o ciclo da cultura foi maior em três dias (Tabelas 12 e 14). É possível que tenha ocorrido algum erro de observação em relação a esta variável.

Dessa forma, apesar do CROPGRO-cowpea não ter caracterizado redução de ciclo entre anos, nos dois locais (Tabelas 11 a 14), pode-se inferir que os resultados apresentados pelo modelo estão coerentes.

Tabela 11. Valores dos eventos fenológicos de duas cultivares de feijão caupi, na fase de calibração do modelo CROPGRO-cowpea para Parnaíba, PI, 1997.

\begin{tabular}{lcccccc}
\hline \multirow{2}{*}{ Evento fenológico } & \multicolumn{3}{c}{ BR 14 - Mulato } & \multicolumn{3}{c}{ BR 17 - Gurguéia } \\
\cline { 2 - 7 } & $\begin{array}{c}\text { Simulado } \\
\text { (dias) }\end{array}$ & $\begin{array}{c}\text { Observado } \\
\text { (dias) }\end{array}$ & Diferença & $\begin{array}{c}\text { Simulado } \\
\text { (dias) }\end{array}$ & $\begin{array}{c}\text { Observado } \\
\text { (dias) }\end{array}$ & Diferença \\
\hline $1^{\text {a }}$ flor & 42 & 42 & 0 & 43 & 44 & -1 \\
$1^{\text {a }}$ vagem & 45 & 45 & 0 & 46 & 47 & -1 \\
$1^{\text {a }}$ semente & 49 & 49 & 0 & 50 & 51 & -1 \\
Maturidade fisiológica & 66 & 68 & -2 & 68 & 70 & -2 \\
\hline
\end{tabular}

Tabela 12. Valores dos eventos fenológicos de duas cultivares de feijão caupi, na fase de calibração do modelo CROPGRO-cowpea para Parnaíba, PI, 1998.

\begin{tabular}{lcccccc}
\hline \multirow{2}{*}{ Evento fenológico } & \multicolumn{3}{c}{ BR 14 - Mulato } & \multicolumn{3}{c}{ BR 17 - Gurguéia } \\
\cline { 2 - 7 } & $\begin{array}{c}\text { Simulado } \\
\text { (dias) }\end{array}$ & $\begin{array}{c}\text { Observado } \\
\text { (dias) }\end{array}$ & Diferença & $\begin{array}{c}\text { Simulado } \\
\text { (dias) }\end{array}$ & $\begin{array}{c}\text { Observado } \\
\text { (dias) }\end{array}$ & Diferença \\
\hline $1^{\text {a }}$ flor & 42 & 40 & 2 & 43 & 40 & 3 \\
$1^{\text {a }}$ vagem & 45 & 43 & 2 & 46 & 43 & 3 \\
$1^{\text {a }}$ semente & 49 & 47 & 2 & 50 & 47 & 3 \\
Maturidade fisiológica & 66 & 63 & 3 & 68 & 63 & 5 \\
\hline
\end{tabular}


Tabela 13. Valores dos eventos fenológicos de duas cultivares de feijão caupi, na fase de calibração do modelo CROPGRO-cowpea para Teresina, PI, 1997.

\begin{tabular}{lcccccc}
\hline \multirow{2}{*}{ Evento fenológico } & \multicolumn{3}{c}{ BR 14 - Mulato } & \multicolumn{3}{c}{ BR 17 - Gurguéia } \\
\cline { 2 - 7 } & $\begin{array}{c}\text { Simulado } \\
\text { (dias) }\end{array}$ & $\begin{array}{c}\text { Observado } \\
\text { (dias) }\end{array}$ & Diferença & $\begin{array}{c}\text { Simulado } \\
\text { (dias) }\end{array}$ & $\begin{array}{c}\text { Observado } \\
\text { (dias) }\end{array}$ & Diferença \\
\hline $1^{\text {a }}$ flor & 43 & 43 & 0 & 44 & 44 & 0 \\
$1^{\text {a }}$ vagem & 46 & 46 & 0 & 47 & 47 & 0 \\
$1^{\text {a }}$ semente & 51 & 50 & 1 & 52 & 51 & 1 \\
Maturidade fisiológica & 68 & 68 & 0 & 70 & 69 & 1 \\
\hline
\end{tabular}

Tabela 14. Valores dos eventos fenológicos de duas cultivares de feijão caupi, na fase de calibração do modelo CROPGRO-cowpea para Teresina, PI, 1998.

\begin{tabular}{lcccccc}
\hline \multirow{2}{*}{ Evento fenológico } & \multicolumn{3}{c}{ BR 14 - Mulato } & \multicolumn{3}{c}{ BR 17 - Gurguéia } \\
\cline { 2 - 7 } & $\begin{array}{c}\text { Simulado } \\
\text { (dias) }\end{array}$ & $\begin{array}{c}\text { Observado } \\
\text { (dias) }\end{array}$ & Diferença & $\begin{array}{c}\text { Simulado } \\
\text { (dias) }\end{array}$ & $\begin{array}{c}\text { Observado } \\
\text { (dias) }\end{array}$ & Diferença \\
\hline $1^{\text {a }}$ flor & 43 & 41 & 2 & 44 & 42 & 2 \\
$1^{\text {a }}$ vagem & 46 & 44 & 2 & 47 & 45 & 2 \\
$1^{\text {a }}$ semente & 50 & 48 & 2 & 51 & 49 & 2 \\
Maturidade fisiológica & 68 & 66 & 2 & 70 & 67 & 3 \\
\hline
\end{tabular}

\subsubsection{Estimativa da matéria seca}

Os dados observados de matéria seca (MS) do feijão caupi (cvs. BR 14 - Mulato e BR 17 - Gurguéia) foram comparados com os valores estimados pelo modelo CROPGRO-cowpea em dois locais do Estado do Piauí (Figuras 8 e 9).

De um modo geral, observa-se que o modelo apresentou boas estimativas da biomassa, a julgar pelos elevados coeficientes de determinação $\left(r^{2}\right)$, que variaram de 0,92 a 0,99 em Parnaíba (Figura 8), e de 0,85 a 0,96 em Teresina (Figura 9). Além disso, os valores do erro absoluto médio (EAM) foram relativamente baixos, variando de 204,3 a 325,6 kg.ha ${ }^{-1}$ em Parnaíba (Figura 8) e de 322,9 a 563,2 kg.ha ${ }^{-1}$ em Teresina (Figura 9). 


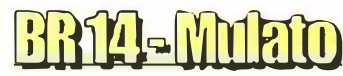
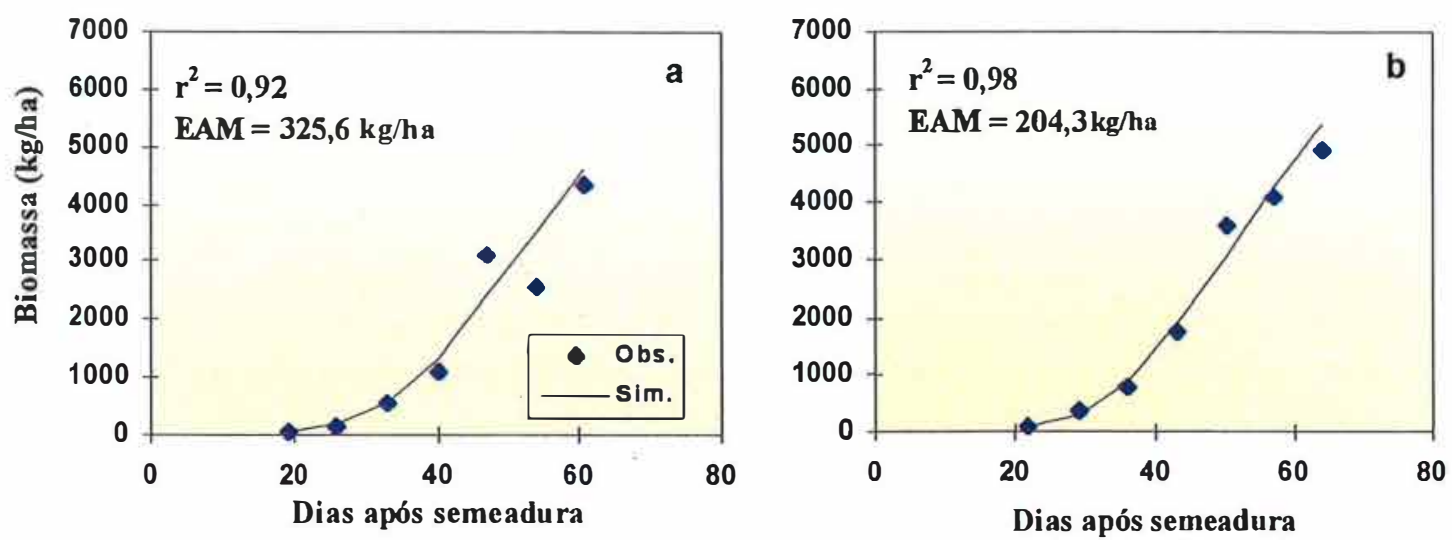

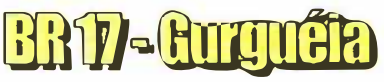
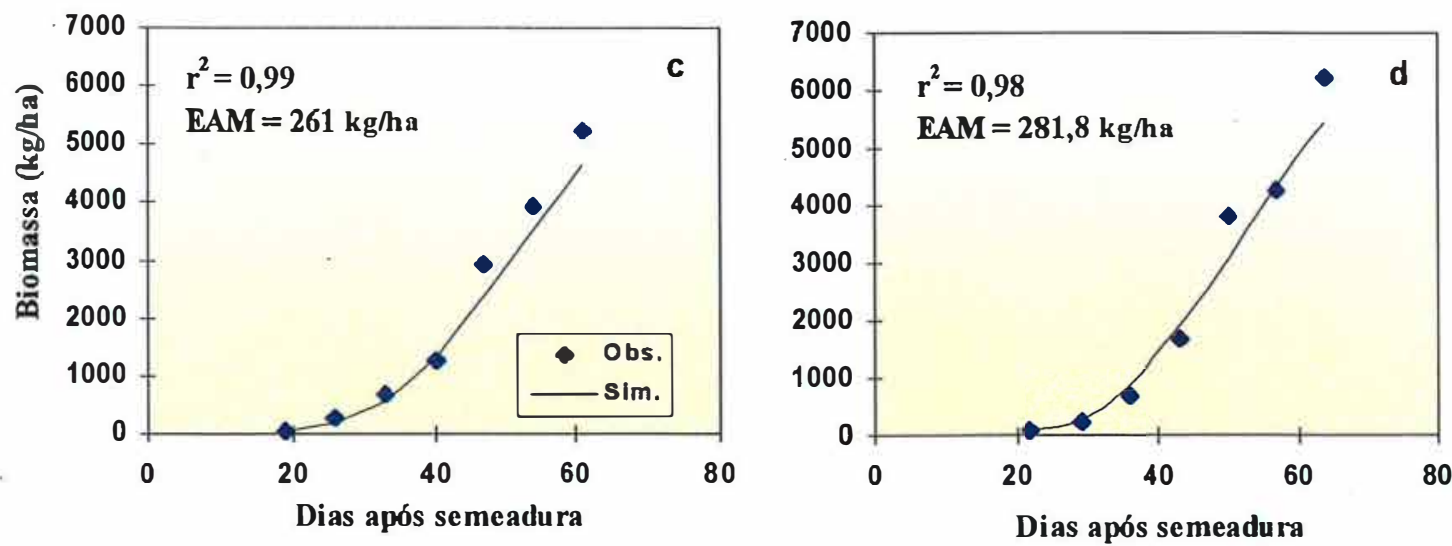

Figura 8. Valores de biomassa de duas cultivares de feijão caupi, na fase de calibração do modelo CROPGRO-cowpea para Parnaiba, PI, durante os anos de 1997 (a e c) e 1998 (b e d). 


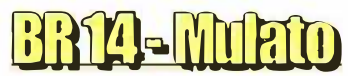
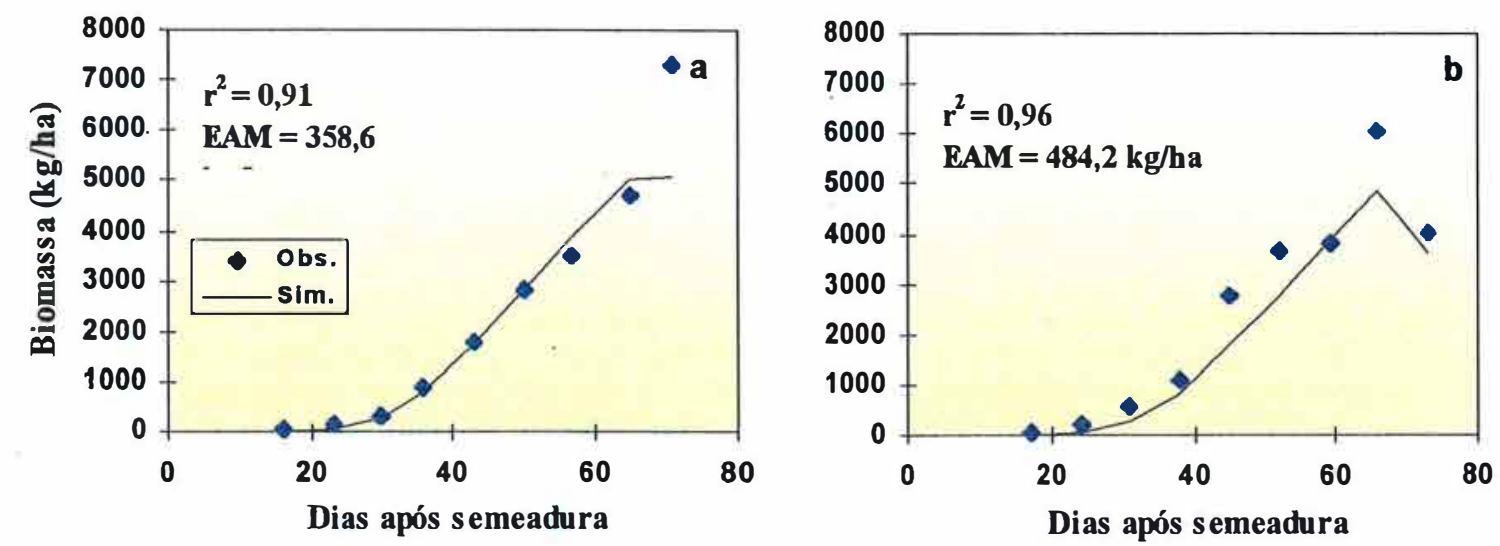

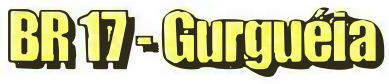
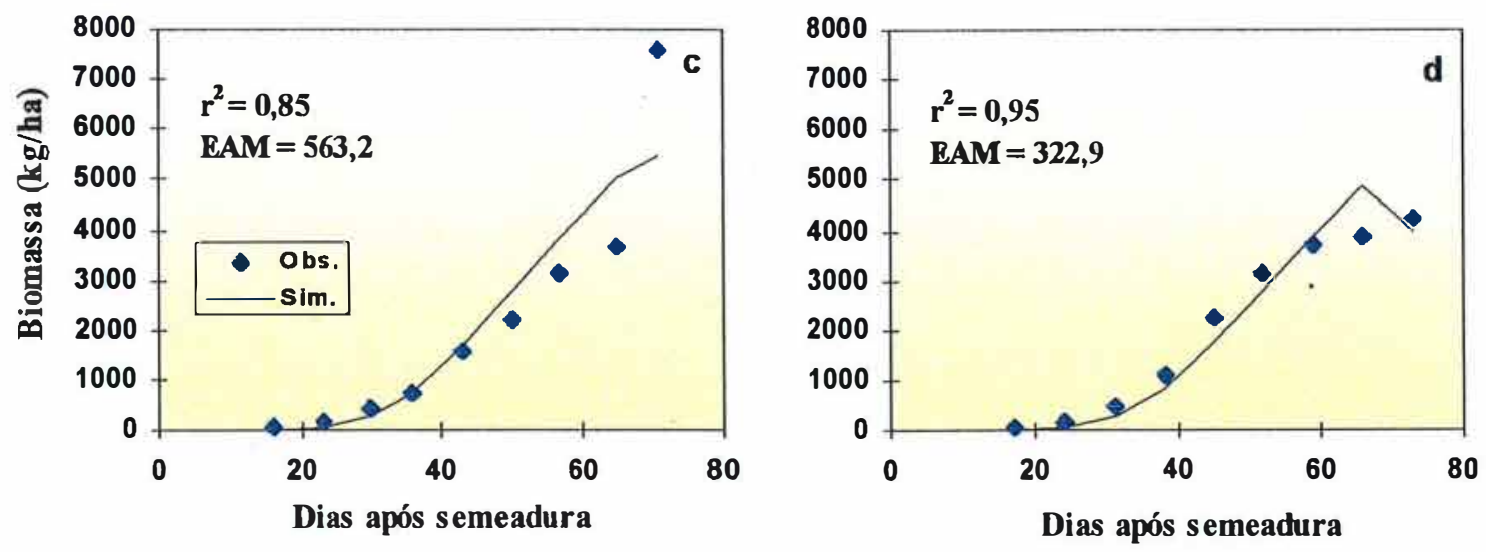

Figura 9. Valores de biomassa de duas cultivares de feijão caupi, na fase de calibração do modelo CROPGRO-cowpea para Teresina, PI, durante os anos de 1997 (a e c) e 1998 (b e d).

Durante a fase vegetativa, que se extende aproximadamente até os 40 dias após a semeadura, verifica-se que os valores estimados de matéria seca foram quase exatos para a maioria dos anos e locais estudados. No entanto, durante o período reprodutivo, as diferenças entre os valores observados e simulados foram maiores. Nesta fase, surgem as flores, vagens e sementes, o que torna o sistema mais complexo e mais difícil de ser 
representado com precisão pois, a partição dos fotoassimilados, antes direcionada apenas para raizes, folhas e colmos, tem de ser alocada também aos órgãos reprodutivos. Com isso, aumenta-se a possibilidade de erros.

Fato semelhante foi observado por Lima (1995) e Barros (1998). Os autores observaram que os modelos simularam precisamente as variações de matéria seca durante o crescimento vegetativo da cultura do milho. Por outro lado, não foram observados ajustes tão bons,durante o período reprodutivo.

Nas Figuras 8 e 9 pode-se constatar um acúmulo lento de biomassa durante a fase vegetativa $\mathrm{e}$, posteriormente, uma evolução rápida devido, principalmente, à contribuição do peso de vagens. Em geral, o pico da produção de matéria seca foi atingido em torno de 65 dias após a semeadura. Estes resultados são concordantes com os obtidos por Castro et al. (1984), trabalhando com as cvs. Epace 1, Epace 6 e Epace 8 no Estado do Ceará e Sivakumar et al. (1996), com a cv. TVX 4659-03 E.

Percebe-se que o modelo apresentou o mesmo padrão de resposta dos dados experimentais, especialmente no município de Pamaíba, onde os valores de biomassa observados e simulados durante todo o ciclo da cultura foram bastante próximos (Figura 8).

Em Teresina, durante o ano de 1998, percebe-se que o modelo subestimou a produção de matéria seca na maior parte do ciclo da cultura (Figuras $9 \mathrm{~b}$ e $9 \mathrm{~d}$ ). Isto pode ser atribuído à ocorrência de temperaturas máximas muito elevadas neste ano $\left(>38^{\circ} \mathrm{C}\right)$ (Figura 3), o que pode ter ocasionado abortamento de flores, conforme constatado por vários pesquisadores (Craufurd et al., 1998; Huxley \& Summerfield, 1976; Roberts et al., 1978; Shouse et al., 1981; Summerfield et al., 1978; Wien \& Summerfield, 1980). Com a queda de flores, parte das vagens e grãos deixam de ser formados e, desde que haja condições favoráveis de água e luz, os fotoassimilados são direcionados à formação de novas folhas, elevando a produção de matéria seca no final do ciclo.

Outro aspecto que merece destaque é que a produção de biomassa, tanto observada como simulada foi maior no município de Teresina, sendo um indicativo da boa performance do modelo. Isto se deve à maior fertilidade do solo de Teresina (Aluvial Eutrófico) comparado ao solo de Parnaíba (Areia Quartzosa). Ressalta-se que o 
CROPGRO-cowpea considera um solo com maior ou menor fertilidade, em função do dado de entrada do teor de matéria orgânica, pois o modelo não leva em conta o balanço de fósforo e de potássio no solo. Stamford et al. (1990) também constataram que, no solo Aluvial Eutrófico, a cultura do feijão caupi apresentou maior quantidade de matéria seca em relação ao solo Podzólico Amarelo, mais arenoso e menos fértil.

\subsubsection{Estimativa do índice de área foliar}

Os valores de índice de área foliar (IAF) observados e simulados das cultivares de caupi BR 14 - Mulato e BR 17 - Gurguéia, nos municípios de Parnaíba e Teresina, estão apresentados nas Figuras 10 e 11.

Em Parnaíba, o modelo mostrou uma excelente performance na estimativa do IAF para as duas cultivares e anos estudados. Isto pode ser constatado pelos elevados valores de $\mathrm{r}^{2}$, que variaram de 0,97 a 0,98 , e pelos baixos valores de EAM, que apresentaram variação de 0,16 a 0,28 (Figura 10).

Em Teresina, houve melhores ajustes no ano de 1997, com valores de $\mathrm{r}^{2}$ variando de 0,87 a 0,90 (Figura 11c e a). Em 1998, devido à ocorrência de elevadas temperaturas, o modelo subestimou os valores de IAF em quase todo o ciclo da cv. BR 14 - Mulato (Figura 1 lb). Estes resultados foram coerentes com os de biomassa, uma vez que esta variável foi subestimada em praticamente todo o ciclo da BR 14 - Mulato durante o ano de 1998 (Figura 9b).

Do ponto de vista fisiológico, as subestimativas do IAF podem ser devidas à ocorrência de elevadas temperaturas em Teresina durante a condução dos experimentos, especialmente no período reprodutivo. A baixa produtividade de grãos deste ano indica que houve abortamento de flores. Este fato, associado às condições favoráveis de água e luz, podem ter ocasionado um intenso crescimento vegetativo da cultura, elevando os valores de IAF das parcelas experimentais.

Em Teresina, subestimativas do IAF também foram verificadas para a BR 17 Gurguéia, entretanto, somente no período vegetativo (até \pm 43 dias). Na fase 
reprodutiva, observou-se o oposto. Esta superestimativa durante o período reprodutivo pode ser atribuída a fato de que o valor máximo de IAF simulado ocorreu alguns dias após o valor máximo observado. Este atraso foi refletido nos demais pontos simulados, proporcionando, dessa forma, uma redução no ajuste do modelo na simulação desse parâmetro $\left(r^{2}=0,77\right)$ (Figura 11d).

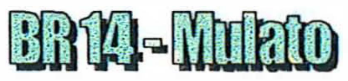
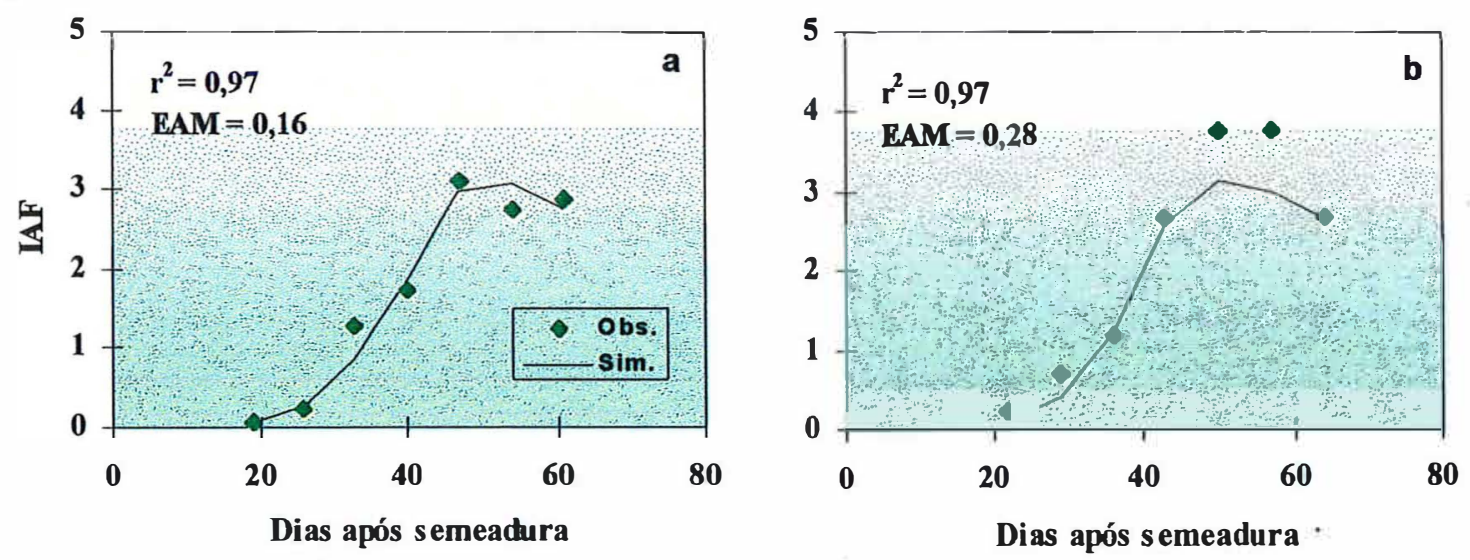

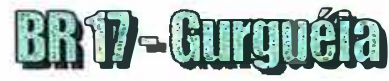
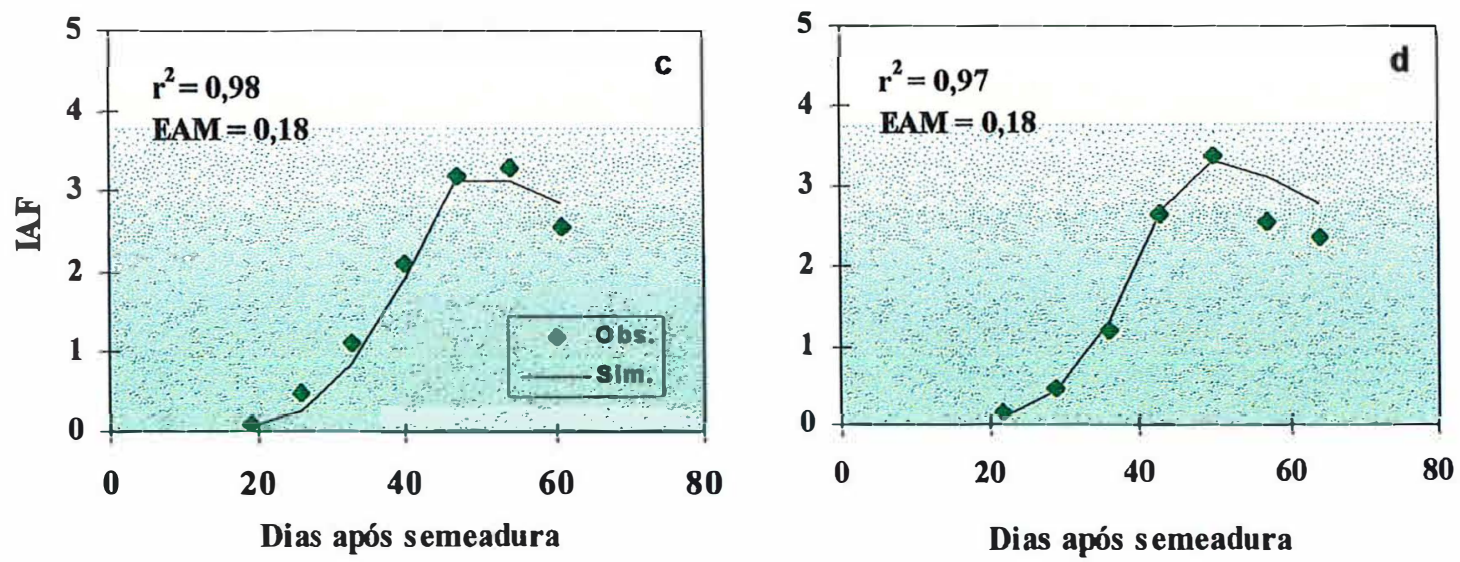

Figura 10. Valores de índice de área foliar (IAF) de duas cultivares de feijão caupi, na fase de calibração do modelo CROPGRO-cowpea para Parnaíba, PI, durante os anos de 1997 (a e c) e 1998 (b e d). 


\section{Bin}

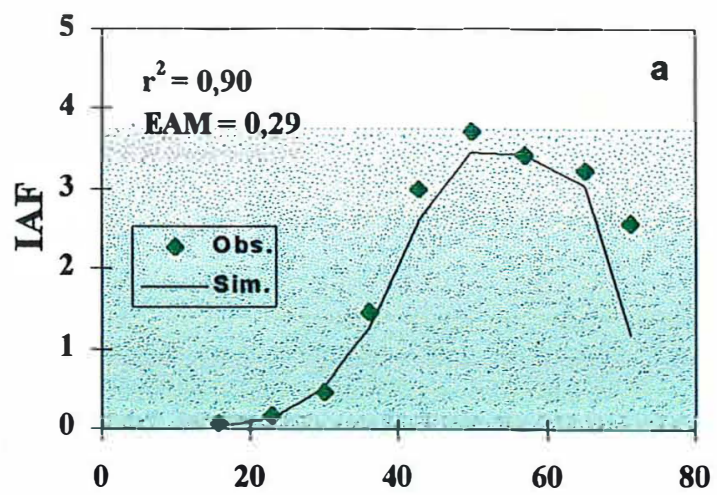

Dias após semeadura

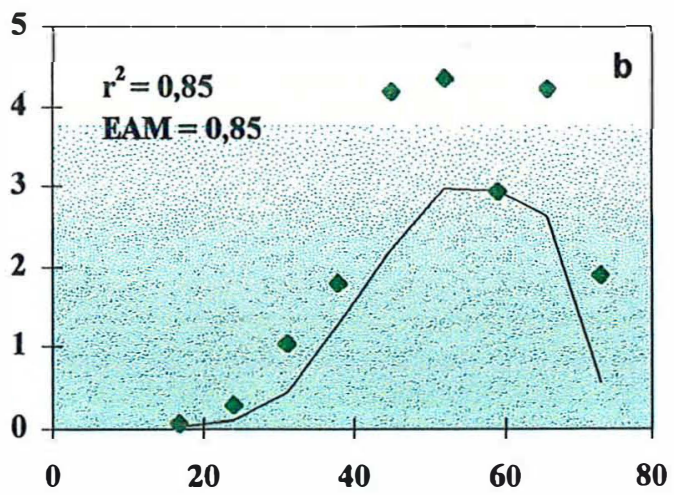

Dias após se meadura

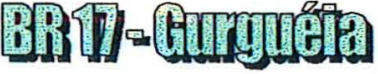

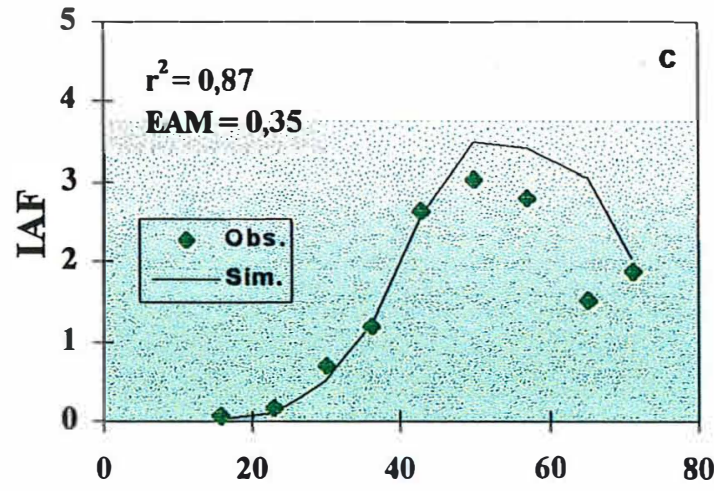

Dias após s e meadura

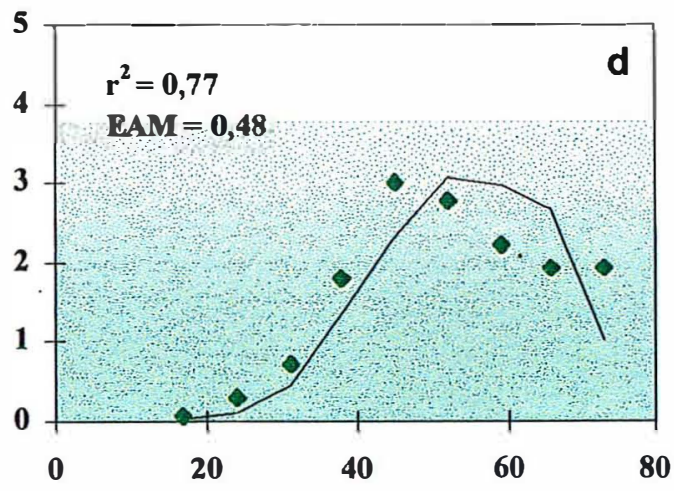

Dias após se meadura

Figura 11. Valores de índice de área foliar (IAF) de duas cultivares de feijão caupi, na fase de calibração do modelo CROPGRO-cowpea para Teresina, PI, durante os anos de 1997 (a e c) e 1998 (b e d).

De um modo geral, pode-se perceber que para os dois locais, os IAFs (observados e simulados) foram muito pequenos $(<0,25)$ até os 25 dias após a semeadura, indicando uma lenta taxa de crescimento da cultura nesta fase inicial. Esta característica é comum no feijão caupi conforme observado por Castro et al. (1984), Littleton et al. (1979a); Phogat et al. (1984); Sivakumar et al. (1996). 
Em seguida, percebe-se um crescimento vegetativo acelerado, com valores máximos de IAF (observados e simulados) variando entre 3 e 4,3 de acordo com o local, cultivar e ano considerados. O número de dias para atingí-los variou de 45 a 60 dias, concordando com os resultados obtidos por Littleton et al. (1979a). Estas diferenças podem estar associadas às diferenças entre cultivares, épocas de semeadura e variação sazonal da temperatura do ar (Summerfield et al., 1983).

Os elevados IAFs (observados e simulados) indicam um crescimento vegetativo intenso devido, principalmente, ao fato de não ter ocorrido déficit hídrico em nenhuma fase do desenvolvimento da cultura. Segundo Phogat et al. (1984), o teor adequado de água no solo proporciona um aumento significativo do IAF em função do restabelecimento do potencial de água na folha e do aumento da fotossíntese líquida. Além disso, valores elevados de radiação solar ocorridos nos dois locais durante a fase experimental (Figura 4) podem ter contribuído para o bom desenvolvimento foliar do feijão caupi, o que está de acordo com Summerfield et al. (1983).

\subsubsection{Estimativa dos componentes de produção}

Os valores observados e simulados dos componentes de produção da cultura do feijão caupi nos dois anos e locais estudados encontram-se nas Tabelas 15 a 18.

Percebe-se que a relação grão/vagem foi a variável que apresentou melhores ajustes, com erros de estimativa variando de 1,1 a 3,8\% para BR 14 - Mulato e de 1,7 a 1,8\% para a BR 17 - Gurguéia, em Pamaíba (Tabela 15). No município de Teresina, também foi observada uma boa performance do modelo na simulação dessa variável, embora com erros mais elevados. Durante os dois anos, os erros de estimativa variaram de 3,1 a 13,3\% (BR 14 - Mulato) e de 0,4 a 8,7\% (BR 17 - Gurguéia) (Tabela 15).

$\mathrm{O}$ peso de 100 grãos (P100) foi o componente de produção que apresentou os piores ajustes, especialmente em 1998. Neste ano, em conseqüência das temperaturas mais elevadas, as diferenças entre os valores observados e simulados foram de $34,3 \%$ (BR 14 - Mulato) e de 13,6\% (BR 17 - Gurguéia), em Parnaíba e de 49,2\% (BR 14 Mulato) e 38,3\% (BR 17 - Gurguéia),em Teresina (Tabela 16). 
Segundo Shouse et al (1981), o P100 reflete a relação entre suprimento e demanda. Quando o P100 é reduzido, há um indicativo de que a produção foi limitada na fonte. Os autores observaram que esta redução é provocada pelo estresse hídrico sobre a fotossíntese, que prejudica a translocação dos fotoassimilados para os grãos.

No presente trabalho, como não houve restrição hídrica nas simulações, acreditase que as subestimativas em relação ao P100, principalmente no ano de 1998 , foram devidas ao estresse térmico, uma vez que, para o modelo, a taxa de crescimento reprodutivo, bem como a translocação de fotoassimilados, são bastante pequenas à temperaturas elevadas.

Cabe ressaltar que o P100 é um dado de entrada. Assim, as subestimativas desta variável poderiam ser facilmente corrigidas, elevando-se o valor deste "input" no arquivo .CUL. Entretanto, para preservar a base fisiológica do modelo, utilizou-se valores obtidos em condições experimentais.

Tabela 15. Valores da relação grão/vagem de duas cultivares de feijão caupi, na fase de calibração do modelo CROPGRO-cowpea para Parnaíba e Teresina, PI, em 1997 e 1998.

\begin{tabular}{|c|c|c|c|c|c|c|}
\hline \multirow{3}{*}{ Município/Ano } & \multicolumn{6}{|c|}{ Relação grão/vagem (\%) } \\
\hline & \multicolumn{3}{|c|}{ BR 14 - Mulato } & \multicolumn{3}{|c|}{ BR 17 - Gurguéia } \\
\hline & Simulado & Observado & $\begin{array}{c}\text { Diferença } \\
(\%)\end{array}$ & Simulado & Observado & $\begin{array}{c}\text { Diferença } \\
(\%)\end{array}$ \\
\hline Parnaíba/1997 & 76,8 & 74,0 & 3,8 & 76,6 & 78,0 & $-1,8$ \\
\hline Pamaíba/1998 & 75,8 & 75,0 & 1,1 & 76,7 & 78,0 & $-1,7$ \\
\hline Média & 76,3 & $\mathbf{7 4 , 5}$ & $2,4^{1}$ & 76,7 & 78,0 & $-1,7^{1}$ \\
\hline Teresina/1997 & 75,9 & 67,0 & 13,3 & 76,1 & 70,0 & 8,7 \\
\hline Teresina/1998 & 73,2 & 71,0 & 3,1 & 72,3 & 72,0 & 0,4 \\
\hline Média & 74,5 & 69,0 & $8,0^{1}$ & 74,2 & 71,0 & $4,5^{1}$ \\
\hline
\end{tabular}


Tabela 16. Valores do peso de 100 grãos de duas cultivares de feijão caupi, na fase de calibração do modelo CROPGRO-cowpea para Parnaíba e Teresina, PI, em 1997 e 1998.

\begin{tabular}{lcccccc}
\hline & \multicolumn{6}{c}{ Peso de 100 grãos (g) } \\
\cline { 2 - 7 } Município/Ano & \multicolumn{5}{c}{ BR 14 - Mulato } & \multicolumn{3}{c}{ BR 17 - Gurguéia } \\
\cline { 2 - 7 } & Simulado & Observado & $\begin{array}{c}\text { Diferença } \\
(\%)\end{array}$ & Simulado & Observado & $\begin{array}{c}\text { Diferença } \\
(\%)\end{array}$ \\
\hline Parnaíba/1997 & 11,0 & 13,9 & $-20,9$ & 11,3 & 11,7 & $-3,4$ \\
Parnaíba/1998 & 8,6 & 13,1 & $-34,3$ & 8,9 & 10,3 & $-13,6$ \\
Média & $\mathbf{9 , 8}$ & $\mathbf{1 3 , 5}$ & $\mathbf{- 2 7 , \mathbf { 4 } ^ { \mathbf { 1 } }}$ & $\mathbf{1 0 , 1}$ & $\mathbf{1 1 , 0}$ & $\mathbf{- 8 , \mathbf { 2 } ^ { \mathbf { 1 } }}$ \\
Teresina/1997 & 9,6 & 12,5 & $-23,2$ & 9,2 & 10,6 & $-13,2$ \\
Teresina/1998 & $\mathbf{6 , 8}$ & 13,4 & $\mathbf{- 4 9 , 2}$ & 7,1 & 11,5 & $\mathbf{- 3 8 , 3}$ \\
Média & $\mathbf{8 , 2}$ & $\mathbf{1 2 , 9}$ & $\mathbf{- 3 6 , \mathbf { 4 } ^ { \mathbf { 1 } }}$ & $\mathbf{8 , 2}$ & $\mathbf{1 1 , 1}$ & $\mathbf{- 2 6 , \mathbf { 1 } ^ { \mathbf { 1 } }}$ \\
\hline
\end{tabular}

${ }^{1}$ Corresponde à diferença entre o valor médio simulado e o observado.

Apesar das diferenças relativamente altas na estimativa do P100 em alguns experimentos, não houve comprometimento das simulações da produtividade de grãos. A explicação para este fato é que, na maioria das vezes, a produção de grãos de caupi é pouco influenciada pelo peso de 100 grãos (Minchin et al, 1980) e está mais relacionada com o número de vagens por planta (NVP) (Cardoso et al, 1995; Littleton et al. 1979b, Minchin et al., 1980).

Em relação ao NVP (Tabela 17), pode-se verificar que o modelo apresentou ajustes satisfatórios nos dois municípios. Em Parnaíba, destacou-se as simulações com a cv. BR 14 - Mulato, que apresentou erros de estimativa de 3,6\% em 1997 e de 8,0\% em 1998. Em Teresina, os resultados simulados do NVP indicaram um erro relativamente alto para esta cultivar no primeiro ano, com uma superestimativa de $33 \%$. Entretanto, o valor simulado de 18,5 vagens por planta está de acordo com o obtido por Cardoso et al. (1997), em estudos com a BR 14 - Mulato, em condições semelhantes à do presente estudo.

Para a BR 17 - Gurguéia, os erros de estimativa do NVP variaram de $22,2 \%$ (1997) a $27,4 \%$ (1998) em Parnaíba e de $8,6 \%$ (1997) a 28,7\% (1998), em Teresina 
(Tabela 17). Estes erros relativamente altos estão associados ao fato de que, em condições experimentais, esta cultivar apresentou maior NVP quando comparada à BR 14 - Mulato. Esta mesma tendência foi constatada no modelo, embora com menor intensidade.

Em relação ao número de grãos por vagem (NGV) (Tabela 18), observa-se que o modelo apresentou excelentes ajustes para os dois locais, anos e cultivares estudados. Em Parnaíba, os erros médios de estimativa dessa variável foram de 1,3 e 0,7\% para as cvs. BR 14 - Mulato e BR 17 - Gurguéia, respectivamente. Em Teresina, estes erros variaram de 0,6\% (BR 14 - Mulato) a 6,7\% (BR 17 - Gurguéia).

Analisando-se os resultados observados e simulados do NGV, constatou-se que, para as duas cultivares, essa variável apresentou pequena variação ao longo dos anos, mesmo com o estresse térmico ocorrido em 1998. Dessa forma, pode-se inferir que o NGV é pouco afetado pela ocorrência de elevadas temperaturas do ar.

Tabela 17. Valores do número de vagens por planta ${ }^{1}$ de duas cultivares de feijão caupi, na fase de calibração do modelo CROPGRO-cowpea para Parnaíba e Teresina, PI, em 1997 e 1998.

\begin{tabular}{|c|c|c|c|c|c|c|}
\hline \multirow{3}{*}{ Município/Ano } & \multicolumn{6}{|c|}{ Número de vagens por planta } \\
\hline & \multicolumn{3}{|c|}{ BR 14 - Mulato } & \multicolumn{3}{|c|}{ BR 17 - Gurguéia } \\
\hline & Simulado & Observado & $\begin{array}{c}\text { Diferença } \\
(\%)\end{array}$ & Simulado & Observado & $\begin{array}{c}\text { Diferença } \\
(\%)\end{array}$ \\
\hline Parnaíba/1997 & 19,3 & 20,0 & $-3,6$ & 21,6 & 26,4 & $-22,2$ \\
\hline Pamaíba/1998 & 16,2 & 14,9 & 8,0 & 18,6 & 23,7 & $-27,4$ \\
\hline Média & 17,8 & 17,5 & $1,7^{2}$ & 20,1 & 25,1 & $-19,9^{2}$ \\
\hline Teresina/1997 & 18,5 & 12,4 & 33,0 & 20,8 & 19,0 & 8,6 \\
\hline Teresina/1998 & 12,2 & 12,0 & 1,6 & 12,2 & 15,7 & $-28,7$ \\
\hline Média & 15,3 & 12,2 & $25,4^{2}$ & 16,5 & 17,3 & $-4,6^{2}$ \\
\hline
\end{tabular}

${ }^{1}$ Calculado a partir do número de plantas $/ \mathrm{m}^{2}$ (dado de entrada) e dos valores simulados do número de grãos $/ \mathrm{m}^{2}$ e do número de grãos por vagem.

${ }^{2}$ Corresponde à diferença entre o valor médio simulado e o observado. 
Tabela 18. Valores do número de grãos por vagem de duas cultivares de feijão caupi, na fase de calibração do modelo CROPGRO-cowpea para Teresina, PI, em 1997 e 1998.

\begin{tabular}{lcccccc}
\hline & \multicolumn{5}{c}{ Número de grãos por vagem } \\
\cline { 2 - 7 } Município/Ano & \multicolumn{3}{c}{ BR 14 - Mulato } & \multicolumn{3}{c}{ BR 17 - Gurguéia } \\
\cline { 2 - 7 } & Simulado & Observado & $\begin{array}{c}\text { Diferença } \\
\text { (\%) }\end{array}$ & Simulado & Observado & $\begin{array}{c}\text { Diferença } \\
(\%)\end{array}$ \\
\hline Parnaíba/1997 & 15,5 & 14,0 & 10,7 & 14,7 & 13,2 & 11,4 \\
Parnaíba/1998 & 15,5 & 17,4 & $-10,9$ & 14,7 & 16,0 & $-8,1$ \\
Média & $\mathbf{1 5 , 5}$ & $\mathbf{1 5 , 7}$ & $\mathbf{- 1 , 3}$ & $\mathbf{1 4 , 7}$ & $\mathbf{1 4 , 6}$ & $\mathbf{0 , 7}$ \\
Teresina/1997 & 15,5 & 16,0 & $-3,1$ & 14,7 & $*$ & - \\
Teresina/1998 & 15,1 & 14,8 & 2,0 & 13,0 & 14,9 & $-12,7$ \\
Média & $\mathbf{1 5 , 3}$ & $\mathbf{1 5 , 4}$ & $\mathbf{- 0 , 6}$ & $\mathbf{1 3 , 9}$ & $\mathbf{1 4 , 9}$ & $\mathbf{6 , 7}$ \\
\hline
\end{tabular}

${ }^{1}$ Corresponde à diferença entre o valor médio simulado e o observado.

* Dado experimental eliminado.

\subsubsection{Estimativa da produtividade de grãos}

Os valores das produtividades de grãos (PG) referentes aos dois locais, cultivares e anos estudados encontram-se na Tabela 19. Em Parnaíba, no ano de 1997, foram obtidos os melhores ajustes em relação à PG, com subestimativas de apenas 2,0 e $0,9 \%$ para as cvs. BR 14 - Mulato e BR 17 Gurguéia, respectivamente.

Em 1998, houve um atraso na semeadura (31/07/98) em relação ao ano anterior $(20 / 06 / 97)$. Isto fez com que o florescimento ( \pm 43 dias) do feijão caupi, cultivado naquele ano, coincidisse com um período de elevadas temperaturas do ar $\left(35^{\circ} \mathrm{C}\right.$ ) (Figura 3), o que provavelmente contribuiu para que a PG experimental fosse reduzida de 2.189 para $1.924 \mathrm{~kg} \cdot \mathrm{ha}^{-1}(12 \%)$ na cultivar BR 14 - Mulato. O modelo CROPGRO-cowpea apresentou a mesma tendência, porém com uma redução um pouco maior (19\%) (Tabela 20).

A diminuição da produtividade de grãos devido às temperaturas muito elevadas $\left(>33^{\circ} \mathrm{C}\right)$ é comum na cultura do feijão caupi (Craufurd et al., 1998; Doto \& Whittington, 1981; Huxley \& Summerfield, 1976; Roberts et al., 1978; Shouse et al., 1981; 
Sivakumar et al., 1996; Summerfield et al., 1978; Wien \& Summerfield, 1980). Este efeito pode ser bastante diferenciado dependendo da cultivar utilizada. Trabalhos têm mostrado que alguns genótipos de feijão caupi, quando cultivados em temperaturas em torno de $33^{\circ} \mathrm{C}$, reduziram a PG em $29 \%$, enquanto outros aumentaram em $3 \%$ (Wien \& Summerfield, 1980).

Fato semelhante foi observado em Parnaíba, onde a cv. BR 17 - Gurguéia teve um aumento de 3,2\% na PG, em 1998, quando comparado à de 1997 (Tabela 21), o oposto do verificado com a BR 14 - Mulato. Os padrões diferenciados de resposta à temperatura do ar entre cultivares são muito dificeis de serem caracterizados pelos modelos de simulação. No CROPGRO-cowpea, a função temperatura é idêntica para as duas cultivares de feijão caupi e, portanto, os valores simulados de PG apresentaram as mesmas tendências nos diferentes anos. Como em 1998, a nível experimental, a resposta da BR 17 à temperatura do ar foi diferente daquela caracterizada pelo modelo, justifica-se a diferença relativamente alta $(28,3 \%)$ entre o valor observado e simulado da PG para esta cultivar (Tabela 19).

Tabela 19. Valores da produtividade de grãos de duas cultivares de feijão caupi, na fase de calibração do modelo CROPGRO-cowpea para Parnaíba e Teresina, PI, em 1997 e 1998.

\begin{tabular}{lcccccc}
\hline \multirow{2}{*}{ Município/Ano } & \multicolumn{5}{c}{ BR 14 - Mulato } & \multicolumn{3}{c}{ BR 17 - Gurguéia } \\
\cline { 2 - 7 } & Simulado & Observado & $\begin{array}{c}\text { Diferença } \\
(\%)\end{array}$ & Simulado & Observado & $\begin{array}{c}\text { Diferença } \\
(\%)\end{array}$ \\
\cline { 2 - 7 } & 2.144 & 2.189 & $-2,0$ & 2.224 & 2.245 & $-0,9$ \\
Parnaíba/1997 & 1.736 & 1.924 & $-9,8$ & 1.660 & 2.317 & $-28,3$ \\
Parnaíba/1998 & $\mathbf{1 . 9 4 0}$ & $\mathbf{2 . 0 5 6}$ & $\mathbf{- 5 , 6 ^ { 1 }}$ & $\mathbf{1 . 9 4 2}$ & $\mathbf{2 . 2 8 1}$ & $\mathbf{- 1 4 , 9 ^ { 1 }}$ \\
Média & 1.787 & 1.301 & 37,3 & 1.661 & 1.303 & 27,5 \\
Teresina/1997 & 614 & 979 & $-37,3$ & 556 & 1.002 & $-44,5$ \\
Teresina/1998 & $\mathbf{1 . 2 0 0}$ & $\mathbf{1 . 1 4 0}$ & $\mathbf{5 , 3 ^ { 1 }}$ & $\mathbf{1 . 1 0 8}$ & $\mathbf{1 . 1 5 2}$ & $\mathbf{- 3 , \mathbf { 8 } ^ { \mathbf { 1 } }}$ \\
Média & &
\end{tabular}

${ }^{1}$ Corresponde à diferença entre o valor médio simulado e o observado. 
Tabela 20. Diferença da produtividade de grãos da cv. BR 14 - Mulato entre os anos de 1997 e 1998, em Parnaíba e Teresina, PI.

\begin{tabular}{lcc}
\hline Município & \multicolumn{2}{c}{ Diferença (\%) } \\
\cline { 2 - 3 } & Experimento $^{1}$ & Modelo $^{2}$ \\
\hline Parnaiba & $-12,0$ & $-19,0$ \\
Teresina & $-24,8$ & $-65,6$ \\
\hline
\end{tabular}

${ }^{1}$ Cálculo com base nas produtividades experimentais.

${ }^{2}$ Cálculo com base nas produtividades simuladas.

Tabela 21. Diferença da produtividade de grãos da cv. BR 17 - Gurguéia entre os anos de 1997 e 1998, em Parnaíba e Teresina, PI.

\begin{tabular}{lcc}
\hline Município & \multicolumn{2}{c}{ Diferença (\%) } \\
\cline { 2 - 3 } & Experimento $^{1}$ & Modelo $^{2}$ \\
\hline Parnaíba & 3,2 & $-25,3$ \\
Teresina & $-23,1$ & $-66,5$ \\
\hline
\end{tabular}

${ }^{1}$ Cálculo com base nas produtividades experimentais.

${ }^{2}$ Cálculo com base nas produtividades simuladas.

Em relação aos experimentos de Teresina (Tabela 19), pode-se perceber que o modelo superestimou a PG em 1997 e subestimou-a em 1998. No primeiro ano (1997), a máxima temperatura do ar atingiu $34{ }^{\circ} \mathrm{C}$ durante o florescimento que, para o modelo, não é um valor capaz de comprometer a PG. Assim, as PG simuladas foram relativamente altas neste ano, $1.770 \mathrm{~kg} \cdot \mathrm{ha}^{-1}$ (BR 14 - Mulato) e $1.642 \mathrm{~kg} \cdot \mathrm{ha}^{-1}$ (BR 17 Gurguéia), as quais são perfeitamente aceitáveis para as condições de Teresina. Cardoso et al. $(1995 ; 1996 \mathrm{a} ; 1997)$, trabalhando no mesmo solo e em condições climáticas semelhantes, obtiveram produtividades de grãos acima de $2.000 \mathrm{~kg} \cdot \mathrm{ha}^{-1}$.

No entanto, as PG experimentais deste ano (1997) foram em torno de $1.300 \mathrm{~kg} \cdot \mathrm{ha}^{-1}$, proporcionando, desta forma, uma superestimativa dessa variável de $37,3 \%$ e 27,5\% para as cultivares BR 14 - Mulato e BR 17 - Gurguéia, respectivamente (Tabela 19). Estas diferenças são relativamente altas, mas comuns em modelagem, 
principalmente quando se procura calibrar o modelo com experimentos de diferentes localidades.

Timsina et al. (1993) compararam os resultados simulados da PG de caupi com dados experimentais de diversos autores. Sob condições de irrigação, foram observadas subestimativas de 20,0 a $25,0 \%$ e superestimativas de $37,5 \%$.

Giraldo et al. (1999), adaptando o modelo DSSAT para outra espécie (Brachiaria decumbens), utilizou dados observados de duas estações experimentais. Na Estação de Gigante, os autores obtiveram excelentes ajustes, com erros de estimativa variando de 0,1 a $12,0 \%$. Por outro lado, na Estação de Urrao, foi verificado, para alguns experimentos, diferenças de até $65,0 \%$.

Em relação ao segundo ano (1998), a temperatura máxima durante a condução dos experimentos atingiu valores superiores à $38^{\circ} \mathrm{C}$ (Figura 3). No modelo CROPGROcowpea, a função de crescimento da cultura é quadrática, ou seja, cresce até um determinado ponto e decresce em seguida. Assim, o modelo assume que, à temperatura de $38^{\circ} \mathrm{C}$ a taxa de crescimento reprodutivo é muito pequena, o que concorreu para os baixos valores de PG simulados, 614 kg. ha ${ }^{-1}$ (BR 14 - Mulato) e $556 \mathrm{~kg}^{-\mathrm{ha}^{-1}}$ (BR 17 Gurguéia) (Tabela 19).

Analisando-se isoladamente os valores simulados de PG para o município de Teresina, percebe-se uma queda de 65,6\% (BR 14 - Mulato) e de 66,5\% (BR 17 Gurguéia) do ano de 1997 para 1998 (Tabelas 20 e 21). Em relação aos dados experimentais, também observou-se esta queda, entretanto, em menores proporções, sendo de 24,8\% (BR 14 - Mulato) e de 23,1\% (BR 17 - Gurguéia), o que comprova o efeito deletério de temperaturas muito elevadas.

Outros autores têm observado que uma mesma cultivar, sob condições semelhantes de fertilidade do solo, água e luz, pode ter grandes variações na PG de um ano para outro devido à mudanças da temperatura do ar (Shouse et al., 1981; Sivakumar et al., 1996). Craufurd et al. (1998) avaliaram a sensibilidade do feijão caupi ao calor e constataram que um período de 10 a 14 dias de elevadas temperaturas durante o florescimento (estádio mais sensível) reduziu em aproximadamente $95 \%$ a produção de vagens, comparado à testemunha. 
Nesse contexto, mesmo com a grande diferença entre os valores observados e simulados de PG no ano de 1998, estes resultados podem ser úteis na identificação de épocas de semeadura mais adequadas para o cultivo irrigado do feijão caupi. Além disso, considerando-se o valor médio da PG dos dois anos, os erros de estimativa reduzem de 37,3 para 5,3\% (cv. BR 14 - Mulato) e de 44,5 para 3,8\% (cv. BR 17 Gurguéia) (Tabela 19). Isto reforça a capacidade do modelo em estimar satisfatoriamente a $\mathrm{PG}$, principalmente utilizando-se um maior número de repetições.

\subsection{Avaliação do modelo CROPGRO-cowpea}

\subsubsection{Estimativa dos eventos fenológicos}

Os valores observados e simulados da fenologia da cv. BR 17 - Gurguéia, na fase de avaliação do modelo, encontram-se nas Tabelas 22 e 23 . Os valores experimentais dos parâmetros avaliados representam uma média para os 16 tratamentos, uma vez que, segundo Cardoso ${ }^{7}$, não foram observados efeitos do fósforo e da densidade de plantas sobre os eventos fenológicos da cultivar em estudo. Oladiran (1994), testando três populações de plantas de feijão caupi $\left(27.700,55.500\right.$ e 111.110 pl.ha $\left.^{-1}\right)$, também constatou que a densidade de plantas não afetou o tempo para o florescimento.

Apesar do modelo não simular o balanço de fósforo no solo, pôde-se comparar os dados experimentais com os valores simulados, uma vez que não houve efeito desse nutriente sobre a fenologia da cultura.

Verificou-se, nos dois municípios, a boa performance do CROPGRO-cowpea em relação à simulação da fenologia da planta, com erros de estimativa de apenas um dia. Estes bons resultados estão associados ao fato de que as condições de temperatura, durante os experimentos utilizados nesta avaliação (1996) (Figura 2), foram semelhantes àquelas dos experimentos da calibração (1997) (Figura 3), nos quais foram verificados bons ajustes (Tabelas 11 e 13).

${ }^{7}$ CARDOSO, M.J. (Embrapa Meio-Norte). Comunicação pessoal, 1998. 
Cabe ressaltar que o florescimento de plantas de caupi em torno dos 43 dias após a semedura é fato comum nos experimentos conduzidos na Embrapa Meio-Norte e está de acordo com os resultados obtidos por Freire Filho et al. (1994), em estudos com a caracterização da cv. BR 17 - Gurguéia. Também é freqüente observar-se uma diferença de 3, 7 e 25 dias entre o florescimento e o aparecimento da primeira vagem, semente e maturidade fisiológica, respectivamente. Isto reforça a capacidade do modelo em estimar satisfatoriamente a fenologia do caupi para os locais estudados.

Tabela 22. Valores dos eventos fenológicos do feijão caupi, cv. BR 17 - Gurguéia, na fase de avaliação do modelo CROPGRO-cowpea para Parnaíba, PI, 1996.

\begin{tabular}{lccc}
\hline Evento fenológico & \multicolumn{2}{c}{ Valores (dias) } & \multirow{2}{*}{$\begin{array}{c}\text { Diferença } \\
\text { (dias) }\end{array}$} \\
\cline { 2 - 3 } & Simulados & Observados & 1 \\
\hline Primeira flor & 43 & 42 & 1 \\
Primeira vagem & 46 & 45 & 0 \\
Primeira semente & 50 & 50 & 1 \\
Maturidade fisiológica & 68 & 67 & \\
\hline
\end{tabular}

Tabela 23. Valores dos eventos fenológicos do feijão caupi, cv. BR 17 - Gurguéia, na fase de avaliação do modelo CROPGRO-cowpea para Teresina, PI, 1996.

\begin{tabular}{|c|c|c|c|}
\hline \multirow[t]{2}{*}{ Evento fenológico } & \multicolumn{2}{|c|}{ Valores (dias) } & \multirow{2}{*}{$\begin{array}{c}\text { Diferença } \\
\text { (dias) }\end{array}$} \\
\hline & Simulados & Observados & \\
\hline Primeira flor & 43 & 42 & 1 \\
\hline Primeira vagem & 46 & 45 & 1 \\
\hline Primeira semente & 50 & 50 & 0 \\
\hline Maturidade fisiológica & 68 & 67 & 1 \\
\hline
\end{tabular}




\subsubsection{Estimativa dos componentes de produção}

Os valores observados e simulados do peso de 100 grãos (P100), do número de grãos por vagem (NGV) e do número de vagens por planta (NVP), na fase de avaliação do CROPGRO-cowpea, são apresentados nas Tabelas 24, 25 e 26, respectivamente. Ressalta-se que não foi possível comparar a relação grão/vagem por não haver disponibilidade de dados observados desta variável.

Em relação ao P100 (Tabela 24), pode-se perceber que o modelo apresentou melhores ajustes em Parnaíba, com erros de estimativa variando de 1 (T15) a $12 \%$ (T11). Em Teresina, esses erros foram maiores, atingindo valores mínimo de $23,8 \%$ (T16) e máximo de 30,8\% (T3).

A melhor performance do modelo em Parnaíba na estimativa desta variável, também observada na fase de calibração, foi devido ao efeito da temperatura. De acordo com a Figura 2, pode-se verificar que, em Teresina, as temperaturas foram mais elevadas atingindo valores máximos em torno de $36^{\circ} \mathrm{C}$ durante o período reprodutivo.

Robert et. al (1978) observaram que temperaturas muito altas reduzem o peso de 100 grãos em feijão caupi porque há redução do período de enchimento de grãos. Os autores constataram que, em ambiente mais frio $\left(\mathrm{Tmin}=19^{\circ} \mathrm{C}\right.$ e $\left.\operatorname{Tmáx}=27^{\circ} \mathrm{C}\right)$ o $\mathrm{P} 100$ foi praticamente o dobro quando comparado àquele mais quente $\left(\mathrm{Tmin}=24^{\circ} \mathrm{C}\right.$ e Tmáx $=$ $33^{\circ} \mathrm{C}$ ). Estes resultados estão concordantes com os obtidos pelo modelo CROPGROcowpea.

Apesar dessa concordância, as subestimativas do P100, nas fases de calibração e avaliação do modelo, indicam a necessidade de um ajuste mais refinado para melhorar as estimativas desta variável, em locais com temperaturas mais elevadas.

Os valores simulados do NGV (Tabela 25) indicaram ajustes satisfatórios para as duas localidades, com erros variando de 4,6 (T13) a 10,9\% (T7), em Parnaíba, e de 4,6 (T2) a 14,9\% (T16), em Teresina. Como o NGV estimado na fase de avaliação foi o mesmo do obtido na calibração $(14,7)$, estes bons ajustes se devem à pequena variação dos valores experimentais dessa variável nos diferentes anos e locais estudados. 
Cabe ressaltar que os valores observados e simulados do P100 e do NGV para a BR 17 - Gurguéia, durante a avaliação do modelo, estão de acordo com os resultados obtidos por Freire Filho et al. (1994) em estudos que avaliaram as características agronômicas desta cultivar.

Tabela 24. Valores do peso de 100 grãos do feijão caupi, cv. BR 17 - Gurguéia, na fase de avaliação do modelo CROPGRO-cowpea para Pamaíba e Teresina, PI, 1996.

\begin{tabular}{|c|c|c|c|c|c|c|}
\hline \multirow{3}{*}{ Tratamento } & \multicolumn{6}{|c|}{ Peso de 100 grãos $(\mathrm{g})$} \\
\hline & \multicolumn{3}{|c|}{ Parnaíba } & \multicolumn{3}{|c|}{ Teresina } \\
\hline & Simulado & Observado & $\begin{array}{c}\text { Diferença } \\
\text { (\%) }\end{array}$ & Simulado & Observado & $\begin{array}{c}\text { Diferença } \\
(\%)\end{array}$ \\
\hline $1\left(0 \mathrm{P}_{2} \mathrm{O}_{5}, 4 \mathrm{pl} \cdot \mathrm{m}^{-2}\right)$ & 10,3 & 9,8 & 5,1 & 8,3 & 11,7 & $-29,1$ \\
\hline $2\left(45 \mathrm{P}_{2} \mathrm{O}_{5}, 4 \mathrm{pl} \cdot \mathrm{m}^{-2}\right)$ & 10,3 & 10,6 & $-2,8$ & 8,3 & 11,7 & $-29,1$ \\
\hline $3\left(90 \mathrm{P}_{2} \mathrm{O}_{5}, 4 \mathrm{pl} \cdot \mathrm{m}^{-2}\right)$ & 10,3 & 10,0 & 3,0 & 8,3 & 12,0 & $-30,8$ \\
\hline $4\left(135 \mathrm{P}_{2} \mathrm{O}_{5}, 4 \mathrm{pl} \cdot \mathrm{m}^{-2}\right)$ & 10,3 & 9,8 & 5,1 & 8,3 & 11,7 & $-29,1$ \\
\hline $5\left(0 \mathrm{P}_{2} \mathrm{O}_{5}, 9 \mathrm{pl} \cdot \mathrm{m}^{-2}\right)$ & 10,3 & 9,7 & 6,2 & 8,3 & 11,7 & $-29,1$ \\
\hline $6\left(45 \mathrm{P}_{2} \mathrm{O}_{5}, 9 \mathrm{pl} \cdot \mathrm{m}^{-2}\right)$ & 10,3 & 9,6 & 7,3 & 8,3 & 11,6 & $-28,4$ \\
\hline $7\left(90 \mathrm{P}_{2} \mathrm{O}_{5}, 9\right.$ pl.m. $\left.\mathrm{m}^{-2}\right)$ & 10,3 & 10,0 & 3,0 & 8,3 & 11,1 & $-25,2$ \\
\hline $8\left(135 \mathrm{P}_{2} \mathrm{O}_{5}, 9 \mathrm{pl} \cdot \mathrm{m}^{-2}\right)$ & 10,3 & 9,7 & 6,2 & 8,3 & 11,6 & $-28,4$ \\
\hline $9\left(0 \mathrm{P}_{2} \mathrm{O}_{5}, 14 \mathrm{pl} \cdot \mathrm{m}^{-2}\right)$ & 10,3 & 9,6 & 7,3 & 8,3 & 11,1 & $-25,2$ \\
\hline $10\left(45 \mathrm{P}_{2} \mathrm{O}_{5}, 14 \mathrm{pl} \cdot \mathrm{m}^{-2}\right)$ & 10,3 & 9,7 & 6,2 & 8,3 & 11,3 & $-26,6$ \\
\hline $11\left(90 \mathrm{P}_{2} \mathrm{O}_{5}, 14 \mathrm{pl} \cdot \mathrm{m}^{-2}\right)$ & 10,3 & 9,2 & 12,0 & 8,3 & 11,3 & $-26,6$ \\
\hline $12\left(135 \mathrm{P}_{2} \mathrm{O}_{5}, 14 \mathrm{pl} \cdot \mathrm{m}^{-2}\right)$ & 10,3 & 9,4 & 9,6 & 8,3 & 11,1 & $-25,2$ \\
\hline $13\left(0 \mathrm{P}_{2} \mathrm{O}_{5}, 18 \mathrm{pl} \cdot \mathrm{m}^{-2}\right)$ & 10,3 & 9,8 & 5,1 & 8,3 & 11,1 & $-25,2$ \\
\hline $14\left(45 \mathrm{P}_{2} \mathrm{O}_{5}, 18 \mathrm{pl} \cdot \mathrm{m}^{-2}\right)$ & 10,3 & 9,7 & 6,2 & 8,3 & 12,0 & $-30,8$ \\
\hline $15\left(90 \mathrm{P}_{2} \mathrm{O}_{5}, 18 \mathrm{pl} \cdot \mathrm{m}^{-2}\right)$ & 10,3 & 10,4 & $-1,0$ & 8,3 & 11,3 & $-26,6$ \\
\hline $16\left(135 \mathrm{P}_{2} \mathrm{O}_{5}, 18 \mathrm{pl} . \mathrm{m}^{-2}\right)$ & 10,3 & 9,3 & 10,8 & 8,3 & 10,9 & $-23,8$ \\
\hline
\end{tabular}


Tabela 25. Valores do número de grãos por vagem do feijão caupi, cv. BR 17 Gurguéia, na fase de avaliação do modelo CROPGRO-cowpea para Parnaíba e Teresina, PI, 1996.

\begin{tabular}{|c|c|c|c|c|c|c|}
\hline \multirow{3}{*}{ Tratamento } & \multicolumn{6}{|c|}{ Números de grãos por vagem } \\
\hline & \multicolumn{3}{|c|}{ Parnaíba } & \multicolumn{3}{|c|}{ Teresina } \\
\hline & Simulado & Observado & $\begin{array}{c}\text { Diferença } \\
(\%)\end{array}$ & Simulado & Observado & $\begin{array}{c}\text { Diferença } \\
(\%)\end{array}$ \\
\hline $1\left(0 \mathrm{P}_{2} \mathrm{O}_{5}, 4 \mathrm{pl} \cdot \mathrm{m}^{-2}\right)$ & 14,7 & 16,1 & $-8,7$ & 14,7 & 16,1 & $-8,7$ \\
\hline $2\left(45 \mathrm{P}_{2} \mathrm{O}_{5}, 4 \mathrm{pl} . \mathrm{m}^{-2}\right)$ & 14,7 & 16,3 & $-9,8$ & 14,7 & 15,4 & $-4,6$ \\
\hline $3\left(90 \mathrm{P}_{2} \mathrm{O}_{5}, 4 \mathrm{pl} . \mathrm{m}^{-2}\right)$ & 14,7 & 16,0 & $-8,1$ & 14,7 & 16,0 & $-8,1$ \\
\hline $4\left(135 \mathrm{P}_{2} \mathrm{O}_{5}, 4 \mathrm{pl} \cdot \mathrm{m}^{-2}\right)$ & 14,7 & 16,1 & $-8,7$ & 14,7 & 15,5 & $-5,2$ \\
\hline $5\left(0 \mathrm{P}_{2} \mathrm{O}_{5}, 9 \mathrm{pl} \cdot \mathrm{m}^{-2}\right)$ & 14,7 & 16,1 & $-8,7$ & 14,3 & 15,5 & $-7,7$ \\
\hline $6\left(45 \mathrm{P}_{2} \mathrm{O}_{5}, 9 \mathrm{pl} . \mathrm{m}^{-2}\right)$ & 14,7 & 16,0 & $-8,1$ & 14,3 & 16,1 & $-11,2$ \\
\hline $7\left(90 \mathrm{P}_{2} \mathrm{O}_{5}, 9 \mathrm{pl} \cdot \mathrm{m}^{-2}\right)$ & 14,7 & 16,5 & $-10,9$ & 14,3 & 15,9 & $-10,1$ \\
\hline $8\left(135 \mathrm{P}_{2} \mathrm{O}_{5}, 9 \mathrm{pl} \cdot \mathrm{m}^{-2}\right)$ & 14,7 & 15,9 & $-7,6$ & 14,3 & 15,5 & $-7,7$ \\
\hline $9\left(0 \mathrm{P}_{2} \mathrm{O}_{5}, 14 \mathrm{pl} \cdot \mathrm{m}^{-2}\right)$ & 14,7 & 16,1 & $-8,7$ & 14,3 & 16,1 & $-11,2$ \\
\hline $10\left(45 \mathrm{P}_{2} \mathrm{O}_{5}, 14 \mathrm{pl} . \mathrm{m}^{-2}\right)$ & 14,7 & 16,1 & $-8,7$ & 14,3 & 15,0 & $-4,7$ \\
\hline $11\left(90 \mathrm{P}_{2} \mathrm{O}_{5}, 14 \mathrm{pl} \cdot \mathrm{m}^{-2}\right)$ & 14,7 & 15,6 & $-5,8$ & 14,3 & 16,1 & $-11,2$ \\
\hline $12\left(135 \mathrm{P}_{2} \mathrm{O}_{5}, 14 \mathrm{pl} \mathrm{m}^{-2}\right)$ & 14,7 & 15,5 & $-5,2$ & 14,3 & 15,7 & $-8,9$ \\
\hline $13\left(0 \mathrm{P}_{2} \mathrm{O}_{5}, 18 \mathrm{pl} . \mathrm{m}^{-2}\right)$ & 14,7 & 15,4 & $-4,6$ & 14,3 & 15,6 & $-8,3$ \\
\hline $14\left(45 \mathrm{P}_{2} \mathrm{O}_{5}, 18 \mathrm{pl} \cdot \mathrm{m}^{-2}\right)$ & 14,7 & 15,7 & $-6,4$ & 14,3 & 16,4 & $-12,8$ \\
\hline $15\left(90 \mathrm{P}_{2} \mathrm{O}_{5}, 18 \mathrm{pl} \cdot \mathrm{m}^{-2}\right)$ & 14,7 & 15,5 & $-5,2$ & 14,3 & 16,2 & $-11,7$ \\
\hline $16\left(135 \mathrm{P}_{2} \mathrm{O}_{5}, 18 \mathrm{pl} \cdot \mathrm{m}^{-2}\right)$ & 14,7 & 15,6 & $-5,8$ & 14,3 & 16,8 & $-14,9$ \\
\hline
\end{tabular}

Em relação ao NVP (Tabela 26), o modelo também mostrou uma boa peformance para os dois municípios. Em Parnaíba, com excessão do tratamento T15, os erros de estimativa variaram de 0,0 (T8) a 16,5\% (T10). Para Teresina, a diferença entre os valores observados e simulados do NVP variou de 0 (T14) a 22,2\% (T1). Pode-se perceber que os valores desta variável foram maiores em Parnaíba, quando comparado aos de Teresina e isto foi caracterizado pelo modelo.

Muitos estudos têm mostrado que o NVP em feijão caupi é bastante influenciado pela densidade de plantas (Cardoso et al., 1997; Ezedinma, 1974; Herbert \& Baggerman, 1983; Oladiran, 1994), fato constatado através das simulações do modelo. Dentro do 
processo produtivo, o número de plantas por área é importante na estimativa da produtividade da cultura, seja do ponto de vista biológico ou econômico. Neste contexto, o fato do CROPGRO-cowpea ter estimado satisfatoriamente o NVP em diferentes densidades de plantas, é um indicativo de que o modelo é capaz de estimar a produtividade de caupi no Estado do Piauí, com um bom nível de confiança.

Outro aspecto a ser destacado é que, como o modelo não simula o balanço de fósforo do solo, os bons ajustes alcançados na estimativa do P100, NGV e NVP para os 16 tratamentos só foi possível, porque, nos dois locais estudados, os resultados experimentais indicaram não haver influência significativa do fósforo sobre esses componentes de produção.

Tabela 26. Valores do número de vagens por planta do feijão caupi, cv. BR 17 Gurguéia, na fase de avaliação do modelo CROPGRO-cowpea para Parnaíba e Teresina, PI, 1996.

\begin{tabular}{|c|c|c|c|c|c|c|}
\hline \multirow{3}{*}{ Tratamento } & \multicolumn{6}{|c|}{ Número de vagens por planta } \\
\hline & \multicolumn{3}{|c|}{ Parnaíba } & \multicolumn{3}{|c|}{ Teresina } \\
\hline & Simulado & Observado & $\begin{array}{c}\text { Diferença } \\
(\%)\end{array}$ & Simulado & Observado & $\begin{array}{c}\text { Diferença } \\
(\%)\end{array}$ \\
\hline $1\left(0 \mathrm{P}_{2} \mathrm{O}_{5}, 4 \mathrm{pl} . \mathrm{m}^{-2}\right)$ & 34,6 & 32,2 & 7,4 & 22,0 & 18,0 & 22,2 \\
\hline $2\left(45 \mathrm{P}_{2} \mathrm{O}_{5}, 4\right.$ pl.m $\left.\mathrm{m}^{-2}\right)$ & 34,6 & 30,0 & 15,3 & 22,0 & 20,3 & 8,4 \\
\hline $3\left(90 \mathrm{P}_{2} \mathrm{O}_{5}, 4 \mathrm{pl} \cdot \mathrm{m}^{-2}\right)$ & 34,6 & 32,9 & 5,2 & 22,0 & 21,8 & 0,9 \\
\hline $4\left(135 \mathrm{P}_{2} \mathrm{O}_{5}, 4 \mathrm{pl} \cdot \mathrm{m}^{-2}\right)$ & 34,6 & 34,0 & 1,8 & 22,0 & 21,7 & 1,4 \\
\hline $5\left(0 \mathrm{P}_{2} \mathrm{O}_{5}, 9 \mathrm{pl} . \mathrm{m}^{-2}\right)$ & 16,8 & 16,6 & 1,2 & 11,7 & 10,5 & 11,4 \\
\hline $6\left(45 \mathrm{P}_{2} \mathrm{O}_{5}, 9 \mathrm{pl} \cdot \mathrm{m}^{-2}\right)$ & 16,8 & 18,0 & 6,7 & 11,7 & 12,4 & $-5,6$ \\
\hline $7\left(90 \mathrm{P}_{2} \mathrm{O}_{5}, 9 \mathrm{pl} \cdot \mathrm{m}^{-2}\right)$ & 16,8 & 15,9 & 5,7 & 11,7 & 11,9 & $-1,7$ \\
\hline $8\left(135 \mathrm{P}_{2} \mathrm{O}_{5}, 9\right.$ pl.m. $\left.\mathrm{m}^{-2}\right)$ & 16,8 & 16,8 & 0,0 & 11,7 & 11,3 & 3,5 \\
\hline $9\left(0 \mathrm{P}_{2} \mathrm{O}_{5}, 14 \mathrm{pl} . \mathrm{m}^{-2}\right)$ & 11,2 & 10,0 & 12,0 & 7,4 & 6,6 & 12,1 \\
\hline $10\left(45 \mathrm{P}_{2} \mathrm{O}_{5}, 14 \mathrm{pl} . \mathrm{m}^{-2}\right)$ & 12,0 & 10,3 & 16,5 & 7,4 & 7,2 & 2,8 \\
\hline $11\left(90 \mathrm{P}_{2} \mathrm{O}_{5}, 14 \mathrm{pl} . \mathrm{m}^{-2}\right)$ & 11,2 & 11,1 & 0,9 & 7,4 & 7,9 & $-6,3$ \\
\hline $12\left(135 \mathrm{P}_{2} \mathrm{O}_{5}, 14 \mathrm{pl} \mathrm{m} \mathrm{m}^{-2}\right)$ & 11,2 & 11,1 & 0,9 & 7,4 & 7,2 & 2,8 \\
\hline $13\left(0 \mathrm{P}_{2} \mathrm{O}_{5}, 18 \mathrm{pl} \cdot \mathrm{m}^{-2}\right)$ & 9,3 & 8,3 & 12,0 & 5,7 & 4,8 & 18,8 \\
\hline $14\left(45 \mathrm{P}_{2} \mathrm{O}_{5}, 18 \mathrm{pl} . \mathrm{m}^{-2}\right)$ & 9,3 & 8,3 & 12,0 & 5,7 & 5,7 & 0,0 \\
\hline $15\left(90 \mathrm{P}_{2} \mathrm{O}_{5}, 18 \mathrm{pl} . \mathrm{m}^{-2}\right)$ & 9,3 & 7,0 & 32,8 & 5,7 & 5,5 & 3,6 \\
\hline $16\left(135 \mathrm{P}_{2} \mathrm{O}_{5}, 18 \mathrm{pl} \cdot \mathrm{m}^{-2}\right)$ & 9,3 & 9,0 & 3,3 & 5,7 & 5,8 & $-1,7$ \\
\hline
\end{tabular}




\subsubsection{Estimativa da produtividade de grãos}

Nas Tabelas 27 e 28 encontram-se os valores observados e simulados da produtividade de grãos (PG) referentes aos experimentos que avaliaram diferentes níveis de fósforo com diferentes densidades de plantas,nos municípios de Parnaíba e Teresina, em 1996.

As PG experimentais dos tratamentos sem fósforo (T1, T5, T9 e T13) foram significativamente inferiores aos demais tratamentos nas duas localidades (análise estatística não apresentada). Isto não pôde ser constatado através dos dados simulados, uma vez que o modelo não considera o efeito do fósforo sobre o desenvolvimento da cultura. Com isso, pode-se perceber que as PG estimadas nas duas localidades crescem a cada quatro tratamentos (Tabelas 27 e 28 ) devido somente ao efeito da densidade de plantas.

Em relação a Parnaíba, a análise estatística dos dados experimentais demonstrou que os níveis de 45 e $90 \mathrm{~kg}^{-h^{-1}}$ de $\mathrm{P}_{2} \mathrm{O}_{5}$ proporcionaram as maiores $\mathrm{PG}$ e foram estatisticamente semelhantes. Pode-se perceber que, nestes tratamentos (T2, T3, T6, T7, T10, T11, T14 e T15), os valores de PG simulados e observados foram relativamente próximos, com erros de estimativa variando de 0,33 a 26,1\% (Tabela 27). Este bom ajuste se deve ao fato de não ter havido limitação de fósforo nestes tratamentos, condição semelhante à do modelo. Isto também explica os erros de estimativa relativamente altos $(17,7 ; 34,4 ; 41,6$ e $56,3 \%)$ para os tratamentos com nível zero de fósforo (T1, T5, T9 e T13). Dessa forma, pode-se inferir que a ausência da rotina do balanço de fósforo no solo pode se constituir em uma fonte de erro considerável se o modelo for aplicado em solos com deficiência desse nutriente.

Em contraste com os resultados obtidos na fase de calibração, verificou-se que, em Teresina, os erros de simulação da PG foram menores em relação a Parnaíba, para a maioria dos tratamentos, variando de 0,3 (T4) a 15,7\% (T1) (Tabela 28). Pode-se observar que, mesmo nos tratamentos com nível zero de fósforo (T1, T5, T9 e T13), as diferenças entre os valores simulados e observados da PG foram relativamente pequenas. Isto pode ser explicado em função de que o solo de Teresina (Aluvial 
Eutrófico), por ser mais fértil, apresentou uma menor resposta da cultura ao fósforo, proporcionando menores variações entre os tratamentos.

Apesar da maior fertilidade do solo de Teresina, a PG dos experimentos neste município $\left( \pm 1.500 \mathrm{~kg} \cdot \mathrm{ha}^{-1}\right)$ foi sensivelmente menor quando comparada à de Parnaiba $\left( \pm 1.900 \mathrm{~kg} \cdot \mathrm{ha}^{-1}\right)$. Isto reforça o efeito deletério das elevadas temperaturas sobre a produtividade da cultura, fato também caracterizado nesta fase de avaliação do CROPGRO-cowpea.

Tabela 27. Valores de produtividade de grãos do feijão caupi, cv. BR 17 - Gurguéia, na fase de avaliação do modelo CROPGRO-cowpea para Parnaíba, PI, 1996.

\begin{tabular}{|c|c|c|c|}
\hline \multirow[t]{2}{*}{ Tratamentos } & \multicolumn{2}{|c|}{ Produtividade de grãos $\left(\mathrm{kg} \cdot \mathrm{ha}^{-1}\right)$} & \multirow[t]{2}{*}{ Diferença $(\%)$} \\
\hline & Simulada & Observada & \\
\hline $1\left(0 \mathrm{P}_{2} \mathrm{O}_{5}, 4 \mathrm{pl} \cdot \mathrm{m}^{-2}\right)$ & 2.086 & 1.773 & 17,7 \\
\hline $2\left(45 \mathrm{P}_{2} \mathrm{O}_{5}, 4 \mathrm{pl} \cdot \mathrm{m}^{-2}\right)$ & 2.086 & 2.047 & 1,9 \\
\hline $3\left(90 \mathrm{P}_{2} \mathrm{O}_{5}, 4 \mathrm{pl} \cdot \mathrm{m}^{-2}\right)$ & 2.086 & 2.093 & $-0,3$ \\
\hline $4\left(135 \mathrm{P}_{2} \mathrm{O}_{5}, 4 \mathrm{pl} \cdot \mathrm{m}^{-2}\right)$ & 2.086 & 1.946 & 7,2 \\
\hline $5\left(0 \mathrm{P}_{2} \mathrm{O}_{5}, 9 \mathrm{pl} \cdot \mathrm{m}^{-2}\right)$ & 2.294 & 1.707 & 34,4 \\
\hline $6\left(45 \mathrm{P}_{2} \mathrm{O}_{5}, 9 \mathrm{pl} \cdot \mathrm{m}^{-2}\right)$ & 2.294 & 1.987 & 15,4 \\
\hline $7\left(90 \mathrm{P}_{2} \mathrm{O}_{5}, 9 \mathrm{pl} \cdot \mathrm{m}^{-2}\right)$ & 2.294 & 2.156 & 6,4 \\
\hline $8\left(135 \mathrm{P}_{2} \mathrm{O}_{5}, 9 \mathrm{pl} \cdot \mathrm{m}^{-2}\right)$ & 2.294 & 1.994 & 15,1 \\
\hline $9\left(0 \mathrm{P}_{2} \mathrm{O}_{5}, 14 \mathrm{pl} \cdot \mathrm{m}^{-2}\right)$ & 2.363 & 1.667 & 41,6 \\
\hline $10\left(45 \mathrm{P}_{2} \mathrm{O}_{5}, 14 \mathrm{pl} \cdot \mathrm{m}^{-2}\right)$ & 2.361 & 2.009 & 17,5 \\
\hline $11\left(90 \mathrm{P}_{2} \mathrm{O}_{5}, 14 \mathrm{pl} \cdot \mathrm{m}^{-2}\right)$ & 2.363 & 2.191 & 7,9 \\
\hline $12\left(135 \mathrm{P}_{2} \mathrm{O}_{5}, 14 \mathrm{pl} \cdot \mathrm{m}^{-2}\right)$ & 2.363 & 1.960 & 20,6 \\
\hline $13\left(0 \mathrm{P}_{2} \mathrm{O}_{5}, 18 \mathrm{pl} \cdot \mathrm{m}^{-2}\right)$ & 2.396 & 1.533 & 56,3 \\
\hline $14\left(45 \mathrm{P}_{2} \mathrm{O}_{5}, 18 \mathrm{pl} \cdot \mathrm{m}^{-2}\right)$ & 2.396 & 1.900 & 26,1 \\
\hline $15\left(90 \mathrm{P}_{2} \mathrm{O}_{5}, 18 \mathrm{pl} \cdot \mathrm{m}^{-2}\right)$ & 2.396 & 2.047 & 17,1 \\
\hline $16\left(135 \mathrm{P}_{2} \mathrm{O}_{5}, 18 \mathrm{pl} . \mathrm{m}^{-2}\right)$ & 2.396 & 1.811 & 32,3 \\
\hline
\end{tabular}


Tabela 28. Valores de produtividade de grãos do feijão caupi, cv. BR 17 - Gurguéia, na fase de avaliação do modelo CROPGRO-cowpea para Teresina, Piauí, 1996.

\begin{tabular}{|c|c|c|c|}
\hline \multirow[t]{2}{*}{ Tratamentos } & \multicolumn{2}{|c|}{ Produtividade de grãos $\left(\mathrm{kg} \cdot \mathrm{ha}^{-1}\right)$} & \multirow[t]{2}{*}{ Diferença (\%) } \\
\hline & Simulada & Observada & \\
\hline $1\left(0 \mathrm{P}_{2} \mathrm{O}_{5}, 4 \mathrm{pl} . \mathrm{m}^{-2}\right)$ & 1.334 & 1.153 & 15,7 \\
\hline $2\left(45 \mathrm{P}_{2} \mathrm{O}_{5}, 4 \mathrm{pl} \cdot \mathrm{m}^{-2}\right)$ & 1.334 & 1.424 & $-6,3$ \\
\hline $3\left(90 \mathrm{P}_{2} \mathrm{O}_{5}, 4 \mathrm{pl} \cdot \mathrm{m}^{-2}\right)$ & 1.334 & 1.528 & $-12,7$ \\
\hline $4\left(135 \mathrm{P}_{2} \mathrm{O}_{5}, 4 \mathrm{pl} \cdot \mathrm{m}^{-2}\right)$ & 1.334 & 1.338 & $-0,3$ \\
\hline $5\left(0 \mathrm{P}_{2} \mathrm{O}_{5}, 9 \mathrm{pl} \cdot \mathrm{m}^{-2}\right)$ & 1.384 & 1.394 & $-0,7$ \\
\hline $6\left(45 \mathrm{P}_{2} \mathrm{O}_{5}, 9 \mathrm{pl} \cdot \mathrm{m}^{-2}\right)$ & 1.384 & 1.605 & $-13,8$ \\
\hline $7\left(90 \mathrm{P}_{2} \mathrm{O}_{5}, 9 \mathrm{pl} \cdot \mathrm{m}^{-2}\right)$ & 1.384 & 1.787 & $-22,6$ \\
\hline $8 \quad\left(135 \mathrm{P}_{2} \mathrm{O}_{5}, 9 \mathrm{pl} . \mathrm{m}^{-2}\right)$ & 1.384 & 1.602 & $-13,6$ \\
\hline $9\left(0 \mathrm{P}_{2} \mathrm{O}_{5}, 14 \mathrm{pl} . \mathrm{m}^{-2}\right)$ & 1.414 & 1.340 & 5,5 \\
\hline $10\left(45 \mathrm{P}_{2} \mathrm{O}_{5}, 14 \mathrm{pl} . \mathrm{m}^{-2}\right)$ & 1.414 & 1.492 & $-5,2$ \\
\hline $11\left(90 \mathrm{P}_{2} \mathrm{O}_{5}, 14 \mathrm{pl} \cdot \mathrm{m}^{-2}\right)$ & 1.414 & 1.601 & $-11,7$ \\
\hline $12\left(135 \mathrm{P}_{2} \mathrm{O}_{5}, 14 \mathrm{pl} \cdot \mathrm{m}^{-2}\right)$ & 1.414 & 1.582 & $-10,6$ \\
\hline $13\left(0 \mathrm{P}_{2} \mathrm{O}_{5}, 18 \mathrm{pl} \cdot \mathrm{m}^{-2}\right)$ & 1.425 & 1.320 & 7,9 \\
\hline $14\left(45 \mathrm{P}_{2} \mathrm{O}_{5}, 18 \mathrm{pl} . \mathrm{m}^{-2}\right)$ & 1.425 & 1.494 & $-4,5$ \\
\hline $15\left(90 \mathrm{P}_{2} \mathrm{O}_{5}, 18 \mathrm{pl} \cdot \mathrm{m}^{-2}\right)$ & 1.425 & 1.652 & $-13,6$ \\
\hline $16\left(135 \mathrm{P}_{2} \mathrm{O}_{5}, 18 \mathrm{pl} \cdot \mathrm{m}^{-2}\right)$ & 1.425 & 1.643 & $-13,1$ \\
\hline
\end{tabular}

\subsection{Aplicação do modelo CROPGRO-cowpea}

$\mathrm{Na}$ Tabela 29, encontram-se os valores médios de produtividade de grãos e de receita líquida resultantes da simulação de tratamentos com diferentes níveis de irrigação e épocas de semeadura, para os municípios de Parnaíba e Teresina, Piauí.

Em Parnaiba, as receitas máximas por hectare ( $\mathrm{R} \$ 1.088,00$ e 1.076,00) foram obtidas com os tratamentos que indicam reiniciar a irrigação quando o solo estiver com 50 e $40 \%$ da capacidade de água disponível (CAD), respectivamente. Os respectivos potenciais matriciais $\left(\psi_{\mathrm{m}}\right)$ para esses valores de CAD são -12,4 e -15,8 kPa (Figura 7a), que estão coerentes, em se tratando de um solo arenoso como o de Parnaíba, cuja 
umidade à capacidade de campo $\left(0,139 \mathrm{~cm}^{3} \cdot \mathrm{cm}^{-}\right)$, se encontra aproximadamente a um $\psi_{\mathrm{m}}$ de $-6 \mathrm{kPa}$.

Apesar dos resultados simulados terem demonstrado que a semeadura em 15/06 é a mais favorável para o feijão caupi sob irrigação do ponto de vista econômico, observou-se que a semeadura nos outros meses (julho, agosto e setembro) possibilita ao agricultor auferir receitas líquidas positivas com o cultivo irrigado: $R \$ 925,00 /$ ha (semeadura em 15/07); R $\$ 831,00 /$ ha (semeadura em 15/08) e R $\$ 839,00 /$ ha (semeadura em 15/09) (Tabela 29). Para a obtenção dessas receitas, o modelo também indica manter o teor de água no solo em níveis de até $50 \%$ da CAD.

Em Teresina, os resultados demonstraram que a estratégia ótima econômica é estabelecer o reinício da irrigação quando o solo atingir $30 \%$ da $\mathrm{CAD}$, o que corresponde à uma depleção da água no solo de 70\%. Ziska et al. (1985) obtiveram resultados semelhantes, constatando que o manejo da irrigação em caupi, efetuado quando o solo atingia $75 \%$ da água disponível, proporcionou elevada produtividade de sementes $\left(2,22 \mathrm{t}^{\mathrm{h}} \mathrm{ha}^{-1}\right)$.

Nesse contexto, pode-se inferir que, em Teresina, o irrigante pode adotar um manejo de irrigação com menor freqüência e maiores lâminas de água em relação à Parnaíba. Considerando-se as características fisico-hídricas destes solos (Tabela 2) esses resultados estão coerentes, pois o solo Aluvial Eutrófico de Teresina, por possuir maior teor de argila e silte (Tabela 2), apresenta uma maior capacidade de retenção de água e, dessa forma, suporta aplicações de água em quantidades maiores, quando comparado ao solo de Parnaíba (Areia Quartzosa).

Entretanto, o valor de $70 \%$ para ser usado como depleção de água no solo $(30 \%$ da $\mathrm{CAD}$ ) pode ser muito alto, especialmente se for considerada a ocorrência comum de elevadas temperaturas em Teresina, nessa época do ano (Figura 3). De acordo com Doorenbos \& Kassam (1994), o fator de depleção ou de esgotamento de água no solo deve ser escolhido em função da cultura e da evapotranspiração máxima (ETM). No referido trabalho, não há recomendação para o feijão caupi, porém, para leguminosas como o feijão comum e o amendoím, um consumo de água até $70 \%$ da CAD só é indicado se a ETM, no local, for em torno de $3 \mathrm{~mm} \cdot \mathrm{dia}^{-1}$. 
Considerando-se que em Teresina os valores de ETM podem chegar até $6 \mathrm{~mm} \cdot \mathrm{dia}^{-1}$ (observações experimentais) e que a diferença da receita líquida entre os tratamentos foi pequena (Tabela 29), pode-se recomendar como estratégia de manejo, reiniciar a irrigação quando o solo atingir $50 \%$ da $\mathrm{CAD}$, o que corresponde a um potencial matricial de $-58 \mathrm{kPa}$ (Figura $7 \mathrm{~b}$ ). Apesar de relativamente baixo, este valor é coerente para um solo Aluvial Eutrófico e está de acordo com o potencial crítico para o caupi, recomendado por Lima et al. (1999); Bezerra \& Saunders (1992) e Silva \& Millar (1981), cujos trabalhos foram conduzidos em solos de textura semelhante.

$\mathrm{O}$ fato de não se recomendar o tratamento indicado pelo modelo como o mais eficiente, não significa que houve erros de simulação. Thornton et al. (1994) alertam que deve-se ter cuidado ao se interpretar os resultados indicados pela "análise de estratégia" no módulo "seasonal" do DSSAT pois nem sempre, os resultados podem estar coerentes. Entretanto, constitui-se em uma importante ferramenta para orientar o pesquisador na escolha das opções de tratamentos que merecem ser investigadas posteriormente.

Ainda com relação a Teresina, percebe-se que os valores de receita líquida são negativos para os tratamentos que consideraram a época de semeadura em 15/08 e 15/09, em qualquer dos níveis de irrigação. Pode-se observar que nestes tratamentos a produtividade de grãos foi baixa, variando de 784 a $827 \mathrm{~kg} . h a^{-1}$ (semeadura em 15/08) e de 840 a $893 \mathrm{~kg}^{-h^{-1}}$ (semeadura em 15/09) (Tabela 29). Esta tendência foi constatada na fase de calibração do modelo CROPGRO-cowpea (Tabela 19), o que reforça a boa performance do modelo em estimar a produtividade de grãos da cultura do feijão caupi nos locais considerados.

Os resultados das simulações para os dois municípios (Tabela 29) demonstraram que não é possível o cultivo do caupi no segundo semestre, sem o uso da irrigação. Isto é devido à baixa precipitação pluviométrica no período, que variou, em média, de 7,2 a $48 \mathrm{~mm}$ (média de 9 anos) em Parnaíba e de 23,9 a $77 \mathrm{~mm}$ (média de 22 anos) em Teresina.

De acordo com os resultados da evapotranspiração da cultura (ETC), da quantidade de água aplicada e da precipitação (Tabela 30), observa-se que os 
tratamentos que consideraram a manutenção do conteúdo de água no solo em níveis de até $50 \%$ da $\mathrm{CAD}$, proporcionaram uma irrigação sem déficit hídrico nos dois municípios. Além disso, as lâminas de irrigação indicadas para este tratamento estão dentro da faixa recomendada para a cultura do feijão caupi, conforme Andrade Júnior et al. (1998); Espínola et al. (1992) e Lima et al. (1999). Considerando-se a coerência destes resultados, pode-se recomendar aos produtores de feijão caupi das duas localidades, um manejo da irrigação mantendo o teor de água no solo em níveis de até $50 \%$ da CAD.

Tabela 29. Valores médios simulados da produtividade de grãos (PG) e da receita líquida (RL), na fase de aplicação do modelo CROPGRO-cowpea para Parnaiba e Teresina, PI.

\begin{tabular}{|c|c|c|c|c|}
\hline \multirow[t]{2}{*}{ Tratamentos } & \multicolumn{2}{|c|}{ Parnaíba } & \multicolumn{2}{|c|}{ Teresina } \\
\hline & PG $\left(\right.$ kg.ha $\left.{ }^{-1}\right)$ & RL (R\$. há $\left.{ }^{-1}\right)$ & PG $\left(\right.$ kg.ha $\left.{ }^{-1}\right)$ & $\mathrm{RL}\left(\mathrm{R} \$ \mathrm{ha}^{-1}\right)$ \\
\hline $15 / 06+60 \%$ CAD & 2.083 & 1063,00 & 1579 & 574,00 \\
\hline $15 / 06+50 \%$ CAD & 2.059 & 1088,00 & 1556 & 626,00 \\
\hline $15 / 06+40 \% \mathrm{CAD}$ & 1.997 & 1076,00 & 1537 & 651,00 \\
\hline $15 / 06+30 \% \mathrm{CAD}$ & 1.946 & 1058,00 & 1515 & 664,00 \\
\hline Sem Irrigação & 261 & $-398,00$ & 333 & $-312,00$ \\
\hline $15 / 07+60 \%$ CAD & 1.991 & 901,00 & 1064 & 12,00 \\
\hline $15 / 07+50 \%$ CAD & 1.959 & 925,00 & 1045 & 71,00 \\
\hline $15 / 07+40 \%$ CAD & 1.904 & 923,00 & 1029 & 107,00 \\
\hline $15 / 07+30 \%$ CAD & 1.817 & 886,00 & 1010 & 128,00 \\
\hline Sem Irrigação & 176 & $-484,00$ & 254 & $-391,00$ \\
\hline $15 / 08+60 \% \mathrm{CAD}$ & 1.930 & 811,00 & 827 & $-239,00$ \\
\hline $15 / 08+50 \%$ CAD & 1.885 & 831,00 & 813 & $-165,00$ \\
\hline $15 / 08+40 \% \mathrm{CAD}$ & 1.812 & 809,00 & 797 & $-128,00$ \\
\hline $15 / 08+30 \% \mathrm{CAD}$ & 1.687 & 746,00 & 784 & $-101,00$ \\
\hline Sem Irrigação & 175 & $-484,00$ & 212 & $-433,00$ \\
\hline $15 / 09+60 \%$ CAD & 1.900 & 810,00 & 893 & $-123,00$ \\
\hline $15 / 09+50 \%$ CAD & 1.863 & 839,00 & 875 & $-56,00$ \\
\hline $15 / 09+40 \%$ CAD & 1.769 & 800,00 & 858 & $-26,00$ \\
\hline $15 / 09+30 \%$ CAD & 1.647 & 726,00 & 840 & $-6,00$ \\
\hline Sem Irrigação & 171 & $-489,00$ & 301 & $-343,00$ \\
\hline
\end{tabular}

' Os valores em negrito indicam as melhores estratégias de manejo de irrigação 
Tabela 30. Precipitação (P) média e valores médios simulados da evapotranspiração da cultura (ETC) e da lâmina de irrigação (L) para Parnaíba e Teresina, Piauí.

\begin{tabular}{|c|c|c|c|c|c|c|}
\hline \multirow[t]{2}{*}{ Tratamentos } & \multicolumn{3}{|c|}{ Parnaíba } & \multicolumn{3}{|c|}{ Teresina } \\
\hline & $\mathrm{P}^{1}(\mathrm{~mm})$ & $\operatorname{ETC}(\mathrm{mm})$ & $\mathrm{L}(\mathrm{mm})$ & $\mathrm{P}^{2}(\mathrm{~mm})$ & $\operatorname{ETC}(\mathrm{mm})$ & $\mathrm{L}(\mathrm{mm})$ \\
\hline $15 / 06+60 \% \mathrm{CAD}$ & 48,0 & 290 & 273 & 25,7 & 337 & 304 \\
\hline $15 / 06+50 \% \mathrm{CAD}$ & 48,0 & 279 & 252 & 25,7 & 306 & 260 \\
\hline $15 / 06+40 \% \mathrm{CAD}$ & 48,0 & 268 & 229 & 25,7 & 292 & 235 \\
\hline $15 / 06+30 \% \mathrm{CAD}$ & 48,0 & 259 & 212 & 25,7 & 278 & 213 \\
\hline Sem Irrigação & 48,0 & 120 & 0 & 25,7 & 133 & 0 \\
\hline $15 / 07+60 \% \mathrm{CAD}$ & 15,7 & 313 & 327 & 23,9 & 373 & 345 \\
\hline $15 / 07+50 \%$ CAD & 15,7 & 297 & 303 & 23,9 & 340 & 302 \\
\hline $15 / 07+40 \%$ CAD & 15,7 & 285 & 282 & 23,9 & 319 & 271 \\
\hline $15 / 07+30 \% \mathrm{CAD}$ & 15,7 & 270 & 256 & 23,9 & 302 & 246 \\
\hline Sem Irrigação & 15,7 & 95,3 & 0 & 23,1 & 129 & 0 \\
\hline $15 / 08+60 \% \mathrm{CAD}$ & 1,0 & 320 & 351 & 38,4 & 392 & 356 \\
\hline $15 / 08+50 \% \mathrm{CAD}$ & 1,0 & 302 & 322 & 38,4 & 354 & 307 \\
\hline $15 / 08+40 \% \mathrm{CAD}$ & 1,0 & 289 & 302 & 38,4 & 334 & 274 \\
\hline $15 / 08+30 \% \mathrm{CAD}$ & 1,0 & 268 & 264 & 38,4 & 316 & 248 \\
\hline Sem Irrigação & 1,0 & 85 & 0 & 35,4 & 141 & 0 \\
\hline $15 / 09+60 \% \mathrm{CAD}$ & 7,2 & 304 & 323 & 77,0 & 370 & 312 \\
\hline $15 / 09+50 \% \mathrm{CAD}$ & 7,2 & 286 & 298 & 77,0 & 337 & 263 \\
\hline $15 / 09+40 \% \mathrm{CAD}$ & 7,2 & 271 & 273 & 77,0 & 317 & 234 \\
\hline $15 / 09+30 \%$ CAD & 7,2 & 251 & 242 & 77,0 & 302 & 208 \\
\hline Sem Irrigação & 7,2 & 89 & 0 & 71,3 & 162 & 0 \\
\hline
\end{tabular}

${ }^{1}$ Valores médios referentes ao período de 1990 a 1998.

${ }^{2}$ Valores médios referentes ao período de 1977 a 1998. 


\subsection{Considerações finais}

As cultivares de feijão caupi utilizadas neste trabalho (BR 14 - Mulato e BR 17 Gurguéia) apresentaram um padrão fenológico semelhante, fato constatado por meio das observações experimentais e das simulações do modelo CROPGRO-cowpea. O referido modelo também pode ser calibrado para cultivares de ciclo precoce, uma vez que, por meio de alterações em coeficientes específicos da cultivar (arquivos .CUL e .ECO), é possível adequá-lo para simular a fenologia da planta, independentemente do seu ciclo.

$\mathrm{Na}$ fase de calibração do CROPGRO-cowpea, foram observados ajustes satisfatórios na estimativa da biomassa e do índice de área foliar para as duas cultivares, locais e anos estudados. Ressalta-se que nos dados experimentais ocorreram alguns valores discrepantes, conforme podem ser visualizados nas figura 9a, b, c (biomassa) e $11 \mathrm{~b}$ (IAF). Isto demonstra a possibilidade de terem ocorrido erros em algumas observações, que segundo Boote et al. (1996), constituem-se em uma das limitações para se calibrar adequadamente um modelo de simulação de cultura.

Dentre os componentes de produção, apenas o peso de 100 grãos (P100) não foi estimado satisfatoriamente. Entretanto, as subestimativas dessa variável não influenciaram nas simulações da produtividade de grãos (PG).

De um modo geral, foram obtidos bons ajustes para as simulações de PG, especialmente para Parnaiba. Em Teresina, porém, observou-se erros de estimativa desta variável de 37,3\% para a cv. BR 14 - Mulato e 44,5\% para a cv. BR 17 - Gurguéia (Tabela 19), o que limitaria projeções econômicas, se fossem consideradas apenas simulações de um ano. Entretanto, comparando-se o valor simulado de PG da cv. BR 17 Gurguéia obtido nos experimentos de 1998, em Teresina (1.002 kg.ha $\left.{ }^{-1}\right)$, com os valores médios de PG resultantes das simulações de 22 anos para os tratamentos com data de semeadura e condições hídricas semelhantes ao referido experimento ( 827 e $\left.813 \mathrm{~kg} \cdot \mathrm{ha}^{-1}\right)$ (Tabela 29), percebe-se que estes erros caem de $44,5 \%$ para 17,5 e $18,9 \%$ (considerando-se as PG dos tratamentos com 60 e 50\% da CAD, respectivamente). Isto evidencia que, quanto maior a série histórica de dados climáticos, maior será a confiança nos resultados simulados. 
Para melhorar a performance do modelo CROPGRO-cowpea, quando aplicado em locais ou épocas onde os valores de temperatura máxima ultrapassem a $36^{\circ} \mathrm{C}$, há necessidade de pesquisas básicas, visando o conhecimento de respostas fisiológicas da cultura do feijão caupi aos fatores ambientais locais, principalmente à temperatura do ar. Dessa forma, alguns dos coeficientes de espécie, requeridos pelo modelo, poderiam ser preenchidos por valores mais adequados.

Em relação à fase de aplicação do CROPGRO-cowpea, os resultados simulados indicaram estratégias de manejo de irrigação, que podem ser utilizadas pelo agricultor, com a obtenção de receitas líquidas positivas (Tabela 29). Em Parnaíba, verificou-se que não houve restrição de época de semeadura para o cultivo irrigado no segundo semestre e que o melhor controle de irrigação seria manter o teor de água no solo em níveis de $50 \%$ da CAD. Este mesmo nível também pode ser recomendado para Teresina. Considerando-se os preços utilizados no presente estudo, referentes a agosto/99, e que as simulações de longo período (22 anos) apresentam um bom nível de confiança, não se recomenda a semeadura do caupi, nos meses de agosto e setembro, neste município.

Estudos para avaliar a variação da profundidade de manejo da irrigação sobre a produtividade econômica de grãos do feijão caupi podem ser uma outra aplicação do modelo CROPGRO-cowpea. Este modelo também pode ser calibrado para condições de sequeiro, tendo a possibilidade de ser aplicado para diversos objetivos, como identificação da melhor época de semeadura, influência da aplicação de adubos nitrogenados ou da incorporação de resíduos culturais sobre a PG, melhor densidade de plantio e outras opções de manejo.

É importante destacar que erros de estimativa de produção de cultura são inevitáveis, especialmente quando se deseja extrapolar os resultados para outras localidades pois são inúmeras as variáveis que influenciam no processo produtivo. Além disso, existe uma grande variabilidade espacial e temporal dos parâmetros requeridos pelos modelos.

Dessa forma, considerando-se: $i$ ) a ampla faixa de variação das condições de solo e clima em que se realizaram a calibração e avaliação do CROPGRO-cowpea; ii) os 
bons resultados de estimativa obtidos no presente estudo e; iii) que o sistema DSSAT permite simulações de longo período, pode-se inferir que o CROPGRO-cowpea constitui-se em uma importante ferramenta, podendo ser utilizada por pesquisadores, técnicos e/ou produtores rurais, na busca de um sistema de produção agrícola adequado para a cultura do feijão caupi, no Estado do Piauí. 


\section{CONCLUSÕES}

- O modelo CROPGRO-cowpea simula satisfatoriamente o crescimento e o desenvolvimento do feijão caupi, para as condições de solo e clima dos municípios de Parnaíba e Teresina, Piauí.

- De acordo com a aplicação do modelo para os dois locais estudados, o manejo de irrigação que maximiza a receita líquida ao produtor de feijão caupi é manter o teor de água no solo em níveis de até $50 \%$ da capacidade de água disponível.

- A semeadura em 15/06 é a mais indicada para o cultivo irrigado do feijão caupi nos dois municípios. Em Pamaíba, é possível estender a semeadura até o mês de setembro, obtendo-se receitas líquidas positivas. Em Teresina, entretanto, esse período se restringe até o mês de julho.

- O modelo CROPGRO-cowpea constitui-se em uma importante ferramenta para auxiliar pesquisadores e/ou produtores rurais na busca de um manejo econômico da irrigação. 


\section{REFERÊNCIAS BIBLIOGRÁFICAS}

ANDRADE, C.L.T. de.; FREITAS, J.A.D.de; LUZ, L.R.Q.P.da. Características fisicohídricas de solos arenosos de tabuleiros litorâneos. In: CONGRESSO NACIONAL DE IRRIGAÇÃO E DRENAGEM, 9., Natal, 1991. Anais. Fortaleza: Associação Brasileira de Irrigação e Drenagem, 1992. p.1068-1096.

ANDRADE JÚNIOR, A. S.; RODRIGUES, B. H. N.; CARDOSO, M. J.; ATHAYDE SOBRINHO, C.; MELO, F. B. Niveis de irrigação e produtividade de grãos secos de feijão caupi. In: REUNIÃO BRASILEIRA DE MANEJO E CONSERVAÇÃO DO SOLO E DA ÁGUA, 12., Fortaleza, 1998. Resumos expandidos. Fortaleza: SBCC; UFCE, 1998. p.83-84.

ANDRADE JÚNIOR, A. S.; RODRIGUES, B. H. N.; FRIZZONE, J. A.; CARDOSO, M. J.; BASTOS, E. A.; MELO, F. B. Niveis de irrigação na cultura do feijão caupi (compact disc). In: CONGRESSO BRASLEIRO DE ENGENHARIA AGRÍCOLA, 28., Pelotas, 1999. Anais. Pelotas: FEA; UFPel; SBEA, 1999.

BABALOLA, O. Water relations of three cowpea cultivars (Vigna unguiculata, L.) Plant and Soil, v.56, p.59-69, 1980.

BARROS, A.H.C. Análise do crescimento, do desenvolvimento e da produtividade da cultura do milho (Zea mays L.): experimentos e modelos. Viçosa, 1998. 85p. Dissertação (M.S.) - Universidade Federal de Viçosa.

BELMANS, C.; WESSELING, J.G.; FEDDES; R.A. Simulation model of the water balance of a cropped soil: Swatre. Journal of Hydrology, v.63, p.271-286, 1983. 
BERNARDO, D.J.; WHITTLESEY, N.K; SAXTON, K.E.; BASSET, D.L. Irrigation optimization under limited water supply. Transactions of the ASAE, v.31, n.3, p.712-719, 1988.

BEZERRA, F. M. L.; SAUNDERS, L. C. U. Irrigação de dois cultivares de feijão-decorda (Vigna unguiculata (L.) Walp.) em três épocas de plantio sob dois níveis de irrigação no Vale do Curu. Ciência Agronômica, v.23, n. 1/2, p.39-44, 1992.

BOOTE, K.J. Training program on computer simulation of crop growth and management responses. Gainesville: University of Florida, International Consortium for Agricultural Systems Applications, International Fertilizer Development Center, 1994. 13p.

BOOTE, K.J.; PICKERING, N.B. Modeling photosynthesis of row crop canopies. HortScience, v.29, n. 12, p.1423-1434, 1994.

BOOTE, K.J.; JONES, J.W.; HOOGENBOOM, G. Simulation of crop growth: CROPGRO model. In: PEART, R.M.; CURRY, R.B. (Ed.) Agricultural systems modeling and simulation. New York: Marcel Dekker, 1998a. p.651-691.

BOOTE, K.J.; JONES, J.W.; PICKERING, N.B. Potential uses and limitations of crop models. Agronomy Journal, v.88, p.707-716, 1996.

BOOTE; K.J.; WILKERSON, G.G.; JONES, J.W. Modeling pod addition, shell growth, and seed growth. In: Simulation models for soybeans and other crops. Taipei: Food and Fertilizer Technology Center for the Asian and Pacific Region, 1987. p.15-24. (FFTC. Technical Bulletin, 106).

BOOTE, K.J.; BATCHELOR, W.D.; JONES, J.W.; PINNSCHMIDT, H.; BOURGEOIS, G. Pest damage relations at the field level. In: PENNING DE VRIES, F.W.T.; TENG, P.S.; METSELAAR, K. (Ed.) Systems approaches for agricultural development. Dordrecht: Kluwer, 1993. p.277-296. 
BOOTE, K.J.; JONES, J.W.; HOOGENBOOM, G.; PICKERING, N.B. The CROPGRO model for grain legumes. In: TSUI, G.Y.; HOOGEBOOM, G.; THORNTON, P.K. (Ed.) Understanding options for agricultural production. Dordrecht: Kluwer, 1998b. p.99-128.

BOWEN, W.T.; JONES, J.W.; THORNTON, P.K. Crop simulation as a potential tool for evaluating sustainable land management. In: INTERNATIONAL SOIL MANAGEMENT WORKSHOP: UTILIZATION OF SOIL SURVEY INFORMATION FOR SUSTAINABLE LAND USE", 8., Washington, 1993. Proceedings. Washington: USDA; Soil Conservation Service; National Soil Survey Center, 1993. p.15-21.

CARDOSO, M.J.; FREIRE FILHO, F.R.; ATHAYDE SOBRINHO, C. BR 14 Mulato: nova cultivar de feijão macassar para o estado do Piauí. Teresina: EMBRAPAUEPAE de Teresina, 1990. 4p. (EMBRAPA-UEPAE de Teresina. Comunicado Técnico, 48)

CARDOSO, M.J.; MELO, F.B.; ANDRADE JÚNIOR, A.S. Densidade de plantas de caupi em regime irrigado. Pesquisa Agropecuária Brasileira, v.32, n.4, p.399-405, 1997.

CARDOSO, M.J.; ANDRADE JÚNIOR, A.S.; MELO, F.B.; FROTA, A.B. Avaliação agroeconômica da produção de sementes de caupi sob irrigação. Teresina: Embrapa-CPAMN, 1995. 6p. (Embrapa-CPAMN. Comunicado Técnico, 62).

CARDOSO, M.J.; MELO, F.B.; FREIRE FILHO, F.R.; FROTA, A.B. Densidade de plantas de caupi de porte enramador e moita em regime de sequeiro. Revista Ceres, v.41, n.233, p.19-27, 1994.

CARDOSO, M.J., MELO, F.B.; BASTOS, E.A.; RIBEIRO, V.Q.; ATHAYDE SOBRINHO, C.; ANDRADE JÚNIOR, A.S. Doses de fósforo e densidades de plantas em caupi. II - Efeito sobre a produtividade de grãos e componentes de produção sob irrigação em solo Aluvial Eutrófico. In: REUNIÃO NACIONAL DE PESQUISA DE CAUPI, 4., Teresina, 1996. Resumos. Teresina: Embrapa-CPAMN, 1996a. p.123-124. 
CARDOSO, M.J., MELO, F.B.; RODRIGUES, B.H.N.; ANDRADE JÚNIOR, A.S; ATHAYDE SOBRINHO, C.; RIBEIRO, V.Q.; BASTOS, E.A. Doses de fósforo e densidades de plantas em caupi. I - Efeito sobre a produtividade de grãos e componentes de produção sob irrigação em solo de Tabuleiro Costeiro. In: REUNIÃO NACIONAL DE PESQUISA DE CAUPI, 4., Teresina, 1996. Resumos. Teresina: Embrapa-CPAMN, 1996b. p.121-122.

CASTRO, P.R.C; BERGAMASCHI, H.; SILVEIRA, J.A.G.; MARTINS, P.F.S. Desenvolvimento comparado de três cultivares de caupi, Vigna unguiculata (L.) Walp. Anais da Escola Superior de Agricultura "Luiz de Queiroz", v.41, n.2, p.555-584, 1984.

COLSON, J.; BOUNIOLS, A.; JONES, J.W. Soybean reproductive development: adapting a model for european cultivars. Agronomy Journal, v.87, p.1129-1139, 1995.

CORDEIRO, L.G.;BEZERRA, F.M.L.; SANTOS, J.J.A.; MIRANDA, E.P. Avaliação da produtividade do feijão caupi (Vigna unguiculata (L.) Walp.) In: CONGRESSO BRASILEIRO DE ENGENHARIA AGRÍCOLA, 27., Poços de Caldas ,1998. Anais. Lavras: SBEA; UFLA, 1998. v.2, p.181-183.

COSTA, L.C. Modelagem e simulação em agrometeorologia (Mesa redonda I). In: CONGRESSO BRASILEIRO DE AGROMETEOROLOGIA, 10., Piracicaba, 1997. Suplemento dos anais. Piracicaba: SBA, 1997. p. 3-6.

COSTA, M.M.M.N.; TAVORA, R.J.A.F.; PINHO, J.L.N.; MELO, F.I.O. Produção, componentes de produção, crescimento e distribuição das raizes de caupi submetido à deficiência hídrica. Pesquisa Agropecuária Brasileira, v.32, n. 1, p.43-50, 1997.

COSTA, R.C.L.; CARDOSO, B.B.; SILVA, J.T.; GOMES FILHO, J.G.F.; SILVEIRA, J.A.G. O estresse hídrico diminui intensamente a assimilação do nitrato e a nodulação em feijão-de-corda (Vigna unguiculata, (L.) Walp.). In: REUNIÃO NACIONAL DE PESQUISA DE CAUPI, 4., Teresina, 1996. Resumos. Teresina: Embrapa-CPAMN, 1996. p.78-79. 
CRAUFURD, P.Q.; BOJANG, M.; WHELER, T.R.; SUMMERFIELD, R.J. Heat tolerance in cowpea: effect of timing and duration of heat stress. Annals of Applied Biology, v. 133, p.257-267, 1998.

CRAUFURD, P.Q.; QI, A.; ELLIS, R.H.; SUMMERFIELD, R.J.; ROBERTS, E.H.

Development in cowpea (Vigna unguiculata) $I$. Effect of temperature and saturation deficit on time to flowering in photoperiod insensive genotypes. Experimental Agriculture, v.32, p. 13-28, 1996a.

CRAUFURD, P.Q.; QI, A.; SUMMERFIELD, R.J.; ELLIS, R.H.; ROBERTS, E.H. Development in cowpea (Vigna unguiculata) III. Effect of temperature and photoperiod on time to flowering in photoperiod sensitive genotypes and screening for photothermal responses. Experimental Agriculture, v.32, p.29-40, $1996 \mathrm{~b}$.

DOORENBOS, J.; KASSAM, A.H. Efeito da água no rendimento das culturas. Trad. de H.R Gheyi, A.A. Sousa, F.A.V. Damasceno e J.F. Medeiros. Campina Grande: UFPB, 1994. cap. 3, p.42-53: Evapotranspiração real (Etr).

DOTO, A.L.; WHITTINGTON, W.J. Responses of cowpea (Vigna unguiculata) varieties and their hybrids to variation in day and night temperature regimes. Annals of Applied Biology, v.97, p.213-219, 1981.

EHLERS, J.D.; HALL, A.E.. Cowpea (Vigna unguiculata L. Walp.). Field Crop Research, v.53, p.187-204, 1997.

ELOWAD, H.O.A.; HALL, A.E. Influences of early and late nitrogen fertilization on yield and nitrogen fixation of cowpea under well-watered and dry field conditions. Field Crop Research, v. 15, p.229-244, 1987.

ESPÍNOLA, F. C. S.; MEDINA, B. F.; MAIA NETO, J. M.; NOGUEIRA, F. C.; AMARO FILHO, J.; MEDEIROS FILHO, J. C. Resposta do feijão caupi (Vigna unguiculata L. Walp.) a diferentes níveis de irrigação. In: CONGRESSO NACIONAL DE IRRIGAÇÃO E DRENAGEM, 9., Natal, 1992. Anais. Fortaleza: ABID, 1992. p.971-995. 
EZEDINMA, F.O.C. Effects of close spacing on cowpeas (Vigna unguiculata (L.) Walp.) in Souther Nigeria. Experimental agriculture, v.10, p.289-298, 1974.

FARIA, R.T.; MADRAMOOTOO, C.A. Simulation of soil moisture profiles for wheat in Brazil. Agricultural and Water Management, v.31, p.35-49, 1996.

FARIA, R.T.; OLIVEIRA, D. de; FOLEGATTI, M.V. Simulação da fenologia e produção do feijoeiro pelo modelo BEANGRO. In.: CONGRESSO BRASILEIRO DE AGROMETEOROlOGIA, 10., Piracicaba, 1997. Anais. Piracicaba: SBA, 1997b. p. 140-142.

FARIA, R.T.; FOLEGATTI, M.V.; FRIZZONE, J.A.; SAAD, A.M. Determination of a long-term optimal irrigation strategy for dry beans in Parana state, Brazil. Scientia. Agricola, Piracicaba, v.54, n. esp., p.155-164. 1997a.

FREIRE FILHO, F.R.; SANTOS, A.A.; CARDOSO, M.J.; SILVA, P.H.S.; RIBEIRO, V.Q. BR 17-Gurguéia: nova culltivar de caupi com resistência a vírus para o Piauí. Teresina: Embrapa-CPAMN, 1994. 6p. (Embrapa-CPAMN. Comunicado Técnico, $61)$.

GEDANKEN, A. Utilização do modelo CERES-maize na avaliação de estratégias de irrigação na cultura do milho em duas regiões de Minas Gerais. Viçosa, 1998. 74 p. Dissertação (M.S.) - Universidade Federal de Viçosa.

GIL MARTINEZ, F. Elementos de fisiologia vegetal. Madrid: Mundi-Prensa, 1995. $1147 \mathrm{p}$.

GIRALDO, L.M.; LIZCANO, L.J.; GIJSMAN, A.J.; RIVERA, B.; FRANCO, L.H. Adaptación del modelo DSSAT para simular la producción de Brachiaria decumbens. Pasturas tropicales, v.20, n.2, p.2-12, 1999.

HADLEY, P.; ROBERTS, E.H.; SUMMERFIELD, R.J. A quantitative model of reproductive development (Vigna unguiculata (L.) Walp.) in relation to photoperiod and temperature, and implications for screening germplasm. Annals of Botany, v.51, p.531-543, 1983. 
HERBERT, S.J.; BAGGERMAM, F.D. Cowpea response to row width, density, and irrigation. Agronomy Journal, v.75, p.982-986., 1983.

HERRIDGE, D.F.; PATE, J.S. Utilization of net photosynthate for nitrogen fixation and protein production in an annual legume. Plant Physiology, v.60, p.759-764, 1977.

HOOGENBOOM, G. DSSAT version 3.5 released. International Consortium for Agricultural Systems Applications (ICASA) News, n.4, p.2, Oct. 1998.

HOOGENBOOM, G.; JONES, J.W.; BOOTE, K.J. Modeling growth, development, and yield of grain legumes using soygro, pnutgro, and beangro: a review. Transactions of the ASAE, v.35, n.6, p.2043-2055, 1992.

HUXLEY, P.A.; SUMMERFIELD, R.J. Effects of daylength and day/night temperatures on growth and seed yield of cowpea cv. K 2809 grown in controlled environments. Annals of Applied Biology, v.83, p.259-271, 1976.

JACOMINE, P.K.T.; CAVALCANTE, A.C.; PESSOA, S.C.P. BURGOS, N.; MELO FILHO, F.R.de; LOPES, A.F; MEDEIRO, L.A. Levantamento exploratório reconhecimento de solos do Estado do Piauí. Rio de Janeiro: EMBRAPA-SNLCS; SUDENE-DRM, 1986. 782p. (EMBRAPA-SNLCS. Boletim de Pesquisa, 36).

JAME, Y.W.; CUTFORTH, H.W. Crop growth models for decision support systems. Canadian Journal of Plant Science, v.76, p.9-19, 1996.

JONES, J.W.; HUNT, L.A.; HOOGENBOOM, G. et al. Input and output files. In: TSUJI, G.Y.; UEHARA, G.; BALAS, S. (Ed.) DSSAT v3. Honolulu: University of Hawaii, 1994. v.2, p.3-94.

JONES, J.W.; MISHOE, J.W.; BOOTE; K.J. Introduction to simulation and modeling. Taipei: Food and Fertilizer Technology Center for the Asian and Pacific Region, 1987. 19p. (FFTC. Technical Bulletin, 100). 
JONES, J.W.; WHITE, J.; BOOTE, K.; HOOGENBOOM, G.; PORTER, C.H. Phenology Module. In: CROPGRO v.3.7 documentation and source code listing. Gainesville: University of Florida, 1998. 21p. (University of Florida, Agricultural and Biological Engineering Department. Research Report, 98-502).

KWAPATA, M.B.; HALL, A.E.; Effects of moisture regime and phosphorus on mycorrhizal infection, nutrient uptake, and growth of cowpeas (Vigna unguiculata (L.) Walp.). Field Crop Research, v.12, p.241-250, 1985.

LABANAUSKAS, C.K.; SHOUSE, P.; STOLZY, L.H. Effects of water stress at various growth stages on seed yield and nutrient concentrations of field-grown cowpeas. Soil Science, v.131, n.4, p.249-256, 1981.

LEITE, M.L.; RODRIGUES, J.D.; VIRGENS FILHO, J.S. Avaliação de cultivares de caupi (Vigna unguiculata (L.) Walp.) quanto à produtividade e componentes de produtividade, sob condições de estufa plástica. Revista de Agricultura, v.72, n.3, p.375-385, 1997.

LIMA, G.P.B.; AGUIAR, J.V.; COSTA, R.N.; PAZ, V.P.S. Rendimento de cultivares de caupi (Vigna unguiculata (L.) Walp.) submetidas a diferentes lâminas de irrigação. Irriga, v.4, n.3, 1999.

LIMA, M. G. Calibração e validação do modelo CERES-maize em condições tropicais do Brasil. Piracicaba, 1995. 119p. Tese (Doutorado) - Escola Superior de Agricultura "Luiz de Queiroz", Universidade de São Paulo.

LITTLETON, E.J.; DENNET, M.D.; ELSTON J.; MONTEITH, J.L. The growth and development of cowpeas (Vigna unguiculata) under tropical field conditions - 1 . Leaf area. Journal of Agricultural Science, v.93, p.291-307, 1979a.

LITTLETON, E.J.; DENNET, M.D.; MONTEITH, J.L. ELSTON J. The growth and development of cowpeas (Vigna unguiculata) under tropical field conditions 2. Accumulation and partition of dry weight. Journal of Agricultural Science, v.93, p.309-320, 1979b. 
LOOMIS, R.S.; WILLIAMS, W.A. Maximum crop productivity: an estimate. Crop Science, v.3, p.67-72, 1963.

MINCHIN, F.R.; SUMMERFIELD, R.J.; NEVES, C.P. Carbon metabolism, nitrogen assimilation, and seed yield of cowpea (Vigna unguiculata L. Walp.) growth in an adverse temperature regime. Journal of Experimental Botany, v.31, n.24, p.1327$1345,1980$.

MONTEITH, J. The quest balance in crop modeling. Agronomy Journal, v.88, p.695695, 1996.

NG, N.Q.; MARÉCHAL, R. Cowpea taxonomy, origin and germplasm. In: SINGH, S.R.; RACHIE, K.O. (Ed.) Cowpea research, production and utilization. Chichester: John Wiley, 1985. p.11-21.

NIELSEN, S.S.; OSUALA, C.I.; BRANDT, W.E. Early leaf harvest reduces yield but not protein concentration of cowpea seeds. Hort Science, v.29, n.6, p.631-632, 1994.

NOGUEIRA, L. C.; NOGUEIRA, L. R. Q. Distribuição do sistema radicular de caupi em solo arenoso sob diferentes lâminas de água e doses de adubação fosfatada. Teresina: Embrapa-CPAMN, 1995. 4p. (Embrapa-CPAMN. Pesquisa em Andamento, 62).

OLADIRAN, J.A. The performance of plants from aged seeds of cowpea (Vigna unguiculata (L.) Walp.) at different plant populations. Scientia Horticulturae, v.59, n.3-4, p.285-290, 1994.

OLIVEIRA, I.P. de; CARVALHO, A.M.de. A cultura do caupi nas condições de clima e de solo dos trópicos úmido e semi-árido do Brasil. In: ARAÚJO, J.P.P.de; WATT, E.E. (Org.) O caupi no Brasil. Brasília: IITA; EMBRAPA, 1988. p.65-96.

PASSIOURA, J.B. Simulation models: science, snake oil, education or engineering? Agronomy Journal, v.88, p.690-694, 1996. 
PEITER, M.X. Estudo do manejo da irrigação via modelo de simulação. São Carlos, 1998. 183p. Tese (Doutorado) - Escola de Engenharia de São Carlos, Universidade de São Paulo.

PHOGAT, B.S.; SINGH, D.P.; SINGH, P. Responses of cowpea (Vigna unguiculata (L.) Walp.) and Mung Bean (Vigna radiata (L.) Wilczek) to irrigation. II. Effects on $\mathrm{CO} 2$ exchange, radiation characteristics and growth. Irrigation Science, v.5, p.61$72,1984$.

PUKKALA, T.; BECKER, P.; KUULUVAINEN, T.; OKER-BLOM, P. Predicting spatial distribution of direct radiation below forest canopies. Agricultural and Forest Meteorology, v.55, p.295-307, 1991.

RITCHIE, J.T. A user orientated model of the soil water balance in wheat. In: FRY, E.; ATKIN, T.K.(Ed.) Wheat growth and modeling. New York: NATO-ASI Ser., 1985. p.293-305.

RITCHIE, J.T. Classification of crop simulation models. In: UHLIR, P.F.; CARTER, G.C. (Ed.) Crop modeling and related environmental data. Paris: CODATA, 1994. p.3-14.

ROBERTS, E.H.; SUMMERFIELD, R.J.; MINCHIN, F.R.; STEWART, K.A.; NDUNGURU, B.J. Effects of air temperature on seed growth and maturation in cowpea (Vigna unguiculata). Annals of Applied Biology, v.90, p.437-446, 1978.

ROGERS, D.H.; ELLIOT; R.I. Irrigation scheduling using crop growth simulation, risk analysis, and wather forecasts. Transactions of the ASAE, v.32, n.5, p.1669-1677, 1989.

SANTOS, J.J.A.; BEZERRA, F.M.L.; MIRANDA, E.P.; CORDEIRO, L.G. Determinação da evapotranspiração de referência (ETo) e evapotranspiração máxima (Etm) em diferentes fases fenológicas do feijão caupi (Vigna unguiculata (L.) Walp.). In: CONGRESSO BRASILEIRO DE ENGENHARIA AGRÍCOLA, 27., Poços de Caldas, 1998. Anais. Lavras: SBEA/UFLA, 1998. v.2, p.184-186. 
SHOUSE, P.; DASBERG, S.; JURY, W.A. STOLZY, L.H. Water deficit effects on water potential, yield and water use of cowpeas. Agronomy Journal, v.73, p.333$336,1981$.

SHOUSE, P.; JURY, W.A.; STOLZY, L.H.; DASBERG, S. Field measurement and modeling of cowpea water use and yield under stressed and well-watered growth conditions. Hilgardia, v. 50, n.6, p.1-25, 1982.

SILVA, M.A. Efeito da lâmina de água e da adubação nitrogenada sobre a produção de feijão-de-corda (Vigna sinensis L. Savi.), utilizando o sistema de irrigação por “aspersão em linha". Viçosa, 1978. 53p. Dissertação (M.S.) - Universidade Federal de Viçosa.

SILVA, M. A.; MLLLAR, A. A. Evapotranspiração do feijão-de-corda. In: EMPRESA BRASILEIRA DE PESQUISA AGROPECUÁRIA. Centro de Pesquisa Agropecuária do Trópico Semi-árido. Pesquisa em irrigação no trópico SemiÁrido: solo, água, planta. Petrolina, 1981. p.15-24. (Embrapa-CPATSA. Boletim de Pesquisa, 4).

SINCLAIR, T.R.; SELIGMAN, N.G. Crop modeling: from infancy to maturity. Agronomy Journal, v.88, p.698-704, 1996.

SIQUEIRA, O.J.F.; FARIAS, J.R.B.; SANS, M.A. Potential effects of global climate change for brazilian agriculture and adaptive strategies for wheat, maize and soybean. Revista Brasileira de Agrometeorologia, v.2, p.115-129, 1994.

SIVAKUMAR, M.V.K.; NTARE, B.R.; ROBERTS, J.M. Growth, yield and plant-water relations of four cowpea (Vigna unguiculata) cultivars in the Sahel. Journal of Agricultural Science, v.126, p.183-190, 1996.

STAMFORD, N.P.; SANTOS, D.R.; SILVA, V.M.; SANTOS, C.E.R.S; MONTEIRO, M.C. Fixação do $\mathrm{N}_{2}$ e matéria seca do caupi em dois solos do semi-árido brasileiro submetidos à deficiência hídrica. Revista Brasileira de Ciência do Solo, v.14, p.283-290, 1990. 
STEELE, W.M.; MEHRA, K.L. Structure, evolution, and adaptation to farming systems and environments in Vigna. In: SUMMERFIELD, R.J.; BUNTING, A.H. (Ed.) Advances in legume science. Kew: Royal Botanic Garden, 1980. p.393-404.

SUDENE. DPG - PRN - HME. Dados Pluviométricos Mensais do Nordeste: Estado do Piauí. Recife, 1990. 236p. (Brasil. SUDENE. Pluviometria, 2).

SUMMERFIELD, R.J.; MINCHIN, F.R.; ROBERTS, E.H.; HADLEY, P. Cowpea. In: SYMPOSIUM ON POTENTIAL PRODUCTIVITY OF FIELD CROPS UNDER DIFFERENT ENVIROMENTS, Los Baños, 1980. Proceedings. Los Baños: IRRI, 1983. p.249-280.

SUMMERFIELD, R.J.; MINCHIN, F.R.; STEWART, K.A.; NDUNGURU, B.J. Growth, reproductive development and yield of effectively nodulated cowpea plants in contrasting aerial environments. Annals of Applied Biology, v.90, p.277-291, 1978.

TEIXEIRA, S.M.; MAY, P.H.; SANTANA, A.C.de. Produção e importância econômica do caupi no Brasil. In: ARAÚJO, J.P.P.de; WATT, E.E. (Org.) O caupi no Brasil. Brasília: IITA; EMBRAPA, 1988. p.101-136.

THORNTON, P.K. Improving management and impact of fertilizers with modeling. INTERNATIONAL COLLOQUIUM OF THE INTERNATIONAL POTASH INSTITUTE, 24., Chiang Mai, 1995. Proceedings. 1995. p.21-24.

THORNTON, P.K.; HOOGENBOOM, G. A computer program to analyze singleseason crop model outputs. Agronomy Journal, v.86, n.5, p.860-868, 1994.

THORNTON, P.K.; HOOGENBOOM, G.; WILKENS, P.W.; JONES, J.W. Analyzing seasonal analysis experiments. In: TSUJI, G.Y.; UEHARA, G.; BALAS, S. (Ed.) DSSAT v3. Honolulu: University of Hawaii, 1994. v.3, p.23-65.

THORNTON, P.K.; SAKA, A.R.; SINGH, U.; KUMWENDA, J.D.T.; BRINK, J.E.; DENT, J.B. Application of a maize crop simulation model in the central region of Malawi. Experimental Agriculture, v.31, p.213-226, 1995. 
TIMSINA, J.; GARRITY, D.P.; PENNING DE VRIES, F.W.T.; PANDEY, R.K. Yield stability of cowpea cultivars in rice-based cropping systems: experimentation and simulation. Agricultural Systems, v. 42, p.359-381, 1993.

TSUJ, G.Y.; UEHARA, G.; BALAS, S. (Ed.) DSSAT v3. Honolulu: University of Hawaii, 1994a. 3v.

TSUJI, G.Y.; JONES, J.W.; HOOGENBOOM, G.; HUNT, L.A; THORNTON, P.K. Introduction. In: TSUJI, G.Y.; UEHARA, G.; BALAS, S. (Ed.) DSSAT v3. Honolulu: University of Hawaii, 1994b. v.1, p.1-11.

TUBIELlO, F.N.; ROSENZWEIG, C.; KIMBALL, B.A. PINTER JR., P.J.; WALL, G.W.; HUNSAKER, D.J.; LAMORTE, R.L.; GARCIA, R.L. Testing CERESwheat with free-air carbon dioxide enrichment (FACE) experiment data: $\mathrm{CO}^{2}$ and water interactions. Agronomy Journal, v.91, p. 247-255, 1999.

VAN GENUCHTEN, M. A closed-form equation for predicting the hydraulic conductivity of unsaturated soils. Soil Science Society American Journal, v.41, p. 892-898, 1980.

WHITE, J.W. Modeling and crop improvement. In: TSUJI, G.Y.; HOOGEBOOM, G.; THORNTON, P.K.(Ed.) Understanding options for agricultural production. Dordrecht: Kluwer, 1998. p.179-188.

WIEN, H.C. Dry matter production, leaf area development, and light interception of cowpea lines with broad and narrow leaflet shape. Crop Science, v.22, p.733-737, 1982.

WIEN, H.C.; SUMMERFIELD, R.J. Adaptation of cowpeas in west Africa: effects of photoperiod and temperature responses in cultivars of diverse origin. In: SUMMERFIELD, R.J.; BUNTING, A.H. (Ed.) Advances in legume science. Kew: Royal Botanic Garden, 1980. p.405-417.

WISIOL, K. Choosing a basis for yield forecasts and estimates. In: WISIOL, K; HESKETH, J.D. Plant growth modeling for resource management. Boca Raton: CRC Press, 1987. v.1, p.75-103. 
ZISKA, L. H.; HALL, A. E.; HOOVER, R. M. Irrigation management methods for reducing water use of cowpea (Vigna unguiculata L. Walp.) and lima bean (Phaseolus vulgaris L.) while maintaining seed yield at maximum levels. Irrigation Science, v.6, p.223-239, 1985. 